Aus der Klinik für Urologie

(Prof. Dr. med. L. Trojan)

der Medizinischen Fakultät der Universität Göttingen

\title{
Der Östrogenrezeptor ER $\beta$ unter dem Einfluss selektiver Östrogenrezeptorliganden in kastrationsresistenten Prostatakarzinomzellen
}

\author{
INAUGURAL-DISSERTATION \\ zur Erlangung des Doktorgrades \\ der Medizinischen Fakultät der \\ Georg-August-Universität zu Göttingen
}

vorgelegt von

Nicole Rudolph

aus Erfurt

Göttingen 2019 
Dekan:

Prof. Dr. rer. nat. H. K. Kroemer

Referent/in:

Prof. Dr. med. L. Trojan

Ko-Referent/in:

Prof. Dr. med. G. Emons

Drittreferent/in:

Tag der mündlichen Prüfung: $\quad 30.06 .2020$ 
Hiermit erkläre ich, die Dissertation mit dem Titel: „Der Östrogenrezeptor ER $\beta$ unter dem Einfluss selektiver Östrogenrezeptorliganden in kastrationsresistenten Prostatakarzinomzellen“ eigenständig angefertigt und keine anderen als die von mir angegebenen Quellen und Hilfsmittel verwendet zu haben.

Göttingen, den

(Unterschrift) 


\section{Inhalt}

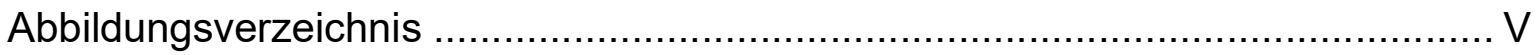

Tabellenverzeichnis .................................................................................. VII

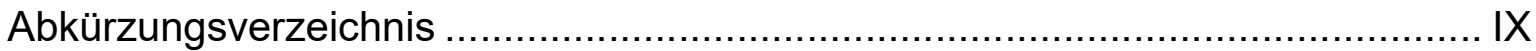

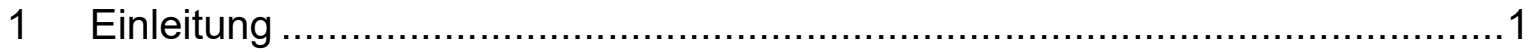

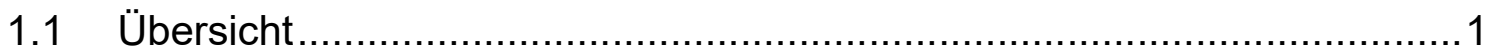

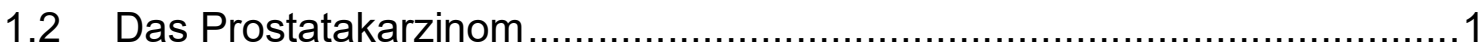

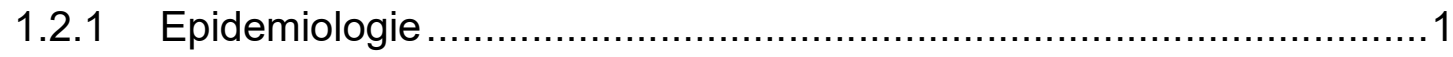

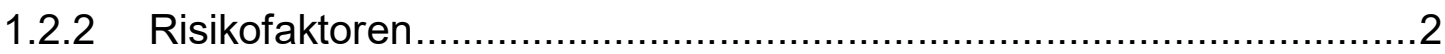

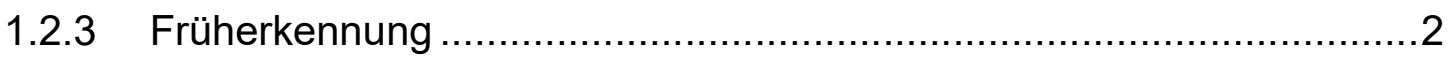

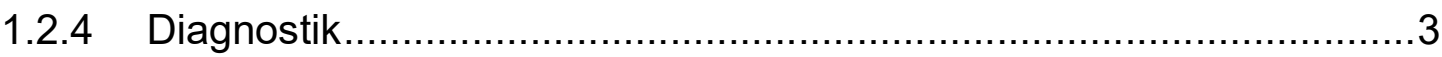

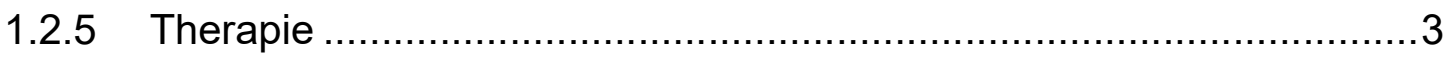

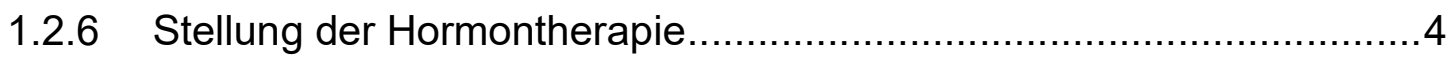

1.2.7 Neue Therapieansätze .........................................................

1.3 Gene und Genprodukte im Prostatakarzinom ....................................

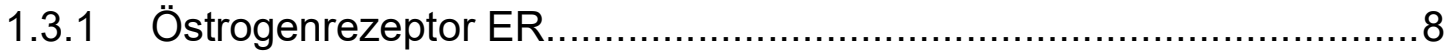

1.3.2 Prostataspezifisches Antigen .................................................11

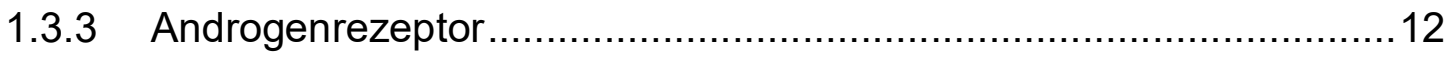

1.3.4 Spleißvarianten des Androgenrezeptors AR-V1 und AR-V7 ............16

1.3.5 Cytochrom P450c17alpha-Enzym A1 (CYP17A1) ..........................17

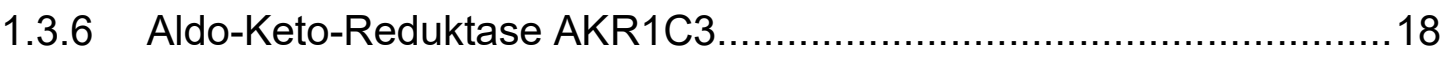

1.3.7 Transmembranöse Protease:Serin 2-ERG Fusion(TMPRSS2-ERG) 19

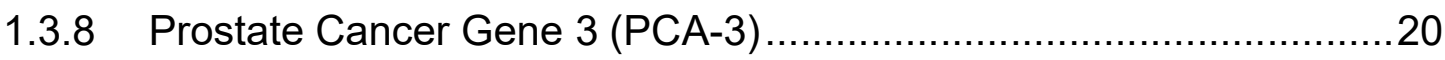

1.4 Selektive Östrogenrezeptorliganden ………....................................21

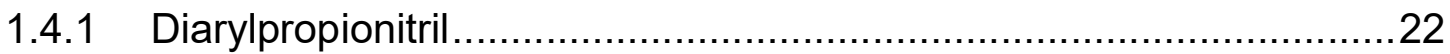

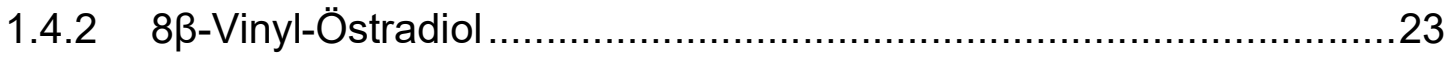




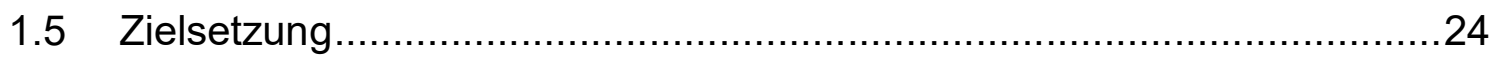

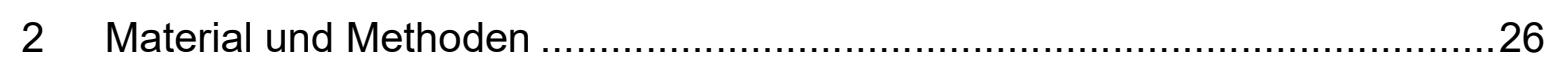

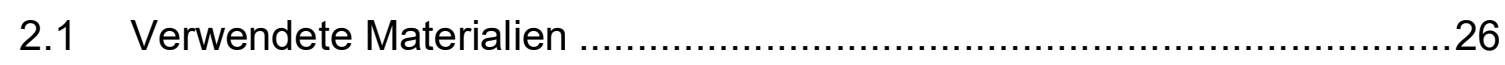

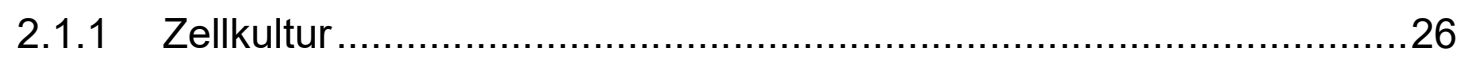

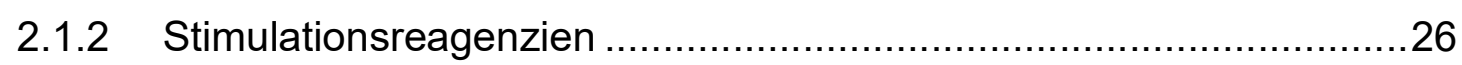

2.1.3 Biologische Substanzen und Chemikalien...................................26

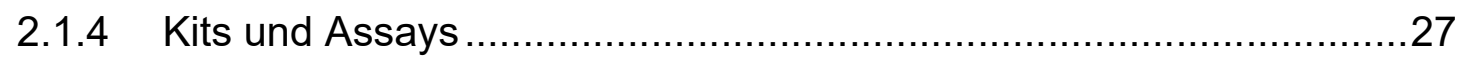

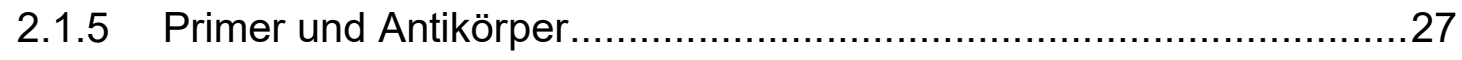

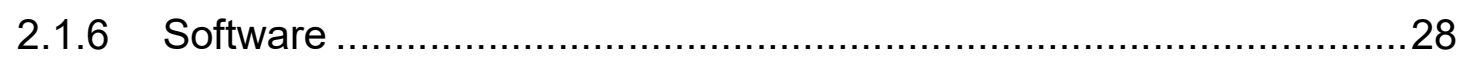

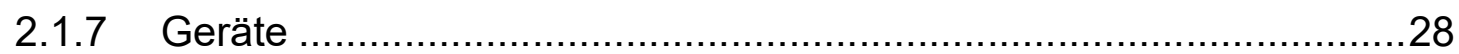

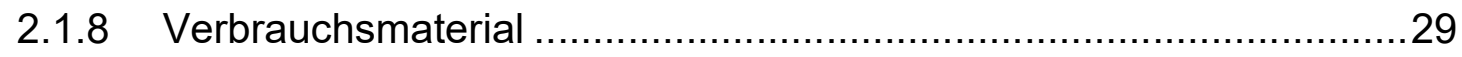

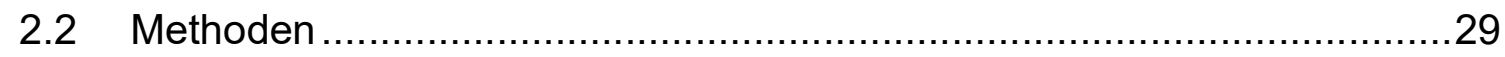

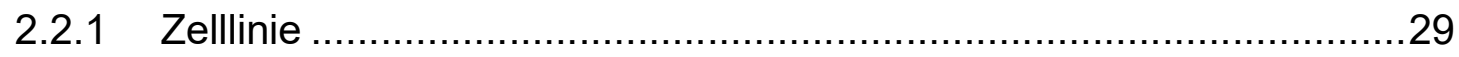

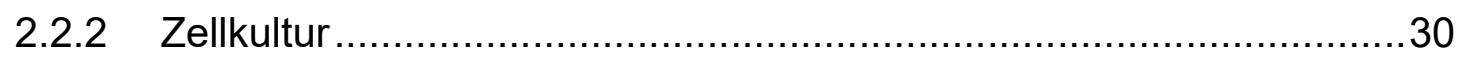

2.2.2.1 Passagieren der Zellen ......................................................... 30

2.2.2.2 Konservierung der Zellen ...................................................... 31

2.2.3 Stimulation der Zellen mit 8 $\beta$-VE2 und DPN.................................31

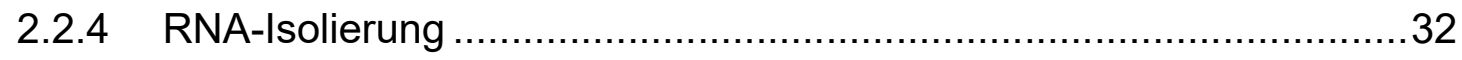

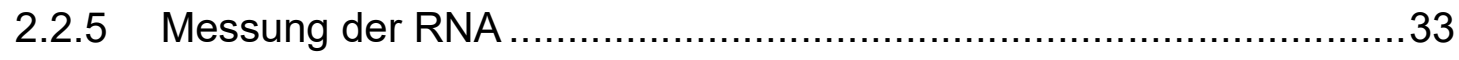

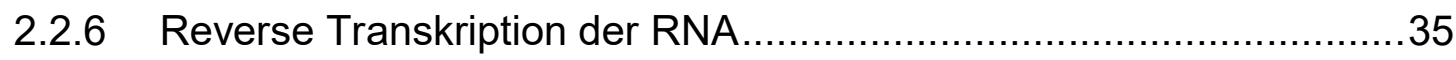

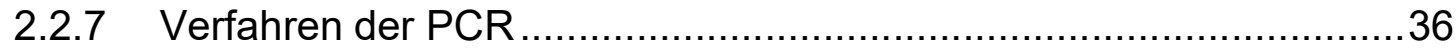

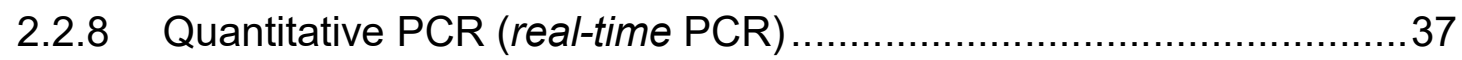

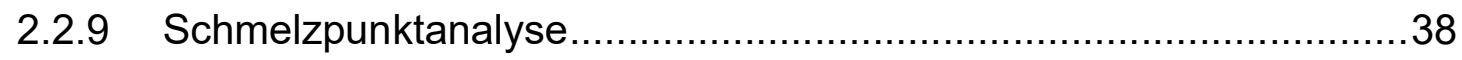

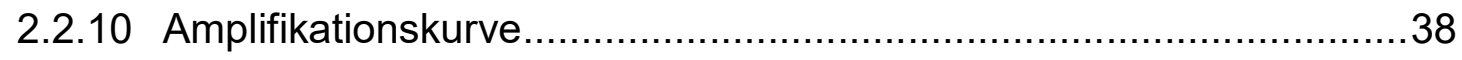

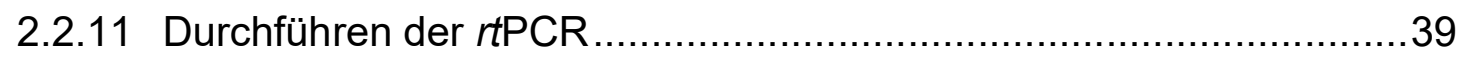

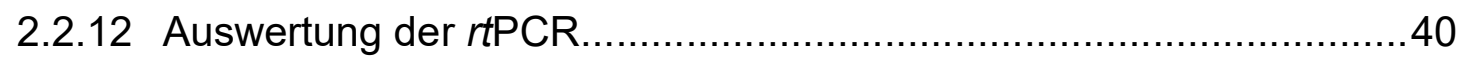

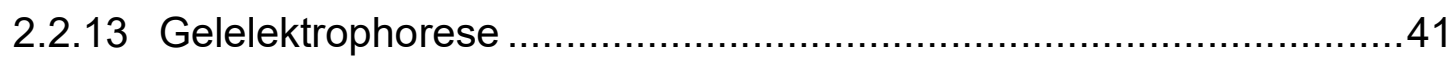




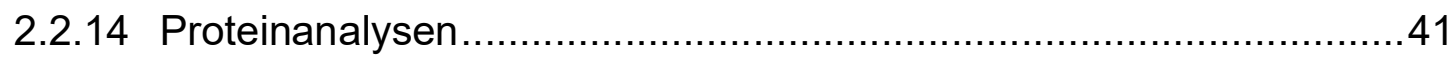

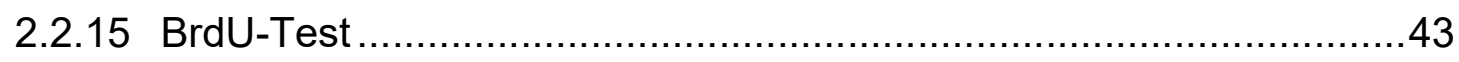

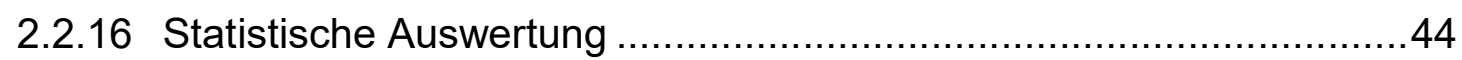

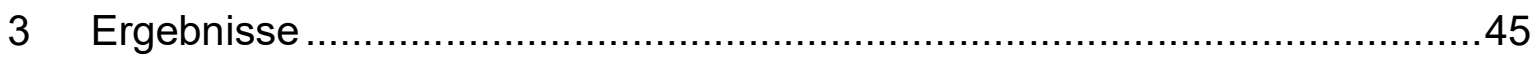

3.1 Stimulation der VCaP-Zellen mit 8ß-VE2 …........................................... 45

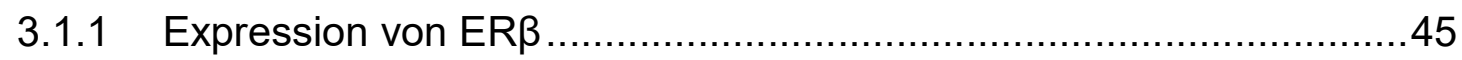

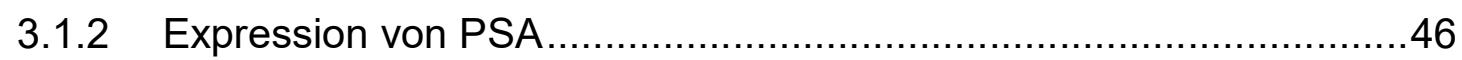

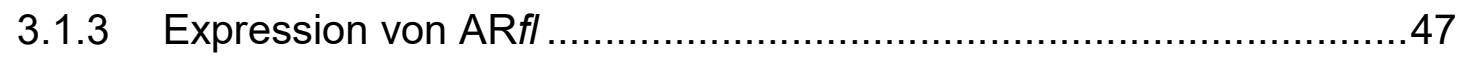

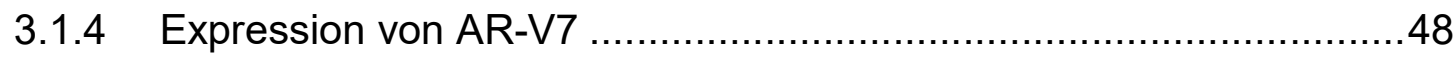

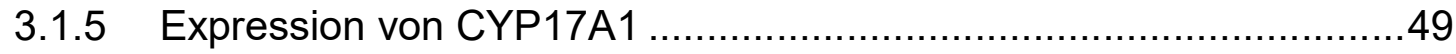

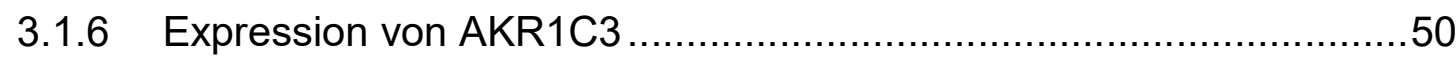

3.1.7 Expression von TMPRSS2-ERG ………...................................

3.1.8 VCaP-Zellen unter dem Einfluss von $8 \beta$-VE2 ...............................52

3.2 Stimulation der VCaP-Zellen mit DPN................................................

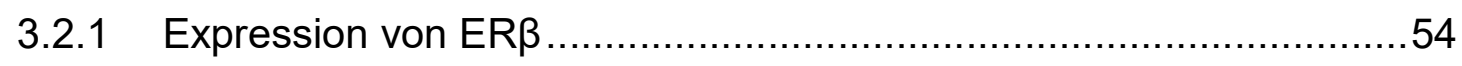

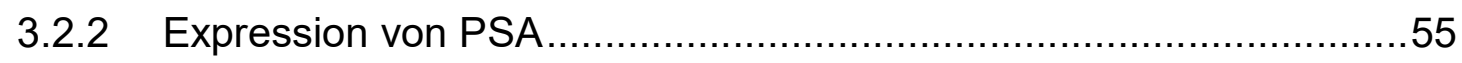

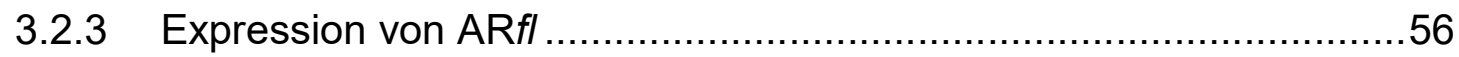

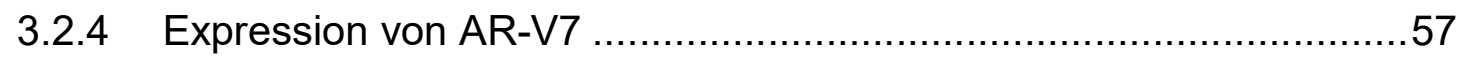

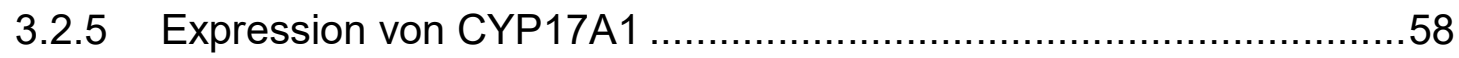

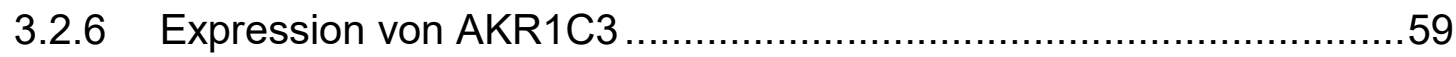

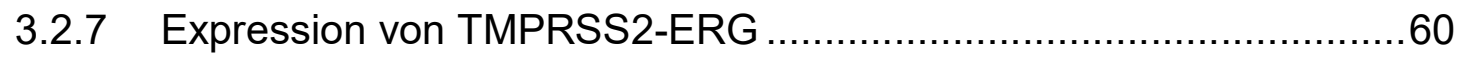

3.2.8 VCaP-Zellen unter dem Einfluss von DPN ...................................61

3.3 Proteinexpression in VCaP-Zellen unter Stimulation von 8ß-VE2 und DPN 63

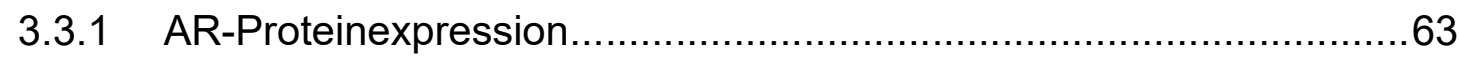

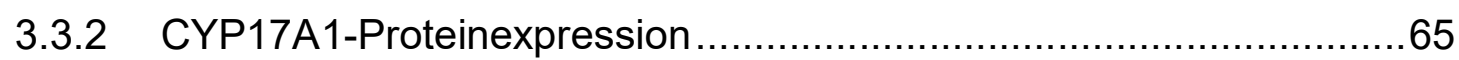

3.4 Proliferationsverhalten der VCaP-Zellen nach Stimulation mit 8ß-VE2 ....66 


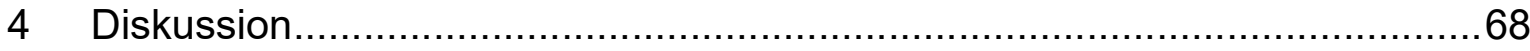

$4.18 \beta$-VE2 senkt die AR-Konzentration in VCaP-Zellen ..........................69

4.2 DPN steigert die AR-Konzentration in VCaP-Zellen ...........................74

4.3 Bedeutung für eine mögliche Therapie .......................................... 75

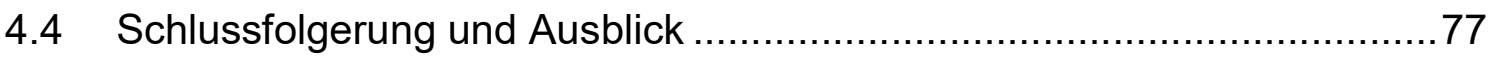

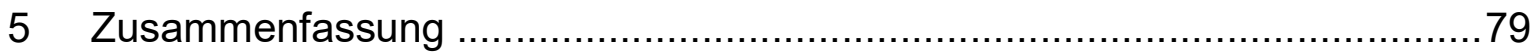

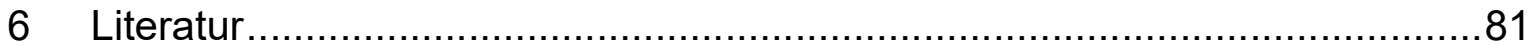




\section{Abbildungsverzeichnis}

Abbildung 1: Strukturformel des planaren ER $\beta$-selektiven Liganden DPN. .22

Abbildung 2: Strukturformel des nicht-planaren ER $\beta$-selektiven Liganden 8$\beta$-VinylÖstradiol (8$\beta-V E 2)$

Abbildung 3: Elektropherogramm mit 18S- und 28S-Bande .35

Abbildung 4: Gel-Darstellung der Bioanalyzer-Messung..... 35

Abbildung 5: threshold cycle zur Bestimmung der cDNA-Konzentration.....

Abbildung 6: ERß-Expression in VCaP-Zellen unter 8 $\beta$-VE2-Stimulation nach Auswertung der rtPCR 46

Abbildung 7: PSA-Expression in VCaP-Zellen unter 8ß-VE2-Stimulation nach Auswertung der rtPCR

Abbildung 8: ARfl-Expression in VCaP-Zellen unter 8 $\beta$-VE2-Stimulation nach Auswertung der rtPCR

Abbildung 9: AR-V7-Expression in VCaP-Zellen unter 8 $\beta$-VE2-Stimulation nach Auswertung der rtPCR

Abbildung 10: CYP17A1-Expression in VCaP-Zellen unter 8 $\beta$-VE2-Stimulation nach Auswertung der rtPCR.

Abbildung 11: AKR1C3-Expression in VCaP-Zellen unter 8 $\beta$-VE2-Stimulation nach Auswertung der rtPCR

Abbildung 12: TMPRSS2-ERG-Expression in VCaP-Zellen unter 8ß-VE2-

Stimulation nach Auswertung der rtPCR.

Abbildung 13: Zusammenfassung der Expression der untersuchten Gene in VCaP-Zellen unter 8 $\beta$-VE2-Stimulation nach Auswertung der rtPCR 53

Abbildung 14: ERß-Expression in VCaP-Zellen unter DPN-Stimulation nach Auswertung der rtPCR 
Abbildung 15: PSA-Expression in VCaP-Zellen unter DPN-Stimulation nach Auswertung der $r$ PCR

Abbildung 16: ARfl-Expression in VCaP-Zellen unter DPN-Stimulation nach Auswertung der rtPCR

Abbildung 17: AR-V7-Expression in VCaP-Zellen unter DPN-Stimulation nach Auswertung der rtPCR 58

Abbildung 18: CYP17A1-Expression in VCaP-Zellen unter DPN-Stimulation nach Auswertung der rtPCR .59

Abbildung 19: AKR1C3-Expression in VCaP-Zellen unter DPN-Stimulation nach Auswertung der rtPCR

Abbildung 20: TMPRSS2-ERG-Expression in VCaP-Zellen unter DPN-Stimulation nach Auswertung der rtPCR.

Abbildung 21: Zusammenfassung der Expression der untersuchten Gene in VCaP-Zellen unter DPN-Stimulation nach Auswertung der rtPCR.

Abbildung 22: Gelelektrophorese der AR-Expression und der $\alpha$-Tubulin-

Expression in VCaP-Zellen nach 8 $\beta$-VE2-Stimulation

Abbildung 23: Gelelektrophorese der AR-Expression und der $\alpha$-Tubulin-

Expression in VCaP-Zellen nach DPN-Stimulation

Abbildung 24: Gelelektrophorese der CYP17A1-Expression in VCaP-Zellen nach 8ß-VE2- Stimulation

Abbildung 25: Gelelektrophorese der CYP17A1-Expression in VCaP-Zellen nach DPN-Stimulation

Abbildung 26: Proliferationsverhalten der VCaP-Zellen nach Stimulation mit 8ßVE2 .67

Abbildung 27: Verhältnisse in VCaP-Zellen, die androgenfrei kultiviert wurden ....69 Abbildung 28: Verhältnisse in VCaP-Zellen, die androgenfrei kultiviert und mit dem selektiven ER $\beta$-Liganden $8 \beta$-VE2 stimuliert wurden .70 
Abbildung 29: Verhältnisse in VCaP-Zellen, die androgenfrei kultiviert und mit dem selektiven ER $\beta$-Liganden $8 \beta$-VE2 stimuliert wurden .74 


\section{Tabellenverzeichnis}

Tabelle 1: Verwendete Zelllinie und Medien .............................................26

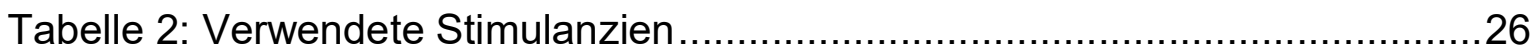

Tabelle 3: Verwendete Substanzen und Chemikalien ................................26

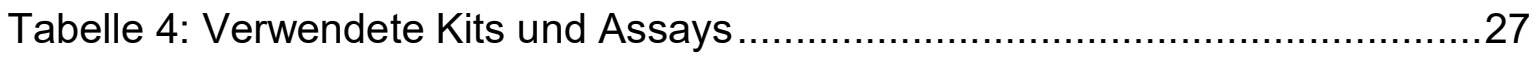

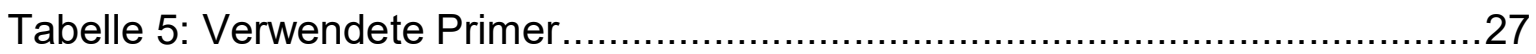

Tabelle 6: Verwendete Gene und ihre Sequenzen........................................27

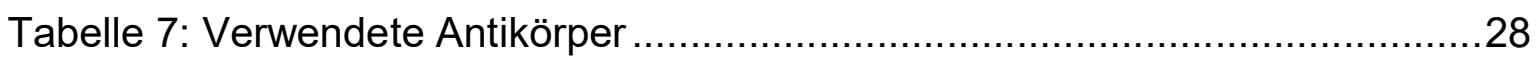

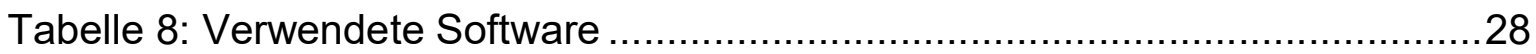

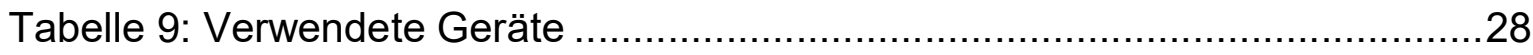

Tabelle 10: Verwendetes Verbrauchsmaterial ............................................29

Tabelle 11: Verwendete Stimulationskonzentrationen ................................... 32

Tabelle 12: Verwendetes PCR-Programm ................................................. 40

Tabelle 13: Optische Dichte der AR-Expression und der $\alpha$-Tubulin-Expression

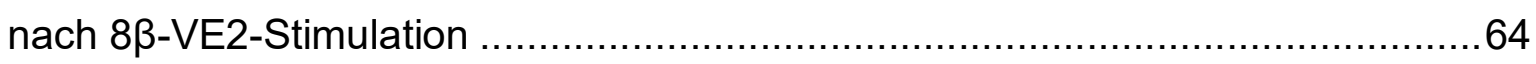

Tabelle 14: Optische Dichte der AR-Expression und der $\alpha$-Tubulin-Expression

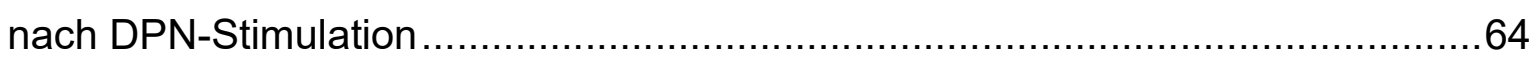

Tabelle 15: Optische Dichte der CYP17A1-Expression nach 8 $\beta$-VE2- Stimulation 66

Tabelle 16: Optische Dichte der CYP17A1-Expression nach DPN-Stimulation ....66 


\section{Abkürzungsverzeichnis}

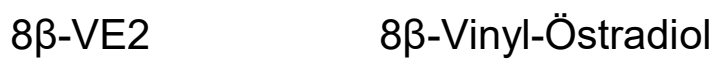

Ak

Antikörper

AR

Androgenrezeptor

ARfl

Androgenrezeptor full length (entspricht dem AR)

AR-V1

AR Variante 1

AR-V7

AR Variante 7

ARP

acidic ribosomal protein

AT

Annealing-Temperatur

bp

Basenpaare

$\mathrm{BPH}$

benigne Prostatahyperplasie

BrdU

Bromdesoxyuridin

cDNA

complementary deoxyribonucleic acid

$\mathrm{CO}_{2}$

Kohlenstoffdioxid

COX-1

Cyclooxygenase-1

cOX-2

Cyclooxygenase-2

CRPC

kastrationsresistentes Prostatakarzinom

$\mathrm{Ct}$

threshold cycle (=Schwellenwertzyklus)

DD3

differential display clone 3 (PCA-3 in der klinischen Anwendung)

DFG Deutsche Forschungsgemeinschaft

DHEA Dehydroepiandrosteron 


\begin{tabular}{|c|c|}
\hline DHT & Dihydrotestosteron \\
\hline DNA & desoxyribonucleic acid (=Desoxyribonukleinsäure) \\
\hline dNTP & Desoxyribonukleosidtriphosphat \\
\hline DPBS & Dulbecco's Phosphate-Buffered Saline \\
\hline DPN & Diarylpropionitrile \\
\hline EDTA & Ethylendiamintetraacetat \\
\hline ER & estrogen receptor \\
\hline ERa & estrogen receptor alpha \\
\hline ER $\beta$ & estrogen receptor beta \\
\hline ERG & ETS-related gene \\
\hline EtOH & Ethanol \\
\hline ETS & erythroblast transformation-specific \\
\hline GnRH & Gonadotropin Releasing-Hormon \\
\hline HDAC & Histon-Deacetylase \\
\hline HDACi & Histon-Deacetylase-Inhibitor \\
\hline HDR & high dose radiography \\
\hline HGPIN & high-grade prostatische intraepitheliale Neoplasie \\
\hline IGF & Insulin-like growth factor \\
\hline $\mathrm{kb}$ & Kilobase \\
\hline LDR & low dose radiography \\
\hline LNCaP & lymph node of cancer of the prostate \\
\hline LUTS & lower urinary tract symptoms \\
\hline
\end{tabular}




\begin{tabular}{|c|c|}
\hline MT & melting temperature \\
\hline NP-40 & Nonidet P-40 (nichtionisches Tensid) \\
\hline NSAID & non steroidal anti inflammatory drugs \\
\hline PC-3 & prostate cancer cell 3 \\
\hline PCA-3 & Umbenennung für DD3 \\
\hline PCR & polymerase chain reaction \\
\hline PMSF & Phenylmethylsulfonylfluorid \\
\hline PSA & Prostata-spezifisches Antigen \\
\hline RNA & ribonucleic acid (=Ribonukleinsäure) \\
\hline RNase & Ribonuklease \\
\hline RPMI & Roswell Park Memorial Institute (Zellkulturmedium) \\
\hline rRNA & ribosomale RNA \\
\hline RT & reverse Transkriptase \\
\hline rtPCR & real-time polymerase chain reaction \\
\hline S & $\begin{array}{l}\text { Svedberg-Einheit für das Sedimentationsverhalten von Ribo- } \\
\text { somen, entspricht deren Masse }\end{array}$ \\
\hline SiRNA & small-interfering RNA \\
\hline taq-Polymerase & $\begin{array}{l}\text { thermostabile DNA-Polymerase des Bakteriums Thermus } \\
\text { aquaticus }\end{array}$ \\
\hline tcRNA & total cellular RNA \\
\hline TG & Tectorigenin \\
\hline tRNA & transfer RNA \\
\hline UMG & Universitätsmedizin Göttingen \\
\hline
\end{tabular}


U/min Umdrehungen pro Minute

UV

ultraviolettes Licht

V

Volt

VCaP

Vertebral-Cancer of the Prostate 


\section{Einleitung}

\section{1 Übersicht}

Die vorliegende Arbeit befasst sich mit der Expressionsverstärkung des Östrogenrezeptors $\beta$ (ER $\beta)$ durch spezifische Östrogenrezeptorliganden und der Wirkung auf die Expression androgenabhängiger Gene im kastrationsresistenten Prostatakarzinom (CRPC). Als spezifischer Östrogenrezeptorligand wurde das synthetisch hergestellte $8 \beta$-Vinyl-Östradiol (8$\beta$-VE2) verwendet. Darüber hinaus wurde der Vergleich $\mathrm{zu}$ einem ebenfalls synthetisch hergestellten spezifischen Östrogenrezeptorligand, Diarylpropionitrile (DPN), auf Prostatakarzinomzellen gezeigt. Der Zusammenhang zwischen ER $\beta$-Expression und der onkoprotektiven Wirkung auf die Androgenrezeptorkaskade hat klinische Relevanz in der hormonspezifischen Behandlung des fortschreitenden kastrationsresistenten Prostatakarzinoms.

\subsection{Das Prostatakarzinom}

\subsubsection{Epidemiologie}

Das Prostatakarzinom ist mit $23 \%$ aller Tumorlokalisationen der gesamten Krebsneuerkrankungen die häufigste Tumorerkrankung des Mannes und belegt Platz 2 unter den häufigsten Krebstodesursachen des Mannes in Deutschland. Bezogen auf die Daten des Robert Koch-Instituts ist die Zahl der Neuerkrankten über Jahrzehnte gestiegen und lag im Jahre 2010 bei 67.300 . Seit 2011 ist ein Rückgang zu verzeichnen. Im Jahre 2014 lag die Zahl der Neuerkrankungen bei 57.370. Etwa 13.700 Patienten starben im Jahr 2014 an den Folgen eines Prostatakarzinoms (Robert Koch-Institut 2017).

Es zeigen sich Unterschiede in der altersstandardisierten und globalen Inzidenz. In Europa ergibt sich ein Gefälle von Norden nach Süden (S3-Leitlinie Prostatakarzinom 2018). 


\subsubsection{Risikofaktoren}

Der wichtigste Risikofaktor ist das Alter der Patienten. Daneben sind genetische Dispositionen zu nennen, vor allem Verwandte ersten Grades, deren Erkrankungsalter und die Anzahl der in der Familie aufgetretenen Fälle. Die männlichen Geschlechtshormone (Testosteron; Dihydrotestosteron, DHT) spielen eindeutig eine wesentliche Rolle.

Global zeigt sich ein signifikantes West-Ost-Gefälle mit niedrigerer Inzidenz im asiatischen Raum. Ursächlich dafür werden die verschiedenen Gewohnheiten der Ernährung und die sozioökonomischen Faktoren genannt (S3-Leitlinie Prostatakarzinom 2018).

Andere Risikofaktoren wie lokale Entzündungen der Prostata und sexuell übertragbare Erkrankungen scheinen das Risiko zu erhöhen, Lebensstil und Umwelteinflüsse sind bisher wenig medizinisch belegt und werden als klinisch nicht ausreichend relevant bewertet (Robert Koch-Institut 2017, S3-Leitlinie Prostatakarzinom 2018).

\subsubsection{Früherkennung}

Zur Früherkennung des Karzinoms wird Männern ab dem 45. Lebensjahr eine digital rektale Untersuchung angeboten. Grund hierfür ist die Lokalisation des Prostatakarzinoms. Während die benigne Prostatahyperplasie $(\mathrm{BPH})$ vor allem im periurethralen Stroma und in der Transitionalzone der Prostata zu finden ist und klinisch durch zunehmende Miktionsstörungen auffällig wird, weshalb die auftretenden Beschwerden auch als lower urinary tract symptoms (LUTS) bezeichnet werden (Schulz et al. 2003, Verhamme et al. 2002), ist das Prostatakarzinom in $60-70 \%$ der beschriebenen Fälle in der peripheren Zone der Prostata zu finden. Durch die Ausbreitung zum Rektum und dem häufigen asymptomatischen Verlauf wird deshalb eine digital rektale Untersuchung empfohlen. Das prostataspezifische Antigen (PSA) ist als Screening-Methode umstritten. Durch die Messung werden auch Karzinome entdeckt, bei denen es keiner Behandlung bedarf. Es liegen unzureichende Ergebnisse des Screenings bezüglich der Senkung der prostatakrebsspezifischen Mortalität vor. 
Eine Prostatabiopsie wird bei PSA-Werten $\geq 4 \mu \mathrm{g} / \mathrm{l}$ unter Berücksichtigung der einfließenden Faktoren, einem auffälligem PSA-Anstieg oder karzinomverdächtiger digitaler rektaler Untersuchung empfohlen (S3-Leitlinie Prostatakarzinom 2018).

\subsubsection{Diagnostik}

Zur Sicherung der Diagnose wird eine systematische Biopsie mit Hilfe des transrektalen Ultraschalls und ggf. gezielter palpatorischer Biopsie eingesetzt. Suspekte Areale der bildgebenden Verfahren sollen zusätzlich gezielt bioptiert werden. Zum weiteren Staging werden CT- oder MRT-Untersuchungen der Beckenorgane und Skelettszintigraphie eingesetzt (S3-Leitlinie Prostatakarzinom 2018).

\subsubsection{Therapie}

Die Behandlung erfolgt gemäß TNM-Klassifikation unter Einschluss der klinischen Faktoren und dem Allgemeinzustand des Patienten. Das Konzept richtet sich individuell nach den Patienten und folgt je nach Ausgangssituation einem bestimmten Therapieplan.

Bei lokal begrenzten Karzinomen kommen chirurgische und strahlentherapeutische Ansätze als kurative Interventionen zum Einsatz. Bei einer radikalen Prostatvesikulektomie werden Prostata, Samenbläschen und regionale Lymphknoten entfernt. Den gleichen Stellenwert besitzt der strahlentherapeutische Ansatz, bei dem eine perkutane Bestrahlung als HD-Radiotherapie (High-DoseRadiotherapie), eine Brachytherapie als LDR-Brachytherapie (Low-Dose-RateBrachytherapie) oder eine HDR-Brachytherapie (High-Dose-Rate-Brachytherapie) zum Einsatz kommt. Die HDR-Brachytherapie kann auch mit der perkutanen Bestrahlung kombiniert werden. Beim lokal begrenzten Karzinom einer höheren Risikogruppe wird durch den Einsatz von Radiotherapie bei einem gleichzeitigen Einsatz der ablativen endokrinen Therapie als neoadjuvante oder adjuvante Option das Überleben verbessert.

Bei älteren Patienten und einer eingeschränkten Lebenserwartung unter 10 Jahren wird aktuell die Option des watchful waiting bevorzugt, bei dem erst bei symp- 
tomatischem Progress palliativ therapiert wird, da in dieser Konstellation das Prostatakarzinom klinisch häufig an Bedeutung verliert.

Bei Patienten mit einem low-risk-Karzinom steht eine weitere Option des active surveillance mit engmaschigen Kontrolluntersuchungen und ggf. späterer Intervention zur Verfügung (S3-Leitlinie Prostatakarzinom 2018).

Beim fortgeschrittenen metastasierten Prostatakarzinom steht die Remissionserhaltung durch hormonelles Eingreifen und die damit verbundene Lebensqualität im Vordergrund. Beim metastasierten, hormonsensitiven Prostatakarzinom sollte bei Patienten mit gutem Allgemeinzustand eine kombinierte Hormon-Chemotherapie mit Docetaxel oder eine zusätzliche antihormonelle Therapie mit Abirateron erfolgen. Beim kastrationsresistenten Prostatakarzinom steht die zusätzliche antihormonelle Therapie mit Enzalutamid zur Verfügung. Knochenmetastasen können durch lokale Strahlentherapie oder durch eine systemische Radionuklidtherapie behandelt werden (S3-Leitlinie Prostatakarzinom 2018).

\subsubsection{Stellung der Hormontherapie}

Den wachstumsfördernden Einfluss der Androgene auf die Entstehung des Prostatakarzinoms beschrieben bereits Huggins und Hodges 1941 (Huggins und Hodges 1941). Aus dieser Erkenntnis entwickelten sich die verschiedenen Therapieansätze der endokrinen Behandlung durch die Beeinflussung des Androgenhaushaltes. Zu den wesentlichen Ansätzen gehören die chemische Kastration mit dem Ziel eines Androgenentzugs und die Androgeninhibition. Dazu zählen die Möglichkeiten der medikamentösen Entzugstherapie, z. B. durch $\mathrm{GnRH}$ (Gonadotropin releasing Hormone) -Agonisten (Buserelin) oder $\mathrm{GnRH}$ Antagonisten (Abarelix, Degarelix). Alternativ kann eine operative Kastration durch beidseitige Orchiektomie durchgeführt werden. Die medikamentöse Therapie mit Östrogenderivaten der Substanzklasse DES (Diethylstilbestrol) hat aufgrund ihres Nebenwirkungsspektrums an Bedeutung verloren. Jedoch lassen neue Präparate mit direkter zytotoxischer Wirkung auf Prostatakarzinomzellen und der Wirksamkeit auch im kastrationsresistenten Prostatakarzinom die Bedeutung dieses Therapiekonzeptes neu aufkeimen (Schröder et al. 2012). 
Zusätzlich empfiehlt es sich, aufgrund des geringeren Nebenwirkungsspektrums Antiandrogene, vor allem der Substanzklasse nicht-steroidaler Antiandrogene (Bicalutamid), einzusetzen (Ganzer et al. 2007). Die intermittierende Androgenblockade zeigt zudem ein geringeres Nebenwirkungsspektrum bei gleichbleibenden Ansprechraten (Tsai et al. 2013).

Im Verlauf kommt es jedoch meist in der späteren Phase zu einem kastrationsresistenten Prostatakarzinom. Das bedeutet, dass trotz eines Testosteronspiegels im Kastrationsbereich (<50 ng/dl oder 1,7 nmol/l) ein weiterer Progress des Karzinoms stattfindet. Dieser ist durch einen PSA-Anstieg erkennbar. Die Ursachen hierfür sind vielfältig. Mutationen im Androgenrezeptor oder die Hochregulation des Androgenrezeptors lassen das Karzinom auch unabhängig von Testosteron wachsen (Graefen et al. 2000). In dieser Phase gelingt es durch eine Chemotherapie mit Docetaxel, das Leben im Durchschnitt um ca. 2,5 Monate zu verlängern (Berthold et al. 2008, Heidenreich und Ohlmann 2005).

In den letzten Jahren kamen neue Therapiemöglichkeiten hinzu. Neben dem Taxan Docetaxel als Chemotherapeutikum ist auch Carbazitaxel bei Progress nach Docetaxel zugelassen. Es schafft einen Überlebensvorteil von durchschnittlich 2,4 Monaten (de Bono et al. 2010). Jedoch ist bei Docetaxel mit erhöhtem Risiko febriler Neutropenien zu rechnen, welche präventiv zu beachten wären.

Außerdem gewinnt Abirateronacetat $\left(Z_{y t i g a}{ }^{\circledR}\right)$ zunehmend an Bedeutung. Der selektive CYP17A1-Inhibitor (Cytochrom P450 c17 alpha-Enzym A1) greift direkt in die Androgensynthese aller Syntheselokalisationen, Nebennierenrinde, Hoden und intrakrine Sekretion ein und verlängert die durchschnittliche Überlebenszeit auf 3 Monate (de Bono et al. 1995). Es wird heute schon mit als first line-Therapieoption bei kastrationsresistentem Prostatakarzinom in Kombination mit Prednisolon eingesetzt (Andersson et al. 1995, Knudsen und Penning 2010). Auch der Androgenrezeptorinhibitor MDV3100, auch als Enzalutamid (Xtandi ${ }^{\circledR}$ ) bekannt, wird bereits unter anderem als first line-Therapie bei kastrationsresistentem Prostatakarzinom eingesetzt. Dieser sorgt für den Erhalt der Glukokortikoidsynthese und blockiert die Signalkaskade des Androgenrezeptors auf drei Stufen. Diese neuen Ansätze versprechen auch Erfolge für Patienten, die bisher nicht auf eine 
endokrine Therapie ansprachen (Attard et al. 2009, Thelen et al. 2010, Thelen et al. 2016).

\subsubsection{Neue Therapieansätze}

Einen erfolgreichen Schritt nach vorn machten neue Inhibitoren der Androgensynthese wie Abirateronacetat und direkte AR-Inhibition mit MDV3100, die steigende Überlebensraten bei den Patienten in klinischen Studien aufwiesen (Mukherji et al. 2012, Thelen et al. 2016). Aktuelle Erkenntnisse über mögliche Therapieresistenzen gegen diese Substanzen und Resistenzen gegen alternative Substanzen, sog. Kreuzresistenzen, lassen die Diskussionen über zukünftige Therapiemöglichkeiten jedoch neu entfachen (Knudsen und Penning 2010, Waltering et al. 2012, Sadar 2011, Thelen et al. 2013). So zeigte sich bei Patienten, die mit Abirateronacetat oder dem neuen AR-Antagonisten Enzalutamid behandelt wurden, innerhalb eines Jahres eine Reaktivierung des AR. Es ist noch ungeklärt, ob eine intrinsische oder erworbene Ursache zugrunde liegt. Daher müssen weitere Analysen folgen, um den möglichen Mechanismus der Resistenz zu verstehen (Yuan et al. 2014).

Auch Seton-Rogers beschreibt eine neue Mutation (F876L) im AR, die Enzalutamid von einem AR-Antagonisten in einen AR-Agonisten konvertieren lässt und mit einer Rekrutierung von Koaktivatoren und steigender Proliferation einhergeht (Seton-Rogers 2013). Klinisch ist zu beobachten, dass bei einem Tumorprogress unter anti-androgener Therapie, nachdem das Antiandrogen abgesetzt wurde, ein kurzzeitiger PSA-Abfall resultiert. Dieser Withdrawal-Effekt ist aufgrund der fehlenden Aktivierung des AR durch den Agonismus des Antiandrogens zu erklären. Auch hier bedarf es einer Abklärung weiterer Mutationen, die zu einer Therapieresistenz führen, um die Resistenzentwicklung anderer Inhibitoren besser zu verstehen. Des Weiteren ist als einer der entscheidenden Resistenzmechanismen die Überexpression von testosteronbildenden Enzymen, vorallem CYP17A1, beschrieben. Diese unterhält die Androgensynthese und bedingt auch die tumoreigene Androgenbildung (Thelen et al. 2016).

Ein neuer Therapieansatz ist, sich die Escapemechanismen zunutze zu machen. So wurde in einer klinischen Studie eine intermittierende Androgendeprivation mit 
Abirateronacetat untersucht. Bei diesem Ansatz wurde die Therapie mit Abirateronacetat nach Tumorprogress unterbrochen, und es zeigte sich bei den Patienten ein passageres Absinken des PSA-Spiegels. Bei einigen Patienten erfolgte eine Androgendeprivations-Re-Therapie, die einen erneuten PSA-Progress weiter verlangsamen konnte. Damit konnte ein Therapieversagen von Abirateronacetat deutlich verzögert werden. Diesem hoffnungsvollen Ansatz sollten in Zukunft weitere größere Studien folgen (Thelen at al. 2016).

Antiandrogene wie Flutamid und Bicalutamid der 1. Generation und insbesondere Enzalutamid der 2.Generation besitzen eine hohe Affinität zum AR und die Gefahr einer Selektion nach einer Mutation liegt bei direkter AR-Blockade nahe und erschwert eine alternative Therapiemöglichkeit in der Folge des Therapieversagens. So könnten sich die Zahl der Liganden erweitern und sich völlig neue Signalkaskaden entwickeln, die wiederum schwer zu durchbrechen wären. Es ist denkbar, dass sich indirekte Antiandrogene ohne Affinität zum AR durchsetzen werden. Das untersuchte $8 \beta$-VE2 weist jedoch nach aktuellen Informationen des Herstellers auf eine unzureichende ER-Subtyp-Selektivität hin, sodass auch Aktivierungsprozesse im ERa stattfinden können (persönliche Mitteilung von Paul Thelen 2016). Diese Hinweise lassen $8 \beta-V E 2$ für einen späteren therapeutischen Nutzen als unzureichend erscheinen. Vielmehr könnten sich im menschlichen Organismus zusätzlich mit der ERa-Aktivierung, der in verschiedenen Organsystemem eine wichtige Rolle spielt, kanzerogene Prozesse entwickeln. So kann z. B. eine erhöhte Inzidenz für Mamma- und Endometriumkarzinome resultieren (Nilsson et al. 2011).

Ein weiterer neuer Ansatz ist, dem unter Androgenentzug entwickelten CRPC erneut Testosteron zu verabreichen. Damit könnten die kastrationsresistenten Mechanismen, welche sich an den Androgenentzug angepasst haben, gehemmt werden. Thelen zeigte an VCaP-Zellen in vitro und in vivo, dass Testosteron im CRPC die Fähigkeit besitzt, Karzinomzellen zum Teil zu eliminieren und in ein weniger malignes Stadium mit androgensensiblen Zellen umzuwandeln. Dies geschah bereits bei physiologisch niedrigen Testosteronwerten. Mit der Senkung des Wachstumsverhaltens ging gleichzeitig eine Abnahme der ARfl-Expression und seiner Spleißvariante AR-V7 einher. Dies eröffnet völlig neue Therapiestrategien mit einem weitaus geringeren Nebenwirkungsspektrum. Die klinischen Analysen 
mit einer intermittierenden Androgendeprivation stehen noch aus. Alternative Behandlungsmethoden können daher neue Möglichkeiten bieten (Thelen et al. 2013). Aktuell wird eine Kombination aus einer intermittierenden Androgendeprivationstherapie nach Therapieversagen mit Abirateronacetat oder Enzalutamid, verbunden mit einer Testosterontherapie untersucht (Thelen et al. 2016).

\subsection{Gene und Genprodukte im Prostatakarzinom}

\subsection{1 Östrogenrezeptor ER}

Östrogene, auch als Estrogene bezeichnet, sind Steroidhormone abgeleitet von der Grundstruktur Estran. Die Synthese findet bei beiden Geschlechtern statt. Sie werden vor allem in den weiblichen Ovarien produziert, in geringeren Konzentrationen in der Nebenniere und in den Hoden des Mannes. Auch im Fettgewebe können unter Vorliegen des Enzyms Aromatase aus Testosteron Östrogene gebildet werden. Sie beeinflussen im weiblichen Organismus die Geschlechtsreife und die sekundären Geschlechtsmerkmale sowie wesentliche Funktionen im Zyklus und in der Schwangerschaft der Frau. Östrogene haben in beiden Geschlechtern Auswirkungen auf den Lipid-, Kohlenhydrat- und Knochenstoffwechsel. Sie tragen durch ihren Einfluss auf den Epiphysenschluss und die Osteoklastenhemmung zum Knochenaufbau bei. Auch Funktionen bei der Homöostase im kardiovaskulären System, im Immunsystem und im zentralen Nervensystem sind bekannt (Rassow et al. 2008, Nilsson et al. 2011).

Die Zielstruktur der Östrogene ist die Gruppe der Östrogenrezeptoren (ER). Zugeteilt werden sie der Gruppe der Steroidrezeptoren mit Zinkfingerelementen, welche nach der Aktivierung als Transkriptionsfaktoren agieren. Es wurden bisher zwei Subtypen von Östrogenrezeptoren unterschieden, Östrogenrezeptor alpha (ER $\alpha$ ), kodiert vom ESR1-Gen auf Chromosom 6 und Östrogenrezeptor beta (ERß), kodiert vom ESR2-Gen auf Chromosom 14.

ERa wurde vorwiegend im Skelettsystem, den Hoden, Nebenhoden, im Stromagewebe der Prostata, Uterus, Ovarien, Mamma und Leber nachgewiesen. ER $\beta$ zeigte sich vor allem in Blase, Epithelgewebe der Prostata, Kolon und Lunge. 
Die Lokalisation kann je nach Alter und Krankheitszustand variieren (Nilsson et al. 2011). Untersuchungen zeigten antagonistische Effekte der beiden Rezeptoren und Veränderungen des Expressionsverhaltens bei malignen Prozessen, welche mit hoher Wahrscheinlichkeit eine wesentliche Rolle im Prostatakarzinom spielen (Chen et al. 2008).

In der Prostata ist ERa in der Basalzellschicht und ER $\beta$ im sekretorischen Epithel lokalisiert. Die Basallzellschicht ist für Proliferation verantwortlich und agiert androgenunabhängig, wohingegen das sekretorische Epithel für androgenabhängige Differenzierungprozesse steht (Bonkhoff et al. 2003). In der Karzinogenese nimmt ERa durch Proliferationssteigerung und inflammatorische Prozesse die Funktion eines Onkogens ein. Dagegen wirkt ER $\beta$ als Tumorsuppressor durch Differenzierung der Zellen und Induktion von Apoptosevorgängen (Bonkhoff und Berges 2009, Ellem und Risbridger 2007, de Marzo et al. 2007).

Während der Entwicklung des Prostatakarzinoms werden auch die ER durch Regulationsvorgänge verändert. So zeigen Tiermodelle eine Hochregulation des ERa in der sog. high-grade prostatischen intraepithelialen Neoplasie (HGPIN), welche wahrscheinlich krebserregende Wirkung über Östradiol vermittelt. In der Progression des ERa und des östrogenregulierten Progesteronrezeptors (PR) im Prostatakarzinom bis hin zum CRPC zeigt sich, dass Östrogen, aber auch Progesteron für das Tumorwachstum genutzt wird.

Auch TMPRSS2-ERG, eine Genfusion im Prostatakarzinom, welche mit aggressivem Wachstum assoziiert ist, wird über Signalwege, die von ER abhängig sind, reguliert. Durch Agonisten des ERa kann die Expression des TMPRSS2-ERG gesteigert werden, wohingegen ERß-Agonisten diese senken (Bonkhoff und Berges 2009, Mak et al. 2010). ERß wird im normalen sekretorischen Gewebe der Prostata noch exprimiert, dagegen wird er bereits im HGPIN nur noch teilweise und bei einem Gleason-Score von 3 - 5 kaum noch nachgewiesen. Dies gilt auch für hormonabhängige Tumore. Im kastrationsresistenten Prostatakarzinom sind nur noch Spuren oder gar kein ER $\beta$ mehr nachweisbar. Wie Studien belegen, kann jedoch die Expression des ER $\beta$ reaktiviert werden. Auslösen können dies ER $\beta$ spezifische Liganden, wie z. B. das Phytoöstrogen Tectorigenin (TG). 
Phytoöstrogene stammen aus dem Sekundärstoffwechsel von Pflanzen mit einer schwachen Östrogenwirkung.

Das Ausschalten von Genen, sogenanntes gene silencing durch HistonDeacetylasen (HDAC), kann durch dementsprechende Histon-DeacetylasenInhibitoren (HDACi) aufgehoben und die ER $\beta$-Expression wieder gesteigert werden. $\mathrm{Zu}$ den HDACi zählen auch Antiepileptika wie Valproat. Damit können Tumorsuppressoren, die im CRPC herunter reguliert wurden, wieder neu aktiviert werden und das Karzinom an Malignität verlieren (Thelen et al. 2004, Stettner et al. 2007, Strauss et al. 2009, Thelen et al. 2010, Stettner et al. 2012).

Beide Substanzen, Phytoöstrogene und HDACi, wirken expressionssteigernd auf ER $\beta$ und führen damit zur Regulation anderer CRPC-relevanter Gene. Bei der Stimulation mit TG zeigen sich Veränderungen in der Androgenkaskade und den androgenabhängigen Genen. So werden unter anderem der AR sowie PSA und PCA-3, ein Prostatakarzinom-spezifisches Indikatorgen mit Reaktivierung des ER $\beta$ in ihrer Expression deutlich gesenkt. Damit ist der aktivierte ERß in der Lage, progressionsfördernde Gene und vor allem zentrale Strukturen, wie den AR in seiner Expression zu hemmen. Dadurch wirkt ER $\beta$ anti-androgen.

Durch spezielle siRNA (small-interfering RNA) lässt sich ER $\beta$ ausschalten und die Prozesse der Expressionsänderungen wieder umkehren. Es zeigen sich erneut Expressionssteigerungen des AR, PSA, PCA-3 und anderer androgenabhängiger Gene (Stettner et al. 2007). Diese Aussagen konnten unter anderem auch für PSA am Mausmodell gezeigt werden (Thelen et al. 2005). Nebenwirkungen des TG sind kaum bis keine vorhanden, jedoch ist die Zusammensetzung der Präparate aufgrund der pflanzlichen Herkunft unterschiedlich. Schwierigkeiten ergeben sich so bei der Isolation, der Ausbeute und der Reinheit aus Pflanzenextrakten im Gegensatz zu chemischer Synthese (persönliche Mitteilung von Paul Thelen 2013).

Setlur konnte auch einen Zusammenhang zwischen dem aggressiveren Prostatakarzinom mit der TMPRSS2-ERG-Fusion und dem ER-Signalweg aufzeigen. In seinen Analysen stellte er ein geringeres Tumorzellwachstum nach der Stimulation mit dem synthetisch hergestellten ERß-Agonisten DPN fest (Setlur et al. 2008). 
Bei Tiermodelluntersuchungen wurden Gemeinsamkeiten in der Genexpression des Prostatakarzinoms bei Menschen und bei ER $\beta$-negativen Mäusen beobachtet. Daraus ergaben sich die Annahmen, dass Mausmodelle auch Aufschluss über die Genexpression im Menschen liefern könnten. Aufgrund der anatomischen Unterschiede der Organe wird dies jedoch diskussionswürdig (Warner und Gustafsson 2010).

Weitere Studien zeigen vielversprechende Ergebnisse an Geweben des Prostatakarzinoms und der BPH. Beide wurden mit dem synthetisch hergestellten selektiven ER $\beta$-Agonisten $8 \beta$-VE2 stimuliert. Es ließen sich induzierte Apoptosen im Stroma und Epithel nachweisen. Damit bietet die selektive Aktivierung des ER $\beta$ eine Therapiemöglichkeit des Prostatakarzinoms und der BPH. Auch die Kombinationstherapie mit ERa-Antagonisten wäre denkbar (Nilsson et al. 2011, siehe 1.3.2). Stettner konnte ebenfalls eine ERß-Expressionssteigerung auf Proteinebene durch die Stimulation mit 8ß-VE2 nachweisen (persönliche Mitteilung von Paul Thelen 2013).

\subsubsection{Prostataspezifisches Antigen}

Das prostataspezifische Antigen (PSA), auch als Semenogelase oder Kallikrein-3 bezeichnet, ist eine Glucoprotein-Serin-Protease, die in das Ejakulat des Mannes sezerniert wird. Es wird in den periurethralen Drüsen u. a. der Prostata produziert und dient der Verflüssigung des Samens. Die Produktion ist androgenabhängig. Erstmals wurde das Protein in den 70er Jahren von Hara beschrieben, der es in der humanen Seminalflüssigkeit nachweisen konnte (Hara et al. 1971). Isoliert wurde es später durch Wang, der es im normalen Prostatagewebe, der BPH und im maligne veränderten Prostatagewebe nachweisen konnte (Wang et al. 1979). Papsidero konnte nachweisen, dass das PSA im Prostatagewebe mit dem im Serum gemessenen identisch war (Papsidero et al. 1980).

In den darauffolgenden Jahren sollte PSA als Tumormarker etabliert werden. Es konnte gezeigt werden, dass das Fortschreiten und das Volumen des Prostatakarzinoms stark mit dem PSA-Wert korreliert. Ebenso konnte gezeigt werden, dass nach einer radikalen Prostatektomie der PSA-Wert in nicht messbare Bereiche sank (Stamey et al. 1987). 
Die PSA-Bestimmung als Screening-Methode ist jedoch bis heute umstritten, da die gewonnene Lebensverlängerung nicht in Relation mit dem Risiko durch Diagnostik und Therapie steht (Schröder et al. 2009). Falsch positive Befunde finden sich auch bei vorangegangener mechanischer Reizung, Entzündungs-prozessen und bei der BPH (Börgermann et al. 2006), obwohl sich beim Prostatakarzinom in Bezug auf die BPH bis zu 10-fach höhere Spiegel messen lassen (Partin et al. 1996). Zudem wird befürchtet, dass es zu vielen unnötigen Behandlungen asymptomatischer Karzinome kommt, die in Bezug auf die verbleibenden Lebensjahre wahrscheinlich unentdeckt geblieben wären und auf die Todesursache keinen Einfluss gehabt hätten.

Jedoch zeigen Studien mit einem längeren Überwachungszeitraum eine effektivere Senkung der Mortalität als sie durch die European Randomized Study of Screening for Prostate Cancer (ERSPC-Studie) gezeigt wurde (Huggosson et al. 2010). Der Aussagewert steigt auch mit der Höhe der gemessenen Konzentration und bei Patienten mit einer Lebenserwartung von über 10-15 Jahren, die von einer rechtzeitigen Behandlung einen lebensverlängernden Nutzen hätten (Haese et al. 2003). Zusammen mit anderen diagnostischen Verfahren hat die PSABestimmung ihren Stellenwert zur Indikation der darauffolgenden Biopsie, wenn der Wert erstmalig über $4 \mathrm{ng} / \mathrm{ml}$ in der Früherkennung liegt oder ein auffälliger PSA-Anstieg vorliegt. Er wird auch zur Einschätzung des Risikos bei lokal begrenzten Karzinomen zusammen mit der TNM-Klassifikation und dem GleasonScore herangezogen (Bergh et al. 2009).

Den wichtigsten Stellenwert besitzt die PSA-Messung jedoch klinisch als Verlaufsparameter nach kurativer Intervention. Als Marker für die Androgenrezeptoraktivität lassen sich Rückschlüsse auf die Proliferationaktivität des Prostatakarzinoms treffen. Ein Ansprechen auf die Therapie und ein Therapieversagen sind somit erkennbar und es können ggf. weitere therapeutische Schritte einleitet werden (Thelen et al. 2016).

\subsubsection{Androgenrezeptor}

Der Androgenrezeptor (AR) gehört wie auch der Östrogenrezeptor zur Klasse der Steroidrezeptoren. Seine Aktivierung erfolgt intrazellulär über Androgene, und er 
vermittelt als Transkriptionsfaktor die Aktivierung androgenregulierter Gene, die für die Proliferation und Differenzierung der Prostatazellen verantwortlich sind. Der Entzug der Androgene äußert sich durch Apoptose der Zellen (Culig et al. 2000, Lu et al. 1997).

Die Androgene Testosteron und vor allem DHT, tragen hauptsächlich zur Proliferation des Prostatakarzinoms bei. Daher spielt seit dieser Erkenntnis die Therapie des Androgenentzugs und das Eingreifen in diese Prozesse eine entscheidende Rolle in der Behandlung des Prostatakarzinoms (Vis und Schröder 2009). Nach anfänglichem Erfolg und dem Sistieren der Erkrankung folgt in den meisten Fällen im Laufe der Jahre die Entwicklung eines kastrationsresistenten Karzinoms. Dieses proliferiert androgenunabhängig oder nur mit Spuren von Androgen weiter (Knudsen und Penning 2010). Es wird auch diskutiert, dass dieser Mechanismus durch Aktivierung von Stammzellen in Gang gesetzt wird (Akakura et al. 1993).

Das Gen, welches für den AR kodiert, befindet sich auf Chromosom Xq11-q13 und ist ca. $180 \mathrm{~kb}$ lang. Seine 8 Exons kodieren das AR-Protein mit seiner transkriptionsregulierten Region und seinen Liganden-bindungsstellen. Der AR befindet sich nach Androgenbindung vor allem intranukleär in den Zellen des Drüsenepithels und in den Stromazellen der Prostata. In nicht proliferierenden Anteilen, wie in epithelialen Basalzellen, ist er gar nicht oder nur schwach vorhanden. Im inaktivierten Zustand liegt der AR an Chaperonen gebunden im Zytoplasma vor.

Während Testosteron vor allem im Blutkreislauf vorhanden ist und für zahlreiche Funktionen im Organismus verantwortlich ist, spielt das aktivierte Testosteron $(\mathrm{DHT})$, welches in einer 6-fach höheren Konzentration als Testosteron im Prostatagewebe vorliegt und eine höhere Affinität zum AR besitzt, die entscheidende Rolle der androgenvermittelten Prozesse innerhalb der Prostata. Nach der Aktivierung des AR durch DHT kommt es zu Konformationsänderungen und es bildet sich ein AR-Liganden-Komplex. Dieser gelangt in den Zellkern und bindet als Dimer an der spezifischen DNA-Bindungsstelle, auch als androgen response elements (ARE) bezeichnet, und leitet die Transkription androgenregulierter Gene, wie z. B. PSA ein. Dadurch spiegelt PSA als Marker die Aktivität des AR wider. 
Auch verschiedene Koaktivatoren werden für die Einleitung der Transkription benötigt, während andere als Korepressoren fungieren (Vis und Schröder 2009, Knudsen und Penning 2010, Feldmann und Feldmann 2001). Durch verschiedene Veränderungen in der Androgensignalkaskade kommt es trotz des Androgenentzugs und einem dadurch bedingten niedrigen Androgenspiegel nach ca. zwei bis drei Jahren durch neue oder verstärkte Signalwege zum kastrationsresistenten Prostatakarzinom und der damit verbundenen Progression der Erkrankung (Knudsen und Scher 2009, Yuan und Balk 2009). Bereits eine Amplifikation und Überexpression des AR würde ausreichen um eine Androgenablation zu kompensieren. Es ist anzunehmen, dass der Verlust von Transkriptionsmodulatoren dabei eine wesentliche Rolle spielt.

Veränderungen in der Ligandenbindungsstelle erweitern das Spektrum der Liganden und erlauben auch anderen Steroidhormonen, z. B. Progesteron, Östrogenen oder bereits minimalen Anteilen von Androgenen eine Induktion auszulösen. Antiandrogene verlieren dadurch an Effektivität und können sogar als Agonisten wirken. Dabei haben die AR-Inhibitoren der neuen Generation, die durch eine höhere Affinität zum AR gekennzeichnet sind, potenziell nach einer Mutation auch eine höhere Effektivität der AR-Aktivierung.

Alternative Spleißvarianten des AR, die auf die Transaktivierungs- und DNABindungsdomäne beschränkt sind und ohne Ligandenbindungsstelle auskommen, agieren völlig unabhängig von Androgenen. Die Entstehung beruht auf Modifikationen in der post-transkriptionellen Phase. Eine Erhöhung der Spleißvarianten wurde im CRPC nachgewiesen. Die Therapie durch direkte AR-Antagonisten wäre dadurch wesentlich eingeschränkt (Knudsen und Penning 2010, Thelen et al. 2016, siehe 1.3.4).

Auch posttranslationale Veränderungen des AR durch bestimmte Modulatoren, wie der Intrgrin like Growth Factor (IGF), tragen z. B. durch Phosphorylierung und Rekrutierung weiterer Kofaktoren zu einer erhöhten ligandenunabhängigen Aktivität des AR bei. Die genaue Regulierung dieser alternativen Kaskaden ist noch weitgehend unbekannt. Koaktivatoren können verschiedene Funktionen modulieren oder entsprechende Enzyme aktivieren oder auch Konformationsänderungen im AR bewirken. Die Deregulation dieser führt entweder zu einer ungehemmten 
Expression und verleiht dadurch dem AR eine Überempfindlichkeit gegenüber Androgenen oder lässt durch Modulationen im AR selbst Antagonisten als Agonisten fungieren; ein entscheidender Punkt beim Übergang vom hormonsensitiven zum kastrationsresistenten Prostatakarzinom. Auch die Herunterregulierung der Korepressoren kann eine solche Wirkung auslösen. Dazu tragen Makrophagen-induzierte Signale und die veränderte Lokalisation der Korepressoren bei. Auch die Suppression Zellzyklus-regulierender Faktoren, u. a. ausgelöst durch alternative Spleißvorgänge, fördert die Aktivität des AR zusätzlich. Das vorher bestehende Gleichgewicht wird nun auf die Seite der Koaktivatoren verlagert und schafft sich damit einen entscheidenden Signalweg zugunsten der Tumorprogression.

Intrakrine und adrenale Androgensynthese werden zusätzlich gesteigert. Die im Tumor bestehende Syntheseaktivität kann die normale Synthese sogar übersteigen und ist durch die niedrige Aktivierungsschwelle des AR noch effektiver. Dies kompensiert auch die Wirkung weniger affiner AR-Antagonisten und wirkt protektiv auf Chemotherapeutika.

Mit dem Wiederkehren der Tumorprogression steigt nicht allein die lokale Androgensynthese, sondern auch die damit verbundene Induktion androgensensibler Gene. Weiterhin tragen die Veränderungen der Abhängigkeit von spezifischen Proteinen dazu bei, die Produktion der Cholesterolsynthese und des freien Cholesterols anzutreiben (Leon et al. 2010, Locke et al. 2010, Knudsen und Penning 2010).

Diese Prozesse stellen eine große Herausforderung an die therapeutischen Maßnahmen, diese Signalwege zu unterbinden. Abirateronacetat ist ein CYP17A1Inhibitor und unterbindet die Reaktion Pregnenolon zu Dehydroepiandrosteron (DHEA) und Progesteron zu $\Delta 4$-Androstene-3,17-dion (siehe 1.3.5). Damit werden entscheidende Schritte in der Androgensynthese blockiert. Die klinische Anwendung erbrachte ein Ansprechen des CRPC und eine Reduzierung der Knochenmetastasen (Attard et al. 2008, Knudsen und Penning 2010).

Auch die adrenale Synthese spricht auf die Blockade an. Es resultiert ein sinkender Testosteronspiegel. Zusätzlich lenkt Abirateronacetat die Synthese zu 
Desoxycorticosterone um, einem Mineralkortikoid mit glucokortikoider Wirkung. Um einen Anstieg dieses Hormons zu unterbinden, wird therapeutisch zusätzlich Prednison oder Dexamethason verabreicht, um die hypophysär-adrenale Achse und die adrenale Kortikoidbildung zu blockieren (Andersson et al. 1995, Knudsen und Penning 2010).

Weiterhin stellt das zu den Aldo-Keto-Reduktasen gehörende Enzym AKR1C3 ein therapeutisches Ziel dar (AKR1C3-Blockade siehe 1.3.6). Neben anderen Katalysatoren scheint es eine dominierende Rolle in der Androgensynthese zu spielen (Montgomery et al. 2008). Indomethacin kann AKR1C3 spezifisch und potenziell hemmen, was darauf hindeutet, dass NSAIDs, die weder COX-1 noch COX-2 beeinflussen, eine effektive therapeutische Möglichkeit bieten (Byrns et al. 2008, Knudsen und Penning 2010). Eine Kombinationstherapie, die an unterschiedlichen Syntheseschritten und alternativen Aktivierungskaskaden ansetzt, könnte neue Therapieerfolge des CRPC erzielen.

MDV3100 (siehe 1.2.6) als selektiver potenzieller AR-Antagonist besitzt eine höhere Affinität als Bicalutamid. Zusätzlich wird die Androgensynthese auf drei verschiedenen Ebenen blockiert. Zum einen blockiert MDV3100, wie auch die Androgen-Inhibitoren der ersten Generation, die Ligandenbindungsstelle des AR. Zudem wird der Transport des aktivierten AR in den Zellkern und die Bindung an die DNA inhibiert. Die Komplexbindung mit dem AR reduziert damit die nukleare Effektivität, beeinträchtigt die Ligandenbindung zum $A R$ und die Aktivierung anderer Koaktivatoren. Es resultieren sinkende PSA-Spiegel, die mit der AR-Aktivität assoziiert sind, bei $43 \%$ der behandelten 30 Patienten mit CRPC in einer klinischen Studie Phase I/II (Tran et al. 2009, Thelen et al. 2016). Es werden Targets untersucht, die sowohl Enzyminhibition als auch AR-Blockade bewirken. Nichtsdestotrotz bilden die Modulationen des AR und die zusätzliche Androgensynthese eine potenzielle Therapieresistenz, die es zukünftig im CRPC zu überwinden gilt (Knudsen und Penning 2010).

\subsubsection{Spleißvarianten des Androgenrezeptors AR-V1 und AR-V7}

Eine gut untersuchte hochexprimierte Spleißvariante im CRPC ist AR-V7 (auch AR3). Dieser aktiviert Reportergene in Abwesenheit eines Liganden und trägt im 
CRPC zum Wachstum bei. Das Wachstum wird durch selektive AR-Antagonisten wie MDV3100 oder durch Herunterregulierung mit Hilfe einer siRNA des ARfI (AR full length) blockiert. Dadurch scheint ein wachstumsfördernder Stimulus für den AR-V7 vom ARfl auszugehen. Es ist anzunehmen, dass der Anstieg des AR-V7 eine akute Antwort auf die Kastration darstellt, um die Aktivität des Tumors zu gewährleisten und keine klonale Vermehrung der kastrationsresistenten Zellen ist (Watson et al. 2010). Dem widersprechen die Aussagen einer klinischen Studie, in der Patienten, bei denen die Spleißvariante AR-V7 exprimiert wurde und die mit modernen Antiandrogenen, wie Abirateronacetat oder Enzalutamid, behandelt wurden, kein Therapie-ansprechen zeigten. Einige anfangs AR-V7-negative Patienten zeigten erst unter der Therapie mit Abirateronacetat oder Enzalutamid eine Expression der Spleißvariante AR-V7 (Thelen et al. 2016).

Transkriptionsprodukte vom AR (ARfl), AR-V1, einer weiteren Spleißvariante des $A R$ und $A R-V 7$ wurden in den meisten Primärtumoren und vermehrt in Metastasen, vor allem in Knochenmetastasen nachgewiesen. Die Spleißvariante AR-V567 konnte in nur ca. $20 \%$ der Knochenmetastasen des CRPC nach-gewiesen werden. Hohe Konzentrationen für AR-V567 und AR-V7 in Knochenmetastasen gingen mit einer gestörten Zellregulation und kurzer Überlebenszeit der Zellen einher. Damit sind diese mit einer schlechteren Prognose assoziiert (Hörnberg et al. 2011).

Im Gegensatz dazu zeigten Zhao et al. 2012, dass weder AR-V1 noch AR-V7Expressionssteigerungen Aussagen über Rezidive beim hochmalignen Prostatakarzinom treffen können. Sie zeigten, dass AR-V1 und AR-V7 sich umgekehrt zum PSA-Spiegel verhalten und mit dem Alter korrelieren. Höhere Expressionen des AR-V1 fanden sich zudem in weniger malignen Tumorstadien (Zhao et al. 2012).

\subsubsection{Cytochrom P450c17alpha-Enzym A1 (CYP17A1)}

Das Gen CYP17 kodiert für Cytochrom P450c17alpha-Enzyme. CYP17A1, als Variante des CYP17, wurde als homozygotes Allel bei deutlich mehr Patienten mit Prostatakarzinom gefunden als andere Allelvarianten dieser Gruppe. Auch höhere Androgenspiegel wurden damit assoziiert (Wadelius et al. 1999). Das Enzym katalysiert in der Androgenbiosynthese die Reaktion von Pregnenolon zu 
Dehydroepiandrosteron (DHEA) und Progesteron zu $\Delta 4$-Androstene-3,17-dion (siehe 1.3.3). Diese Syntheseschritte sind in Metastasen des Prostatakarzinoms und Tumorrezidiven konsistent vermehrt aktiv und bilden damit wichtige Vorstufen des Testosterons. Damit trägt CYP17A1 zur Tumorprogression bei (Mostaghel et al. 2011). Auch die Aggressivität des Tumors wird damit assoziiert (Loukola et al. 2004).

Abirateronacetat, ein selektiver CYP17A1-Inhibitor, unterdrückt das Tumorwachstum bei Patienten mit CRPC durch Unterbindung der tumoreigenen Androgensynthese (siehe 1.3.3). Jedoch kann die Blockade weitere Mechanismen der Kompensation hervorrufen. Es kann die Hochregulation der Transaktivatoren des AR und dessen Spleißvarianten induzieren, auch eine Steigerung des CYP17A1 ist möglich und stellt damit zusätzliche Herausforderungen an die Therapieoptionen dar (Mostaghel et al. 2011). Cai zeigte die erhöhte Expression von CYP17A1 nach der Therapie mit CYP17A1- Inhibitoren und eine vermehrte Mutation des AR, welcher unabhängig von CYP17A1, aber weiter abhängig von der Steroidsynthese und anderen CYP-Enzymen bleibt (Cai et al. 2011).

\subsubsection{Aldo-Keto-Reduktase AKR1C3}

Das zur Familie der Aldo-Keto-Reduktasen gehörende Enzym AKR1C3, auch unter dem Namen 3a-Hydroxysteroiddehydrogenase Typ 2 bekannt, katalysiert verschiedene Prozesse in der Androgen-, Östrogen-, Progesteron- und Prostaglandinsynthese. Im Prostatagewebe katalysiert AKR1C3 bevorzugt die Reaktion von $\Delta^{4}$-Androstendion zu Testosteron. Dadurch reguliert AKR1C3 die Androgensynthese und die damit verbundene Aktivierung des Androgenrezeptors. Es konnte durch einen spezifischen AKR1C3-bindenden Antikörper immunhistochemisch gezeigt werden, dass vor allem in primären Adenokarzinomen eine Aktivität zu messen war. Im Gegensatz zeigten normale Prostataepithelzellen wenig bis keine Aktivität. Es wurde angenommen, dass AKR1C3 Einfluss auf Androgene und Prostaglangine in den Epithelzellen der Prostata ausübt (Fung et al. 2006). Lewis untersuchte unter anderem die Expression von AKR1C3 im Progesteronstoffwechsel des Brustgewebes. Er fand heraus, 
dass AKR1C3 vermindert in Tumorgeweben im Vergleich zum normalen Brustgewebe exprimiert wurde (Lewis et al. 2004).

Die erhöhte Expression in lokal begrenzten und fortgeschrittenen Karzinomen der Prostata wurde durch Wang bestätigt. Der Metabolismus des Prostaglandin $D_{2}$ wird auch durch AKR1C3 und der weiteren Isoform AKR1C2 beeinflusst und dadurch die Proliferation der Prostatazellen gefördert. Mit Hilfe der Transfektion von AKR1C3- und AKR1C2-cDNA in die androgenunabhängige Prostatakarzinomzelllinie PC-3 und fehlendem AR, konnte eine steigende Expression dieser nachgewiesen werden und zeigte damit eine steigende Proliferation der Zellen in Abhängigkeit der $\mathrm{PGD}_{2}-$ Stimulation (Wang et al. 2008).

Dozmorov bestätigte, dass die AKR1C3-Expression mit steigender Aggressivität des Tumors einhergeht. Er zeigte an der Prostatakarzinomzellinie PC-3 den Einfluss der AKR1C3 auf den Östrogen- und Androgenstoffwechsel, sowie die Aktivierung des IGF-1, des Akt-Signalweges und der Förderung der tumorvermittelten Angiogenese (Dozmorov et al. 2010). Mit diesen vielversprechenden Entwicklungen wird durch einen AKR1C3-Inhibitor versucht, diesen Prozess zu durchbrechen (Chen et al. 2012).

\subsubsection{Transmembranöse Protease:Serin 2-ERG Fusion (TMPRSS2-ERG)}

Das androgenkontrollierte Gen kodiert für eine transmembranöse Protease: Serin 2. In der Promotorregion befindet sich das androgenabhängige Element dieses Gens. In der VCaP-Zelllinie liegt dieses Gen fusioniert mit einem Mitglied der ETSFamilie der onkogenen Transkriptionsfaktoren vor (siehe 2.2.1). Somit regulieren auch Androgene die Expression dieser Transkriptionsfaktoren (Tomlins et al. 2005). Die TMPRSS2-ERG-Fusion vermittelt eine vermehrte Invasion der Tumorzellen. Eine Progression in Bezug auf aggressives Wachstumsverhalten wird auch damit assoziiert (Tomlins et al. 2008, Kumar-Sinha et al. 2008).

Es ist wahrscheinlich, dass die TMPRSS2-ERG-Fusion bereits im frühen Prostatakarzinom eine Rolle in der Entwicklung und Progression spielt. In der Studie von Perner wurden verschiedene Stadien des Prostatakarzinoms auf die TMPRSS2ERG-Fusion untersucht. Er konnte zeigen, dass nahezu 50\% der lokalisierten 
Prostatakarzinome, 30\% der hormonnaiven Metastasen, 33\% der kastrationsresistenten Metastasen und bereits 19\% der hochgradigen intraepithelialen Neoplasieherde die Fusion aufwiesen. Er beschrieb damit, bezogen auf die Inzidenz des Prostatakarzinoms, die Genfusion TMPRSS2-ERG als häufigste genetische Aberration, die bisher in Tumoren festgestellt wurde (Perner et al. 2007). Auch eine klinische Anwendung als Biomarker für einen zusätzlichen diagnostischen Test könnte aufgrund der hohen Spezifität von Nutzen sein. In einer Zusammenfassung der verschiedenen spezifischen Biomarker für das Prostatakarzinom, welche auf ihren diagnostischen und therapeutischen Nutzen getestet wurden, sind besonders PCA-3 und TMPRSS2-ERG herausragend. Während PCA-3 bereits in Form eines Urintests Anwendung findet, zeigt die TMPRSS2-ERG Genfusion eine weitere Option der Diagnostik auf (Salagierski et al. 2012). Der PCA-3Urintest ergab eine Sensitivität von 93\%, wobei der gleiche Test für TMPRSS2ERG eine höhere Spezifität von $87 \%$ aufwies. Aus dieser Schlussfolgerung sollte auch eine diagnostische Stanzbiopsie bei einem PSA $<10 \mathrm{ng} / \mathrm{ml}$ und positiven Urintest für PCA-3 oder TMPRSS2-ERG durchgeführt werden (Salami et al. 2013).

Weiterhin konnte beobachtet werden, dass nach der Androgendeprivation auch die Expression des TMPRSS2-ERG in vitro und in vivo sank. Im CRPC erholte sich am Beispiel der VCaP-Zelllinie nach Reaktivierung der Androgenrezeptorvermittelten Expression die Expression der TMPRSS2-ERG wieder vollständig. Dies gelang auch mit anderen androgenregulierten Genen (Cai et al. 2009).

\subsubsection{Prostate Cancer Gene 3 (PCA-3)}

Das prostataspezifische Gen wurde erstmals von Bussemakers 1999 beschrieben. Es zeigte im Vergleich zum gesunden Prostatagewebe, in welchem keine Expression nachgewiesen wurde, eine starke Überexpression im Prostatakarzinom. Andere Tumorgewebe wie Mamma-, Ovarial-, Endometrium-, Zervix- oder auch Hodenkarzinome zeigten keine Expression. Detektiert wurde das damals noch als DD3 (differential display clone 3) bezeichnete Gen auf Chromosom 9q21-22. Es konnte keine Funktion außer eines nicht kodierenden Abschnittes einer RNA festgestellt werden, womit davon auszugehen ist, dass kein Protein kodiert wird. Des 
Weiteren waren im Abgleich mit Datenbanken keine vergleichbaren Gene zu finden (Bussemakers et al. 1999).

Aus dem Namen DD3-Gen wurde später PCA-3 (prostate cancer gene 3), um der Prostataspezifität Ausdruck zu verleihen. Den histologischen Nachweis erbrachte Popa. In seiner Untersuchung konnte er zeigen, dass PCA-3 von den meisten HGPIN (high-grade prostatic intraepithelial neoplasia) exprimiert wurde und dies bei gesundem Drüsengewebe fern vom Tumor nicht zutraf. In der Nähe des Karzinoms stieg die Expression jedoch an (Popa et al. 2007). Auch Landers untersuchte einige Biomarker im Hinblick der molekularen Diagnose des Prostatakarzinoms und fand heraus, dass PCA-3 140-fach höher exprimiert wurde als im Gewebe einer BPH (Landers et al. 2005). Daher wurde PCA-3 als Marker bei der Diagnose verwendet. Er wird nach digitaler rektaler Prostatamassage im Urin gemessen und lässt Rückschlüsse zu, wie hoch die Wahrscheinlichkeit ist, dass eine bevorstehende Prostatabiopsie positiv ist. In diesem Test ist PCA-3 dem PSA überlegen (Haese et al. 2008). Die Datenlage zur weiteren Regulierung dieses Genes zeigte bisher noch keine klaren Ergebnisse.

\subsection{Selektive Östrogenrezeptorliganden}

Selektive Östrogenrezeptorliganden für den Typ ER können eine Reaktivierung bei zuvor verloren gegangener Expression und den damit verbundenen Funktionen erreichen (siehe 1.3.1). Liganden, die die Eigenschaft besitzen, spezifisch ER $\beta$ zu binden, sind in der Lage, nur Homodimere vom Typ ER zu bilden. Im Gegensatz dazu können ERa-Liganden zusätzlich zu ERa-Homodimeren auch ERa-ERß-Heterodimere bilden, wobei ERa mit seinen Funktionen dominiert (Powell und Wu 2008, Nilsson et al. 2011). Damit zeigte sich eine ligandenabhängige Formation je nachdem, ob sich Homodimere oder Heterodimere bilden (Monroe et al. 2005, Nilsson et al. 2011). Spezifische Liganden lösen eine Konformationsänderung in der Ligandenbindungsdomäne (LBD) des ER aus und induzieren dadurch mit Hilfe des nukleären Rezeptors Interaktionen mit speziellen Koaktivatoren (Hall und McDonnell 2005, Persissi et al. 2005, Nilsson et al. 2010, 2011). 
Unterschiedliche Liganden lösen je nach ER-Typ, an den sie binden, auch unterschiedliche Konformationsänderungen und damit auch unterschiedliche genregulative Prozesse aus (Leitman et al. 2010). In einer Untersuchung des ER $\beta$ zeigte dieser auch massive Effekte auf die Inhibition inflammatorisch wirkender Gene (Saijo et al. 2011, Nilsson et al 2011). Ein wichtiges Ziel ist es, bei selektiven Liganden größtmögliche Affinität zu ihren bestimmten ER-Subtypen zu erreichen.

\subsubsection{Diarylpropionitril}

Nachdem Phytoöstrogene für ihre selektiven Bindungseigenschaften am ER $\beta$ bekannt wurden, wurden auch synthetisch hergestellte Substanzen entwickelt. Meyers fand heraus, dass 2,3-bis(4-Hydroxyphenyl)Propionitril (Diarylpropionitril, DPN, Abbildung 1) ein potenzieller ER-Agonist ist, welcher eine 70-fach höhere Selektivität zu ER $\beta$ als zu ERa besitzt. Er konnte zeigen, dass die zweifache Nitrilgruppe im DPN für die Affinität und Selektivität zum ER $\beta$ verantwortlich ist (Meyers et al. 2001). Harrington bestätigte DPN eine 30-fach höhere Selektivität zum ER $\beta$ als zum ERa (Harrington et al. 2003).

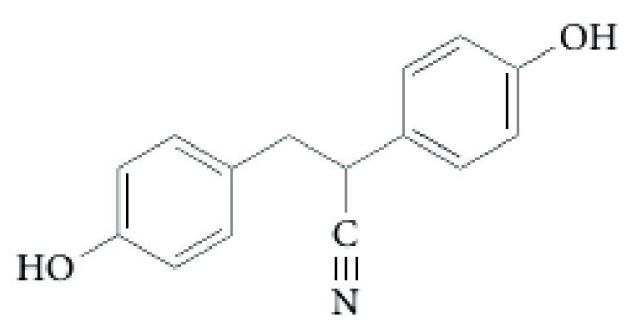

Diarylpropionitrile

(DPN)

Abbildung 1: Strukturformel des planaren ERß-selektiven Liganden DPN

Quelle: Nilsson et al. 2011, Seite 784

Jedoch zeigt DPN ähnlich moderate Bindungseigenschaften zum ER $\beta$ wie Phytoöstrogene (Meyers et al. 2001, Nilsson et al. 2011). Genau wie Phytoöstrogene besitzt DPN eine planare räumliche Struktur. Der Grund für die Selektivität der planaren Liganden ist, dass die Bindungstasche des ER $\beta$ flacher 
ist als die des ERa (Manas et al. 2004, Nilsson et al. 2011). Diese ermöglicht eine Passgenauigkeit der Liganden. Die Grenzen dieser Liganden zeigen sich jedoch in der Energiekurve. Es bestehen geringe Anziehungskräfte und Wechselwirkungsenergien der beiden Interaktionspartner vor allem auf Distanz. Diese tragen entscheidend zur moderaten Selektivität bei (Nilsson et al. 2011).

\subsubsection{8ß-Vinyl-Östradiol}

Es stellte sich heraus, dass Abstände unterhalb des Optimums zwischen Liganden und Rezeptor starke abstoßende Wechselwirkungen auslösen. Das Ziel war es, Liganden mit starken abstoßenden Wechselwirkungen zum ERa und gleichzeitig gegenteilige Effekte zum ER $\beta$ zu erzeugen, um die Selektivität und Bindungsstabilität zum Letzteren zu erhöhen. Dafür muss der Ligand in Bereichen, in denen sich die Aminosäurestrukturen des ERa und ER $\beta$ unterscheiden, eine größere Kongruenz zum ER $\beta$ aufweisen.

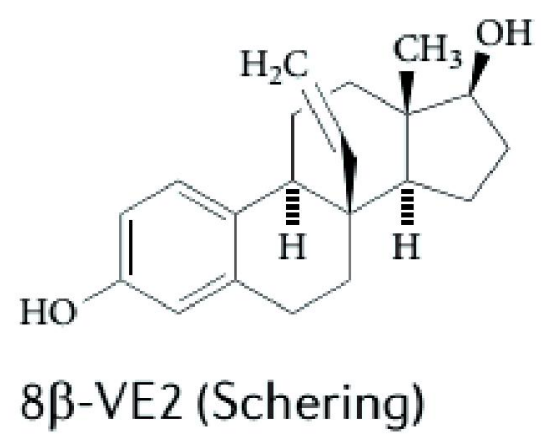

Abbildung 2: Strukturformel des nicht-planaren ER $\beta$-selektiven Liganden 8 8 -VinylÖstradiol (8ß-VE2)

Quelle: Nilsson et al. 2011, Seite 784

Um die Alternativen der unterschiedlichen Bindungsmodalitäten und Konformationsänderungen der Liganden zu umgehen, benötigt es einen unflexiblen, starren Liganden. 8ß-Vinyl-Östradiol (8-Vinylestra-1,3,5(10)-trien-3,17ß-diol oder $8 \beta$-VE2) ist ein asymmetrischer, sehr rigider und nicht-planarer Ligand mit hoher Selektivität zum ERß (Abbildung 2). Für die rezeptorgebundene Konformation, die eine energiearme Ligandenbindung mit dem ER $\beta$ zulässt, wurde 
Östradiol als Modellvorlage verwendet. In Studien an Prostatakarzinomgewebe und $\mathrm{BPH}$, die mit dem selektiven ER $\beta$-Agonisten behandelt wurden, zeigten sich Apoptosevorgänge in Epithelgewebe und im Stroma. Dadurch erhärtet sich die Annahme, mit selektiven ER $\beta$-Agonisten eine weitere wichtige Therapieoption in der Behandlung des Prostatakarzinoms und der BPH zu erzielen (Nilsson et al. 2011, McPherson et al. 2010, Dey et al. 2013).

Auch Hussain konnte zeigen, dass 8 $\beta$-VE2 die Regeneration der Prostatazellen beeinträchtigt. Diese ging mit Zellatrophie und Erschöpfung der Basalzellen einher. Außerdem beeinträchtigte sie die Klonogenität und die Selbsterneuerung der Prostatastammzellen (Hussain et al. 2012).

\subsection{Zielsetzung}

Der hohe Anteil des Prostatakarzinoms an den Tumorerkrankungen und die Anzahl der Neuerkrankungen pro Jahr, die stetig zunimmt, rücken das Prostatakarzinom immer stärker in den Fokus der medizinischen Wissenschaft. Gerade im Hinblick auf das Fortschreiten des Karzinoms bis zur Kastrationsresistenz und die heute noch unzureichenden Therapieoptionen in dieser Phase sind weitere wissenschaftliche Erkenntnisse nötig. Aktuell treten klinisch die Probleme der Therapieresistenz, der Kreuzresistenzen und der Entzugssyndrome bei der Behandlung des metastasierenden Prostatakarzinoms auf. Die androgene Signalkaskade als zentrale Achse, die durch den Tumorsuppressor ER $\beta$ beeinflusst werden kann, soll in dieser Arbeit thematisiert werden.

Ziel der vorliegenden Arbeit ist, die Wirkungsweise zweier östrogenspezifischer Rezeptorliganden zu untersuchen und den Zusammenhang zwischen ERßExpression und der onkoprotektiven Wirkung auf kastrationsresistente Prostatakarzinomzellen zu zeigen. Langfristig soll diese Arbeit einen Beitrag zu alternativen Therapieansätzen des kastrationsresistenten Prostatakarzinoms leisten.

Um dies zu erreichen, sollte die Auswirkung von zwei selektiven Östrogenrezeptorliganden - Diarylprorprionitril und 8ß-Vinyl-Östradiol - auf adrogenabhängige Gene in Prostatakarzinomzellen gezeigt und miteinander ver- 
glichen werden. Hierfür wurden Zellen der Vertebral Cancer of the ProstateZelllinie (VCaP) in vitro mit den beiden Rezeptorliganden stimuliert.

Daran anschließend wurden die Effekte der Aktivierung auf RNA-Ebene mit Hilfe einer quantitativen rtPCR überprüft. Dabei wurden vor allem folgende androgenabhängige Gene berücksichtigt: AKR1C3, ARfl, ARV1 und seine Spleißvariante AR-V7, CYP17A1, ERß, PSA und TMPRESS2-ERG. Des Weiteren erfolgte die Analyse der Expression von AR und CYP17A1 mittels Gelelektrophorese und Western-Blot. 


\section{Material und Methoden}

\subsection{Verwendete Materialien}

\subsubsection{Zellkultur}

Tabelle 1: Verwendete Zelllinie und Medien

\begin{tabular}{|l|l|}
\hline Material & Hersteller und Firmensitz \\
\hline VCaP & ATCC, LGC Standards GmbH, Wesel, Deutschland \\
\hline RPMI 1640 & PAN-Systems GmbH, Nürnberg, Deutschland \\
enthält & \\
$10 \%$ fetales Kälberserum & Sigma, Taufkirchen, Deutschland \\
$2 \%$ Amino-Acid-Solution & Sigma, Taufkirchen, Deutschland \\
$1 \%$ L-Glutamin & PAA, Cölbe, Deutschland \\
\hline Trypsin EDTA & Lonza, Verviers, Belgien \\
\hline Ethanol (EtOH) & Merck, Darmstadt, Deutschland \\
\hline
\end{tabular}

\subsubsection{Stimulationsreagenzien}

Tabelle 2: Verwendete Stimulanzien

\begin{tabular}{|l|l|}
\hline Stimulationsreagenz & Hersteller und Firmensitz \\
\hline $8 \beta-V E 2$ & Bayer®, Leverkusen, Deutschland \\
\hline DPN & Tocris Bioscience, Minneapolis, USA \\
\hline
\end{tabular}

\subsubsection{Biologische Substanzen und Chemikalien}

Tabelle 3: Verwendete Substanzen und Chemikalien

\begin{tabular}{|l|l|}
\hline Biologische Substanzen und Chemikalien & Hersteller und Firmensitz \\
\hline Agarose & Invitrogen, Karlsruhe, Deutschland \\
\hline Gene Ruler ${ }^{\text {TM }}$ 100bp DNA Leader & Fermentas, St. Leon-Rot, Deutschland \\
\hline 6x Loading Dye Solution & Fermentas, St. Leon-Rot, Deutschland \\
\hline 10x TAE-Buffer & Invitrogen, Karlsruhe, Deutschland \\
\hline qPCR Master Mix & Eurogentec, Köln, Deutschland \\
\hline Plus SYBR ${ }^{\circledR}$ Green I with fluorescein & Eurogentec, Köln, Deutschland \\
\hline RNAse-Inhibitor & Eppendorf, Hamburg, Deutschland \\
\hline Novex ${ }^{\circledR}$ Precast Gels & $\begin{array}{l}\text { Life Technologies GmbH, Karlsruhe, } \\
\text { Deutschland }\end{array}$ \\
\hline Pierce $^{\circledR}$ RIPA Buffer & Thermo Scientific, Rockford, Illinois, USA \\
\hline Protran $^{\circledR}$ Nitrozellulosemembran & Whatman GmbH, Dassel, Deutschland \\
\hline
\end{tabular}




\begin{tabular}{|l|l|}
\hline Western Lightning ${ }^{\circledR}$ Plus-ECL & $\begin{array}{l}\text { Perkin Elmer, Waltham, Massachusetts, } \\
\text { USA }\end{array}$ \\
\hline ProteinSimpleFluorChem E & BioZym, Hessisch Oldendorf, Deutschland \\
\hline
\end{tabular}

\subsubsection{Kits und Assays}

Tabelle 4: Verwendete Kits und Assays

\begin{tabular}{|l|l|}
\hline Kits und Assays & Hersteller und Firmensitz \\
\hline Agilent RNA 6000 Nano Kit & $\begin{array}{l}\text { Agilent Technologies, Waldbronn, Deutsch- } \\
\text { land }\end{array}$ \\
\hline AlmarBlue-Assay & Serotec, Düsseldorf, Deutschland \\
\hline $\begin{array}{l}\text { Cell Proliferation ELISA, BrdU (calorime- } \\
\text { tric) }\end{array}$ & Roche, Mannheim, Deutschland \\
\hline Mini RNA Isolation II Kit ${ }^{\text {TM }}$ & Zymo Research, Freiburg, Deutschland \\
\hline Omniscript $^{\circledR}$ RT Kit & Qiagen, Hilden, Deutschland \\
\hline RNeasy $^{\circledR}$ Mini Kit & Qiagen, Hilden, Deutschland \\
\hline Roti $^{\circledR}$-Nanoquant Kit & Carl Roth, Karlsruhe, Deutschland \\
\hline Quantitect ${ }^{\text {TM }}$ SYBR ${ }^{\circledR}$ Green RTPCR Kit & Eurogentec, Seraring, Deutschland \\
\hline pPCR MasterMix Plus for SYBR ${ }^{\circledR}$ Green & Eurogentec, Seraring, Deutschland \\
\hline Total PSA ELISA EIA-3719 & $\begin{array}{l}\text { DRG Instruments GmbH, Marburg, Deutsch- } \\
\text { land }\end{array}$ \\
\hline
\end{tabular}

\subsubsection{Primer und Antikörper}

Tabelle 5: Verwendete Primer

\begin{tabular}{|l|l|}
\hline Primer und Antikörper & Hersteller und Firmensitz \\
\hline Spezifische sense Primer & IBA, Göttingen, Deutschland \\
\hline Spezifische antisense Primer & IBA, Göttingen, Deutschland \\
\hline Random Primer & Invitrogen, Karlsruhe, Deutschland \\
\hline
\end{tabular}

Tabelle 6: Verwendete Gene und ihre Sequenzen

\begin{tabular}{|c|c|c|c|c|}
\hline Gen & Sequenz (sense) & Sequenz (antisense) & $\begin{array}{l}\text { AT in } \\
{ }^{\circ} \mathrm{C}\end{array}$ & $\begin{array}{l}\text { MT } \\
\text { in }{ }^{\circ} \mathrm{C}\end{array}$ \\
\hline $\begin{array}{l}\text { AKR1C3 } \\
2012\end{array}$ & $\begin{array}{l}\text { 5'CGA GAC AAA CGA TGG } \\
\text { GTG G 3' }\end{array}$ & $\begin{array}{l}5^{\prime} \text { GGC ACA AAG GAC TGG } \\
\text { GTC CT } 3^{\prime}\end{array}$ & 63 & 82 \\
\hline ARP & $\begin{array}{l}\text { 5'CGA CCT GGA AGT CCA } \\
\text { ACT AC } 3^{\prime}\end{array}$ & $\begin{array}{l}\text { 5'ATC TGC TGC ATC TGC } \\
\text { TTG 3, }\end{array}$ & 60 & 77 \\
\hline ARfl 02/12 & $\begin{array}{l}\text { 5'CCA TCT TGT CGT CTT } \\
\text { CGG AAA TGT TAT GAA GC } \\
3^{\prime}\end{array}$ & $\begin{array}{l}\text { 5'AGC TTC TGG GTT GTC } \\
\text { TCC TCA GTG G 3' }\end{array}$ & 69 & 83 \\
\hline
\end{tabular}




\begin{tabular}{|c|c|c|c|c|}
\hline ARV1 0212 & $\begin{array}{l}5^{\prime} \text { CCA TCT TGT CGT CTT } \\
\text { CGG AAA TGT TAT GAA GC } \\
3^{\prime}\end{array}$ & $\begin{array}{l}\text { 5'CTG TTG TGG ATG AGC } \\
\text { AGC TGA GAG TCT 3' }\end{array}$ & 70 & 81 \\
\hline ARV7 0212 & $\begin{array}{l}5^{\prime} \text { CCA TCT TGT CGT CTT } \\
\text { CGG AAA TGT TAT GAA GC } \\
3^{\prime}\end{array}$ & $\begin{array}{l}5^{\prime} \text { TTT GAA TGA GGC AAG } \\
\text { TCA GCC TTT CT 3' }\end{array}$ & 65 & 81 \\
\hline $\begin{array}{l}\text { Cyp17A1 } \\
03 / 12\end{array}$ & $\begin{array}{l}\text { 5'GCT GAC TCT GGC GCA } \\
\text { CAC T 3' }\end{array}$ & $\begin{array}{l}5^{\prime} \text { TTG AAC AGG GCA AAG } \\
\text { GTG G } 3^{\prime}\end{array}$ & 60 & 85 \\
\hline$E R-\beta a b c$ & $\begin{array}{l}\text { 5'TTG CTG AAC GCC GTG } \\
\text { ACC GA 3' }\end{array}$ & $\begin{array}{l}5^{\prime} \text { CCT CGC ATG CCT GAC } \\
\text { GTG GG 3' }\end{array}$ & 60 & 86 \\
\hline PSA & $\begin{array}{l}\text { 5'TGA ACC AGA GGA GTT } \\
\text { CTT GAC 3' }\end{array}$ & $\begin{array}{l}5^{\prime} \text { CCC CAG AAT CAC CCG } \\
\text { AGC AG } 3^{\prime}\end{array}$ & 61 & 87 \\
\hline $\begin{array}{l}\text { TMPRSS2- } \\
\text { ERG }\end{array}$ & $\begin{array}{l}\text { 5' CAG GAG GCG GAG GCG } \\
\text { GA 3' }\end{array}$ & $\begin{array}{l}5^{\prime} \text { CCG TAG GCA CAC TCA } \\
\text { AAC AAC GA } 3^{\prime}\end{array}$ & 60 & 83 \\
\hline
\end{tabular}

Tabelle 7: Verwendete Antikörper

\begin{tabular}{|c|c|}
\hline Antikörper & Hersteller und Firmensitz \\
\hline AR-Ak Ab-2 (Cat.\# RB-1358) & $\begin{array}{lcl}\text { Lab Visions } & \text { Corporation, } & \text { Fremont, } \\
\text { Kalifornien, USA } & & \end{array}$ \\
\hline Anti-a-Tubulin clone B-5-1-2 (\# T 5168) & Sigma, St. Louis, Missouri, USA \\
\hline CYP17A1 (Cat. 14447-1-AP) & Protein Tech, Manchester, UK \\
\hline Rabbit secondary antibody (P0448) & Dako, Glostrup, Dänemark \\
\hline
\end{tabular}

\subsubsection{Software}

Tabelle 8: Verwendete Software

\begin{tabular}{|l|l|}
\hline Software & Hersteller und Firmensitz \\
\hline Agilent Expert-Software & $\begin{array}{l}\text { Agilent Technologies, Waldbronn, Deutsch- } \\
\text { land }\end{array}$ \\
\hline iCycler iQ ${ }^{\circledR}$ Real Time Detection Software & BioRad, München, Deutschland \\
\hline E.A.S.Y. Enhanced Analysis System & Herolab, Wiesloch, Deutschland \\
\hline GraphPad Prism ${ }^{\circledR} 5.0$ & GraphPad Software, San Diego (CA), USA \\
\hline ImageJ & http://imagej.nih.gov/ij/ (free download) \\
\hline
\end{tabular}

\subsubsection{Geräte}

Tabelle 9: Verwendete Geräte

\begin{tabular}{|l|l|}
\hline Geräte & Hersteller und Firmensitz \\
\hline Brutschrank $\mathrm{CO}_{2}$-Auto-Zero & Heraeus, Hanau, Deutschland \\
\hline Lichtmikroskop & Leitz, Bensheim, Deutschland \\
\hline Werkbank und Abzug HA 2472 GS & Heraeus Lamin Air, Hanau, Deutschland \\
\hline Laborfuge 400R/ GL & Heraeus, Hanau, Deutschland \\
\hline Nano-Chip-Priming-Station & Agilent Technologies, Waldbronn, Deutschland \\
\hline
\end{tabular}




\begin{tabular}{|l|l|}
\hline Agilent 2100 Bioanalyzer & Agilent Technologies, Waldbronn, Deutschland \\
\hline GenAmp PCR System 2400 & PerkinElmer, Rodgau-Jügesheim, Deutschland \\
\hline iCycler & BioRad, München, Deutschland \\
\hline Mikrowelle & Bauknecht, Stuttgart, Deutschland \\
\hline Gelschlitten mit Taschenkamm & BioRad, München, Deutschland \\
\hline $\begin{array}{l}\text { Geldokumentationsanlage E.A.S.Y. } \\
\text { RH-3 }\end{array}$ & $\begin{array}{l}\text { Herolab GmbH Laborgeräte, Wiesloch, } \\
\text { Deutschland }\end{array}$ \\
\hline Omnifuge 2.0 RS & Heraeus, Hanau, Deutschland \\
\hline Thermomixer 5436 & Eppendorf, Hamburg, Deutschland \\
\hline Mikroplatten-Reader MR5000 & Dynatech, Denkendorf, Deutschland \\
\hline Becherglas & Schott, Mainz, Deutschland \\
\hline
\end{tabular}

\begin{tabular}{|l|l|}
\hline Geräte & Hersteller und Firmensitz \\
\hline Neubauer Zählkammer & $\begin{array}{l}\text { Assistent Glaswarenfabrik Karl Hecht, Sond- } \\
\text { heim, Deutschland }\end{array}$ \\
\hline Vortexer & IKA, Staufen, Deutschland \\
\hline RNA Nano Chip & Agilent Technologies, Waldbronn, Deutschland \\
\hline MS1 Minishaker & IKA, Staufen, Deutschland \\
\hline
\end{tabular}

\subsubsection{Verbrauchsmaterial}

Tabelle 10: Verwendetes Verbrauchsmaterial

\begin{tabular}{|c|c|}
\hline Verbrauchsmaterial & Hersteller und Firmensitz \\
\hline Einweghandschuhe & Meditrade $^{\circledR}$, Kiefersfelden, Deutschland \\
\hline 50ml Gewebekulturflaschen & Nunc, Wiesbaden, Deutschland \\
\hline Quarzglas-Küvetten & Brand, Wertheim, Deutschland \\
\hline Pipettenspitzen $10 \mu \mathrm{l}-1000 \mu \mathrm{l}$ & Nunc, Wiesbaden, Deutschland \\
\hline 6-well-Platten (Cellstar) & Greiner bio-one, Frickenhausen, Deutschland \\
\hline Eppendorf-Gefäße 1,5ml & Eppendorf, Wesseling-Berzdorf, Deutschland \\
\hline Pipetten $2,5-1000 \mu \mathrm{l}$ & Eppendorf, Wesseling-Berzdorf, Deutschland \\
\hline Serologie Pipetten $10 \mathrm{ml}$ & Sarstedt, Nümbrecht, Deutschland \\
\hline
\end{tabular}

\subsection{Methoden}

\subsubsection{Zelllinie}

Die VCaP (Vertebral-Cancer of the Prostate) -Zelllinie entstammt einer Knochenmetastase im Bereich der Lendenwirbelsäule, die von einem Patienten mit kastrationsresistentem Prostatakarzinom 1997 gewonnen wurde. Sie zeigt eine 
Androgensensibilität sowohl in vitro als auch in vivo und exprimiert PSA sowie den AR. Gemeinsam mit der ETS-Familie trägt sie das prostataspezifische, androgenregulierte Gen TMPRSS2 (Korenchuk et al. 2001). Die häufigste Genfusion mit TMPRSS2 ist die TMPRSS2-ERG-Genfusion. Sie ist circa bei $50 \%$ der Patienten mit auffälligen PSA-Werten, anschließender Biopsie und operativem Eingriff, im Bioptat enthalten. Weiterhin zeigen 90\% aller Prostatakarzinome eine gesteigerte ERG-Expression, die die TMPRSS2-ERG-Fusion aufweist (Tomlins et al. 2005). Aufgrund dieser Charakteristik ist die VCaP-Zelllinie ein repräsentatives Modell für Studien des fortgeschrittenen Prostatakarzinoms (Korenchuk et al. 2001).

\subsubsection{Zellkultur}

Zur Aufbewahrung der Zellen dienten 50-ml-Kulturflaschen mit entsprechendem RPMI Medium, dem 10\% Kälberserum, 2\% Aminosäurelösung und 1\% L-Glutamin beigesetzt waren. Diese wurden im Brutschrank bei $37{ }^{\circ} \mathrm{C}$ und $5 \% \mathrm{CO}_{2}$-Gehalt gelagert und wöchentlich passagiert.

\subsubsection{Passagieren der Zellen}

Das Passagieren der Zellen fand wöchentlich statt; je nach Zellwachstum auch ausschließlich ein Wechsel des Mediums. Dieses Vorgehen wurde unter sterilen Bedingungen in der Werkbank und dem Tragen von Handschuhen vollzogen. Nach Kontrolle der Vitalität und der Zelldichte unter dem Lichtmikroskop wurde das Kulturmedium vorsichtig abgesaugt. Fand ein reiner Wechsel des Mediums statt, wurden vorsichtig $3 \mathrm{ml}$ des auf $37^{\circ} \mathrm{C}$ erwärmten Mediums beigefügt und die Zellen wieder im Brutschrank gelagert. Zur Passage wurden nach dem Absaugen $2 \mathrm{ml}$ Trypsin zur Lyse zugegeben, sodass der Boden der Flasche vollständig bedeckt war. Zur besseren Wirkung der Lyse wurden die Zellen 5 min in den Inkubator überführt. Nach Kontrolle der Lösung der Zellen wurden diese in Reagenzröhrchen übertragen und $3 \mathrm{ml}$ Medium beigefügt, um die lytische Wirkung des Trypsins zu verringern. Das Gemisch wurde bei $10.000 \mathrm{U} / \mathrm{min} 10 \mathrm{~min}$ zentrifugiert. Die Zellen reicherten sich am Boden in Form eines Pellets an. Der Überstand wurde sehr behutsam unter dem Abzug abgesaugt und die Zellen erneut mit 2 ml Medi- 
um überschichtend angereichert. Diese wurden mit jeweils $1 \mathrm{ml}$ Medium auf zwei neue Zellflaschen verteilt und zusätzlich noch einmal mit $2 \mathrm{ml}$ Medium versetzt. Anschließend wurden diese wieder im Brutschrank unter den in Kapitel 2.2.2 beschriebenen Bedingungen gelagert.

\subsubsection{Konservierung der Zellen}

Um die Zellen längerfristig zu lagern und für spätere Versuche bereit zu halten, wurden sie in flüssigem Stickstoff bei $-196{ }^{\circ} \mathrm{C}$ eingefroren. Dafür wurden die Zellen, wie unter Punkt 2.2.2.1 beschrieben, herausgelöst und anschließend zentrifugiert. Das daraus entstandene Zellpellet wurde mit Hilfe von Cell Freezing Medium suspendiert und anschließend in Gefäße $(1,8 \mathrm{ml})$ überführt. Danach erfolgte die stufenweise Herunterkühlung von $-20{ }^{\circ} \mathrm{C}$ auf $-196{ }^{\circ} \mathrm{C}$ im Zeitraum von drei Tagen mit entsprechender Lagerung. Zur Wiederverwendung wurden die Zellen in $37^{\circ} \mathrm{C}$ warmem Wasser aufgetaut und wieder in Kulturflaschen überführt.

\subsubsection{Stimulation der Zellen mit 8ß-VE2 und DPN}

Um die Zellen auf Genexpression und Wachstum zu untersuchen, wurden diese einer bestimmten Konzentration der verschiedenen Substanzen ausgesetzt. Danach wurde die gesamte zelluläre RNA isoliert und nach quantitativer Messung in cDNA umgeschrieben. Die Genexpression wurde mittels spezifischer Primer und der real-time PCR bestimmt.

Anhand der Neubauerzählkammer wurde die Anzahl der Zellen pro ml bestimmt. Die angestrebte Zellzahl betrug 300.000 Zellen pro ml. Die Zellen wurden in der entsprechenden Verdünnung in $1 \mathrm{ml}$ Nährmedium in jeweils eine Vertiefung (well) der 6-well-Platten überführt und anschließend für 48 Stunden im Brutschrank inkubiert. Am 3. Tag erfolgte die Stimulation mit 10-3 molarer Konzentration des $8 \beta-V E 2$ bzw. des DPN. Für 8$\beta-V E 2$ wurden drei Vertiefungen und für DPN vier Vertiefungen benötigt (siehe Tabelle 11). Da DPN in 100\%igem Ethanol gelöst ist, wurde eine zusätzliche Kontrolle mit Ethanol angelegt. 
Tabelle 11: Verwendete Stimulationskonzentrationen

\begin{tabular}{|l|l|}
\hline $\mathbf{8} \beta$-VE2-Stimulation pro well & DPN-Stimulation pro well \\
\hline Mediumkontrolle RPMI & Mediumkontrolle RPMI \\
\hline & Ethanol \\
\hline $50 \mu \mathrm{mol}$ & $50 \mu \mathrm{mol}$ \\
\hline $100 \mu \mathrm{mol}$ & $100 \mu \mathrm{mol}$ \\
\hline
\end{tabular}

Nach der Stimulation betrug die Inkubationszeit im Brutschrank 24 Stunden. Am 4.Tag fand die Isolation der RNA statt.

\subsubsection{RNA-Isolierung}

Mit Hilfe des Mini RNA Isolation II Kit ${ }^{\mathrm{TM}}$ wurde die RNA aus den Zellen extrahiert und gereinigt. Diese Methode ist geeignet für die spätere Analyse der Genexpression. Die Isolation erfolgte gemäß des Protokolls der Firma Zymo Research. Die durchgeführte Methode beruht auf dem Prinzip der Affinität. Die Durchführung erfolgte in kleinen Säulen, die Membranpartikel auf Silicabasis enthalten und durch ihre hohe Affinität zu RNA gekennzeichnet sind. Dadurch hafteten RNA-Partikel, während andere Bestandteile ungehindert durchflossen. Am Ende der Reinigung erfolgte die Elution der RNA mit Hilfe von RNase-freiem Wasser. Die einzelnen Schritte werden im Folgenden erläutert:

Nach Prüfung der Zellen auf Vitalität unter dem Lichtmikroskop wurde der Überstand aus den 4 bzw. 3 angesetzten wells der 6-well-Platten vorsichtig abgesaugt.

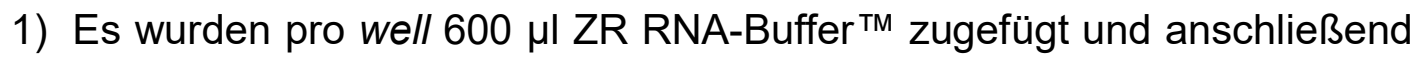
für ca. 5 Minuten in den Inkubator überführt. In dieser Zeit wurden die Säulen mit einem entsprechenden Eppendorfgefäß vorbereitet.

2) Das Gemisch aus ZR RNA-Buffer ${ }^{T M}$ und Zellen wurde in die Säulen übertragen und anschließend eine Minute bei $13.000 \mathrm{U} / \mathrm{min}$ zentrifugiert. Die angesammelte Flüssigkeit in der Tube wurde verworfen.

3) Anschließend wurden jeweils $400 \mu$ RNA Pre-Wash Buffer zugegeben und bei $13000 \mathrm{U} / \mathrm{min}$ für eine Minute zentrifugiert. Die Flüssigkeit in den Eppendorfgefäßen wurde wieder verworfen. 
4) Im nächsten Schritt wurden jeweils $700 \mu \mathrm{l}$ RNA Wash-Buffer in die Säulen pipettiert und 30 Sekunden bei $13.000 \mathrm{U} / \mathrm{min}$ zentrifugiert. Der Durchfluss wurde verworfen.

5) Es folgte die Wiederholung des in Punkt 4 beschriebenen Durchganges mit $400 \mu \mathrm{l}$ RNA Wash-Buffer.

6) Daraufhin wurden die Säulen mit leeren Tuben erneut bei $13.000 \mathrm{U} / \mathrm{min}$ für zwei Minuten zentrifugiert, um den RNA Wash-Buffer vollständig zu entfernen.

7) Die Säulen wurden in RNase-freie Gefäße überführt. Es wurden jeweils $35 \mu \mathrm{l}$ DNase- und RNase-freies Wasser direkt auf die Matrix in die Säulen pipettiert und ruhten bei Raumtemperatur für eine Minute. AnschlieBend wurden die Säulen mit ihren Tuben bei $13.000 \mathrm{U} / \mathrm{min}$ für $30 \mathrm{Se}$ kunden zentrifugiert. Die gewonnene RNA befand sich in den Tuben und konnte sofort verwendet oder bei $-20^{\circ} \mathrm{C}$ gelagert werden.

Zur weiteren Verwendung war es aufgrund der hohen Empfindlichkeit gegenüber RNasen erforderlich, unter besonders reinlichen Bedingungen zu arbeiten. Dies beinhaltete das Tragen von Handschuhen, das Arbeiten in einem RNase-freien Bereich und das Benutzen von RNase-freien Materialien. Weiterhin war darauf zu achten, dass die isolierte RNA während der Verwendung auf Eis gelagert wurde.

\subsubsection{Messung der RNA}

Um die Konzentration der RNA der jeweiligen Probe zu bestimmen, wurde ein Bioanalyzer der Firma Agilent verwendet. Basierend auf der MikrofluidikTechnologie ermöglicht er eine schnelle quantitative und qualitative Bestimmung der RNA. Die lab on a chip-Technologie enthält alle Proben und Reagenzien auf einem Chip. Die Proben bewegen sich durch die angelegte Spannung vom Probegefäß durch Mikrokanäle und werden dort elektrophoretisch aufgetrennt. Durch interkalierende Fluoreszenzfarbstoffe werden die einzelnen Komponenten detektiert und in Banden und Elektropherogramme (Peaks) übersetzt. Ebenfalls wird eine genaue Konzentration der RNA mit Hilfe der Software angegeben. Zur Bestimmung der Konzentration wurde das Agilent RNA 6000 Nano Kit genutzt. Die 
einzelnen Schritte gemäß dem Protokoll des Herstellers werden im Folgenden beschrieben:

1) Zuerst wurden $65 \mu \mathrm{l}$ RNA 6000 Gelmatrix gemäß den Angaben des Herstellers gefertigt und zusätzlich $1 \mu \mathrm{R}$ RA 6000 Nano dye concentrate zugegeben.

2) Der hergestellte Gel-Farbstoffmix wurde bei $13.000 \mathrm{U} / \mathrm{min}$ für 10 Minuten zentrifugiert.

3) Mit Hilfe der dazugehörigen primingstation wurde der RNA Nano Chip mit dem angefertigten Gel-Farbstoffmix beladen.

4) Anschließend wurden die für die Proben vorgesehenen wells mit $5 \mu \mathrm{l}$ RNA Nano Marker beladen und dazu jeweils $1 \mu \mathrm{l}$ der zu messenden Proben pipettiert. Nicht benötigte wells wurden mit $1 \mu$ I RNA Nano Marker zusätzlich beladen.

5) Daraufhin wurde ein zuvor auf Raumtemperatur gebrachter Leitermix mit $1 \mu \mathrm{l}$ in das dafür vorgesehene well überführt.

6) Der beladene Chip wurde für 1 Minute mit dem dafür vorgesehenen IKA Vortexer vorbereitet.

7) Der Chip wurde in den Agilent 2100 Bioanalyzer platziert und die Software zur Bestimmung der RNA-Konzentration gestartet.

8) Nach der Messung erfolgte die Reinigung der Elektroden anhand eines Elektrodenreinigungschips, der mit $350 \mu$ RNase-freiem Wasser zuvor beladen wurde.

Die Elektropherogramme geben Aufschluss über die Reinheit und Intaktheit der RNA. In dem folgenden Diagramm ist die Fluoreszenz gegen die Zeit in Sekunden aufgetragen (Abbildung 3). Trifft die Aussage über angemessene Reinheit und Intaktheit zu, lassen sich 3 Peaks im Diagramm erkennen. Der erste Peak wird als Marker-Peak bezeichnet. Er sollte bei allen Proben erkennbar sein und ist als Eichung zu werten. Er repräsentiert die 5S Untereinheiten der tRNA. Der zweite Peak stellt die 18S und der dritte Peak die 28S Untereinheit der rRNA eukaryonter Zellen dar. Zwischen dem zweiten und dritten Peak sollten keine weiteren Peaks auftreten, sondern nur eine Hintergrundfloureszenz erkennbar sein; andernfalls würde es für degenerierte RNA sprechen. Zur weiteren Auswertung kann die 
rRNA-Ratio aus 28S/18S gebildet werden. Liegen die Werte über 1,7, kann eine Aussage über eine qualitativ hochwertige rRNA getroffen werden. Das dazugehörige Gelformat (siehe Abbildung 4) zeigt drei scharf abzugrenzende Banden. Die Marker, welche die 18S- und 28S-Untereinheit der rRNA darstellen, sind für die Unversehrtheit der RNA zu werten.

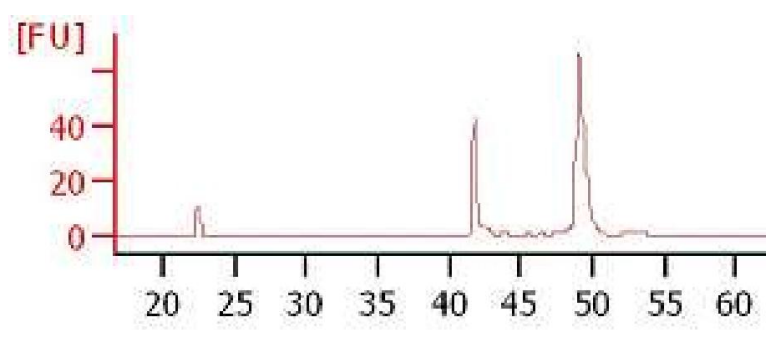

Abbildung 3: Elektropherogramm mit 18S- und 28S-Bande
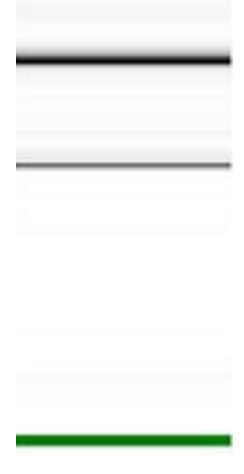

Abbildung 4: Gel-Darstellung der Bioanalyzer-Messung

\subsubsection{Reverse Transkription der RNA}

Für die spätere Reproduktion der PCR wurden einzelsträngige Abschnitte der cDNA benötigt. Für die Herstellung wurde zunächst RNA durch reverse Transkriptase in cDNA umgeschrieben. Voraussetzung dafür ist eine reine und intakte RNA.

Hierfür wurde das Omniscript® RT Kit verwendet. Dieses beinhaltet eine Omniscript reverse Transkriptase, die aus E. coli Zellen isoliert wurde und die Funktionen einer RNA-abhängigen DNA-Polymerase und eine Hybrid-abhängige Exonuklease (Ribonuklease $\mathrm{H}$ ) erfüllt. Die DNA-Polymerase sorgt für die Synthese der zur RNA komplementären DNA-Abschnitte. Im Kit enthaltene Primer binden 
zunächst an die RNA und bilden den Anlagepunkt für die DNA-Polymerase. Diese bildet mit Hilfe der im Kit enthaltenen dNTPs den zur RNA komplementären DNAStrang. Die Ribonuklease H spaltet nun die RNA-Matrize vom entstandenen RNADNA-Hybrid ab. Es besteht keine Affinität zu nicht-hybridisierter RNA.

Der experimentelle Ablauf der reversen Transkription wird im Folgenden beschrieben:

Es wurde ein Ansatz von $20 \mu$ l benötigt, der sich aus 14,2 $\mu$ l RNase-freiem Wasser mit darin enthaltenen 500 ng RNA und 5,8 $\mu$ l Mastermix zusammensetzte. Zunächst wurden die 14,2 $\mu \mathrm{l}$, bestehend aus RNA und RNase-freiem Wasser bei $65^{\circ} \mathrm{C}$ für fünf Minuten inkubiert. Danach erfolgt die Zugabe von 5,8 $\mu$ l Mastermix, der sich wie folgt zusammensetzt:

$\begin{array}{ll}\text { 10x RT Buffer } & 2 \mu \mathrm{l} \\ \text { 5mM dNTPs } & 2 \mu \mathrm{l} \\ \text { RT } & 1 \mu \mathrm{l} \\ \text { RNase Inhibitor } & 0,3 \mu \mathrm{l} \\ \text { Random Primer } & 0,5 \mu \mathrm{l}\end{array}$

Im Thermocycler der Firma GenTech erfolgte die Synthese der cDNA nach folgendem Schema:

$\begin{array}{ll}10 \text { min } & 25^{\circ} \mathrm{C} \\ 60 \text { min } & 37{ }^{\circ} \mathrm{C} \\ 5 \text { min } & 93^{\circ} \mathrm{C} \\ \text { Erhaltung } & 4{ }^{\circ} \mathrm{C}\end{array}$

Anschließend wurde das Produkt der reversen Transkription in einem Verhältnis von 1:4 mit RNase-freiem Wasser verdünnt.

\subsubsection{Verfahren der PCR}

Zur Amplifikation der cDNA werden bestimmte Primer benötigt, die an ausgewählte Stellen der cDNA binden und diese dann durch Anlagerung der DNA- 
Polymerase vervielfältigen. Zuvor wird die DNA-Doppelhelix in Einzelstränge aufgetrennt. Durch das Erhitzen auf eine Temperatur von $94{ }^{\circ} \mathrm{C}$ werden beide DNAStränge durch Denaturierung voneinander getrennt. Nach Absenken der Temperatur können sich Primer, die aus Oligonukleotiden bestehen, an das freie 3 '-Ende der DNA anlagern. Besteht ein Primer aus sense und antisense, lagert sich der andere am 5 -Ende der DNA an und begrenzt den replizierten Abschnitt. Die Primer charakterisiert eine spezifische Annealing-Temperatur (siehe Tabelle 6), die für das Anlagern vorliegen muss. Sie liegt 5-10 ${ }^{\circ} \mathrm{C}$ unter dem Schmelzpunkt der Primersequenzen.

Die DNA-Polymerase synthetisiert in 5'-3'-Richtung und erzeugt mit Hilfe der enthaltenen dNTPs einen komplementären DNA-Strang (Elongation). Dieser Abschnitt erfolgt mit einer hitzestabilen taq-Polymerase bei einer Temperatur von 68$72{ }^{\circ} \mathrm{C}$. Danach startet der Zyklus erneut. Dadurch wird eine exponentielle Amplifikation gewährleistet. Durch das Anfallen kürzerer Segmente, als der gewünschte DNA-Abschnitt, vor allem in den späteren Zyklen, endet die PCR nach ca. 30 Zyklen. Das PCR-Produkt kann durch Agarose-Gelelektrophorese anhand seiner Größe aufgetrennt und durch den Vergleich entsprechender DNA-Leitern mit bekannten DNA-Fragmenten identifiziert werden.

\subsubsection{Quantitative PCR (real-time PCR)}

Bei diesem Verfahren lässt sich in Echtzeit die quantitative Messung anhand eines Fluoreszenzsignals der PCR-Produkte messen. Der interkalierende Farbstoff SYBR ${ }^{\circledR}$ Green bindet an doppelsträngige DNA-Abschnitte. Zunächst inaktiv beigemischt wird dieser durch DNA-Produktion aktiviert. Die Messung findet nach jedem Zyklus statt und erlaubt eine Aussage über die Menge der amplifizierten DNAAbschnitte in Abhängigkeit zur Intensität des fluoreszierenden Signals. Somit lässt diese Methode einen Rückschluss auf die im Zyklus neu entstandenen DNAAbschnitte zu. Die Unterscheidung zwischen den gezielten DNA-Sequenzen (sog. Targets) und unerwünschter Nebenprodukte ist nicht möglich. Zur qualitativen Bewertung der rtPCR eignet sich die direkt im Anschluss der rtPCR durchgeführte Schmelzpunktanalyse oder eine Agarose-Gelelektrophorese. 


\subsubsection{Schmelzpunktanalyse}

Dieses Verfahren eignet sich mit Hilfe eines verwendeten Fluoreszenzmarkers zur qualitativen Auswertung der PCR-Produkte. Nach Abschluss der rtPCR wird die Temperatur von $50{ }^{\circ} \mathrm{C}$ auf $95{ }^{\circ} \mathrm{C}$ stetig um 0,5 K erhöht. Durch Denaturierung und dem damit verbundenen Zerfall der DNA-Doppelstränge in ihre Einzelstränge resultiert ein Signalabfall durch Lösen des Farbstoffes von der DNA. Dieser Peak wird als Schmelzpunkt bezeichnet. Die Schmelzpunkttemperatur ist spezifisch für das zu messende PCR-Produkt. Der Peak ist abhängig von der Länge des PCRProduktes und dem Verhältnis der Nukleinbasen Guanin-Cytosin und ThyminAdenin.

\subsubsection{Amplifikationskurve}

Die Auswertung erfolgte anhand des Amplifikationsdiagrammes der rtPCR. Die Fluoreszenzintensität wird gegen die Anzahl der Zyklen aufgetragen. Der Verlauf der sigmoidalen Kurve wird in 4 Phasen differenziert.

\section{Lineare Grundphase}

Die erste Phase ist durch eine lineare Fluoreszenz gekennzeichnet, dabei überschreitet die Fluoreszenz noch nicht die Hintergrundfluoreszenz. Die Dauer der sogenannten Baseline beträgt ca. 20 Zyklen.

\section{Frühe exponentielle Phase}

In dieser Phase steigt die Fluoreszenz rapide an und übersteigt den Schwellenwert (Threshold), der dem 10-Fachen an Fluoreszenz der Baseline entspricht. Der Zyklus, der den Threshold schneidet, wird auch als threshold cycle bezeichnet. Er ist der Beginn der exponentiellen Phase (log-Phase) und dient der späteren Berechnung zur Einsetzung der steigenden cDNA-Konzentration.

\section{Exponentielle Phase}

Die Amplifikation erreicht ihr Optimum. Es kommt unter idealen Bedingungen zur Verdopplung der PCR-Produkte nach jedem Zyklus. 


\section{Plateau-Phase}

Die PCR-Effizienz sinkt nun mit steigendem Zyklus und es kommt zu keiner weiteren Fluoreszenzzunahme. Gründe hierfür liegen in der Abnahme der Reagenzkonzentrationen, die zunehmende Instabilität der Polymerase und der Produktinhibition. Die Plateau-Phase kennzeichnet das Ende der rtPCR.

Zur Erstellung der Amplifikationskurven wurde für die Datenanalyse die Software rt-detection der Firma BioRad verwendet.

\subsubsection{Durchführen der rtPCR}

Für die Durchführung wurden alle Komponenten in einem separaten Raum in einem Reaktionsansatz zusammengeführt. Zur Verwendung kam der qPCR MasterMix Plus SYBR ${ }^{\circledR}$ Green I with Fluorescein der Firma Eurogentec. Der Ansatz einer Probe setzte sich wie folgt zusammen:

$\begin{array}{ll}\text { Mastermix } & 10 \mu \mathrm{l} \\ \text { sense-Primer } & 0,2 \mu \mathrm{l} \\ \text { antisense-Primer } & 0,2 \mu \mathrm{l} \\ \mathrm{H}_{2} \mathrm{O} & 4,6 \mu \mathrm{l} \\ \text { cDNA } & 5 \mu \mathrm{l}\end{array}$

Eine zusätzliche cDNA-freie Probe wurde bei jeder Messung als Kontrolle mitgeführt. Alle Substanzen, mit Ausnahme des $\mathrm{H}_{2} \mathrm{O}$, wurden zunächst bei Raumtemperatur aufgetaut. Der fertige Reaktionsansatz wurde bei $13.000 \mathrm{U} / \mathrm{min}$ für 5 Minuten zentrifugiert und anschließend direkt in den iCycler $\mathrm{iQ}^{\circledR}$ der Firma BioRad überführt. Es wurde folgendes Programm durchgeführt. 
Tabelle 12: Verwendetes PCR-Programm

\begin{tabular}{|l|l|l|l|l|}
\hline Zyklus & Wiederholungen & Temperatur & Dauer & Funktionaltät \\
\hline 1 & $1 \mathrm{x}$ & $95{ }^{\circ} \mathrm{C}$ & $30 \mathrm{~s}$ & $\begin{array}{l}\text { Aktivierung der Polymerase; } \\
\text { beginnende Denaturierung }\end{array}$ \\
\hline 2 & Step1 60x & $\begin{array}{l}9{ }^{\circ} \mathrm{C} \\
55-72{ }^{\circ} \mathrm{C}\end{array}$ & $\begin{array}{l}10 \mathrm{~s} \\
30 \mathrm{~s}\end{array}$ & $\begin{array}{l}\text { Denaturierung } \\
\text { Annealing und Elongation }\end{array}$ \\
\hline \multirow{3}{*}{3} & Step2 60x & $\begin{array}{l}60-95{ }^{\circ} \mathrm{C} \\
\text { Anstieg um }\end{array}$ & je 15s & Schmelzpunktanalyse \\
\hline 4 & $71 \mathrm{x}$ & $0,5 \mathrm{~K}$ & & \\
\hline
\end{tabular}

\subsubsection{Auswertung der rtPCR}

Um die Konzentration der spezifischen cDNA in den Proben zu bestimmen, wurde der threshold cycle (CT-Wert) zur Berechnung herangezogen. Es wurde ein Diagramm mit Proben erstellt, deren unterschiedliche Fragment-Konzentrationen bekannt sind. Die CT-Werte der Standardproben wurden gegen den Logarithmus der cDNA-Kopien aufgetragen. Durch lineare Verbindung entstand die Standardlinie zur Bestimmung unbekannter cDNA-Konzentrationen. Durch Auftragen der CTWerte unbekannter Probenkonzentrationen wird der Logarithmus der DNA-Kopien ermittelt, welcher durch Umrechnung die Ausgangsmenge der zu untersuchenden Probe ergibt (siehe Abbildung 5).

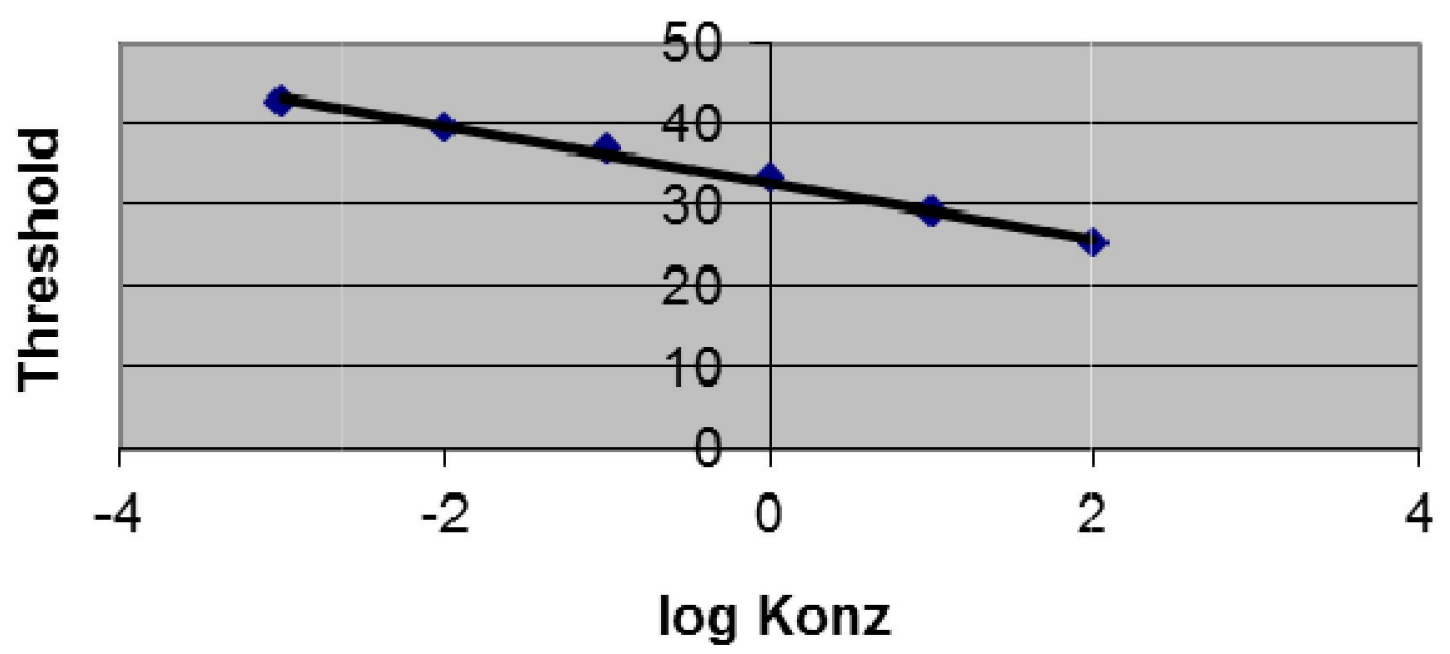

Abbildung 5: Threshold cycle zur Bestimmung der cDNA-Konzentration 
Die Erstellung der Standardkurve und die Berechnung der Ausgangskonzentrationen erfolgten mit Microsoft ${ }^{\circledR}$ Excel. Die statistische Auswertung der ermittelten Konzentrationen erfolgte mit dem Programm GraphPad Prism ${ }^{\circledR}$ 5.0.

\subsubsection{Gelelektrophorese}

Die Gelelektrophorese dient zur Identifizierung des Genproduktes, sofern die Größe der DNA bekannt ist. Diese kann zusätzlich zur Schmelzpunktanalyse eine Aussage über die Qualität der PCR geben. Durch Anlage einer elektrischen Spannung werden die DNA-Produkte ihrer Größe nach aufgetrennt. Als Lauffeld dient Agarosegel, das, je kleiner das Amplikon ist, umso schneller in Spannungsrichtung durchlaufen wird.

Für die Durchführung wurde $1,5 \mathrm{~g}$ Agarose in $100 \mathrm{ml}$ TAE-Buffer durch Erhitzen gelöst. Die entstandene 1,5\%ige-Lösung wurde in einen Gelschlitten mit enthaltenen Taschenkammern übertragen. Nach der Aushärtung des Gels wurden die Proben, die zuvor mit 6-fach Load-Buffer vermischt wurden, in die Taschenkammern übertragen. In die erste Kammer wurde die Leiter übertragen. Nach Anlage einer Spannung von $80 \mathrm{~V}$ und einer Dauer von 75 min war die Gelelektrophorese abgeschlossen.

Um die entstandenen Banden unter UV-Licht sichtbar zu machen, wurde das ausgehärtete Gel in Ethidiumbromid-Lösung gelegt. Ethidiumbromid interkaliert mit den Nukleinsäuren und lässt die Banden unter UV-Licht aufleuchten. Das dafür genutzte Gel-Dokumentationssystem E.A.S.Y. RH-3 der Firma Herolab macht die Banden sichtbar und bietet die Möglichkeit das Ergebnis fotographisch festzuhalten. Mit Hilfe der Leiter lassen sich die aufgetrennten DNA-Produkte vergleichen und bei bekannter Größe identifizieren. Unerwünschte Produkte sind häufig als unscharfe zusätzliche Banden zu erkennen.

\subsubsection{Proteinanalysen}

Um eine genaue Aussage über die Veränderungen der Proteinexpression nach der Stimulation treffen zu können, wurde ein Western Blot durchgeführt. Hierbei 
wurden die Proteine nach der Auftrennung über eine PolyacrylamidGelelektrophorese auf eine Trägermembran übertragen.

Zunächst wurden die Proteine aus ihren Zellflaschen nach der Stimulation mit $8 \beta-V E 2$ und DPN aus ihrer Zellkultur isoliert. Die Stimulationskonzentration betrug $100 \mu \mathrm{Mol}$ (Kapitel 2.2.3). Nach einer Inkubationszeit von 48 Stunden wurde der Überstand entfernt. Um sämtliche Rückstände des Mediums zu entfernen, wurden 2-3 ml DPBS pro Zellflasche zugegeben und verteilt, um anschließend wieder behutsam entfernt zu werden. Die Zellen wurden mit jeweils $200 \mu$ Lysis-Puffer (Modified RIPA) gewaschen und 10 min auf Eis gelagert. Danach wurden zusätzlich durch mechanische Hilfsmittel Zellreste vom Boden der Zellflasche gelöst. Der Lysis-Puffer setzte sich wie folgt zusammen:

$\begin{array}{ll}\mathrm{NaCl} & 150 \mathrm{mM} \\ \text { EDTA } & 1 \mathrm{mM} \\ \text { Tris-HCl }(\mathrm{pH} \mathrm{7,4)} & 50 \mathrm{mM} \\ \mathrm{NP}-40 & 1 \% \\ \mathrm{Na}-\mathrm{Desoxycholat} & 0,25 \% \\ \mathrm{PMSF} & 1 \mathrm{mM} \\ \text { Aprotinin, Leupeptin, Pepistatin } & \text { jeweils } 1 \mu \mathrm{g} / \mathrm{l} \\ \mathrm{Na}_{3} \mathrm{VO}_{4} & 1 \mathrm{mM} \\ \mathrm{NaF} & 1 \mathrm{mM}\end{array}$

Überführt in Eppendorfgefäße wurden die Zellen bei $4{ }^{\circ} \mathrm{C}$ und $13.000 \mathrm{U} / \mathrm{min}$ für 10 Minuten zentrifugiert, um nicht gelöste Bestandteile zu trennen. Ein Teil des Überstandes wurde für eine eventuelle Wiederholung der Bestimmung der Proteinkonzentration bei $-20{ }^{\circ} \mathrm{C}$ aufbewahrt.

Es folgte die Berechnung der Proteinkonzentration als Voraussetzung für die Gelelektrophorese, die ein Auftragen von gleichen Konzentrationen benötigt. Es wurde die Verschiebung der Absorption photometrisch gemessen und in eine geeichte Standardgerade übertragen. Anhand dieser wurde die Konzentration der Proteine errechnet. Für die Absorptionsverschiebung wurde der Brillant-Coomassie-Blau- 
Farbstoff aus dem Roti $^{\circledR}$-Nanoquant Kit verwendet. Dieser führt durch Bindung an die Proteine zu einer Verschiebung des Absorptionsmaximums.

Für die Proteinexpression des AR wurde für den Western Blot der AR-Antikörper Ab-2 der Lab Visions Corperation (Fremond, Kalifornien, USA) und CYP17A1 (Cat. 14447-1-AP, protein tech, Manchester, Vereinigtes Königreich) verwendet. Dabei diente $\alpha$-Tubulin mit dem monoklonalen $\alpha$-Tubulin-Antikörper clone B-5-1-2 der Firma Sigma als Ladekontrolle.

Für die Elektrophorese dienten die vorgefertigten Gele Novex ${ }^{\circledR}$ der Firma Life Technologies $\mathrm{GmbH}$ und Potran ${ }^{\circledR}$ Nitrozellulosemembrane der Whatman $\mathrm{GmbH}$. Die proteinbindende Membran hybridisiert dabei mit den Antikörpern. Um die Proteine anschließend sichtbar zu machen, wurde ein zweiter Antikörper der Firma Dako mit einem Fluoreszenzmarker FluorChem E der Firma BioZym eingesetzt. Zur Visualisierung diente der Western Lightning ${ }^{\circledR}$ Plus-ECL. Für die optische Dichte der einzelnen Banden wurde die ImageJ-Methode (http://imagej.nih.gov/ij/) verwendet.

\subsubsection{BrdU-Test}

Um das Wachstumsverhalten der Zellen nach Stimulation zu quantifizieren, wurde der Bromdesoxyuridin-Test (BrdU) angewendet. Bromdesoxyuridin ist ein synthetisches Analogon zu dem Nukleosid Thymidin bzw. Desoxythymidin. Dabei wird es nach Aufnahme in die Zellen phosphoryliert und in der S-Phase der DNAReplikation anstelle des Desoxythymidins eingebaut.

Zur immunhistochemischen Quantifizierung der Menge an BrdU in den denaturierten DNA-Strängen wird die indirekte Immunfluoreszenz-Methode angewandt. Dabei wird zunächst ein spezifischer Primärantikörper an die freiliegenden BrdUNukleoside gebunden. Anschließend kann ein mit einem Peroxidase-Konjugat versehener Sekundärantikörper an den Primärantikörper aufgetragen werden. Schließlich erfolgt eine Kalorometrie-Messung oder ein ELISA, in dem die Farbreaktion der Peroxydase bestimmt wird. Die Extinktionsmessung steht im Verhältnis zur Proliferation der Zellen. 
Für die Durchführung wurde das ELISA-BrdU-cell proliferation-Kit verwendet. Die Zellen wurden auf 96-well-Platten mit einer Dichte von 5000 Zellen pro well angesetzt und für 48 Stunden inkubiert. Anschließend erfolgte die Stimulation mit 8ß-VE2. Des Weiteren folgte eine Zugabe von BrdU labeling in einer Konzentration von $1 \mu \mathrm{M}$. Nach einer weiteren Inkubationszeit von 24 Stunden erfolgten die immunhistochemischen Färbungen und die darauffolgende Chemilumineszenz nach den Angaben des Herstellers. Hierfür wurde der Mikroplatten-Reader MR5000 der Firma Dynatech verwendet. Zum Schluss folgte die Auswertung der Chemilumineszenzdaten.

\subsubsection{Statistische Auswertung}

Die Ergebnisse beruhen auf einer Reihe von Experimenten in Einfach- und vor allem in Dreifachbestimmungen. Mit der GraphPad Prism 5.0 Software erfolgte die statistische Auswertung. Zur Übersicht wurden Balkendiagramme mit Standardabweichung und Mittelwert genutzt. Dafür wurde der ungepaarte t-Test mit einem Konfidenzintervall von 95\% verwendet. Statistische Signifikanz wurde bei einem pWert von $<0,05$ anerkannt. Auch die $p-W e r t e$ sind in den Balkendiagrammen aufgeführt. 


\section{Ergebnisse}

Es folgen die Ergebnisse der Stimulationsversuche an VCaP-Zellen mit $8 \beta$-VE2 und DPN und deren Auswirkungen auf die im CRPC relevanten Gene. Ein besonderer Schwerpunkt lag auf dem ER $\beta$ und dessen Einfluss auf die im kastrationsresistenten Prostatakarzinom hochregulierten Gene. So folgen die Ergebnisse der cDNA-Analysen nach den Stimulationen mit 8ß-VE2 und DPN sowie die Ergebnisse des Proliferationstests.

\subsection{Stimulation der VCaP-Zellen mit 8 $\beta$-VE2}

Es folgen die Ergebnisse der Stimulation der VCaP-Zelllinie unter dem selektiven ERß-Agonisten 8ß-VE2 mit jeweils $50 \mu \mathrm{M}$ und $100 \mu \mathrm{M}$. Zur Kontrolle wurde das Medium RPMI verwendet. Die Ergebnisse folgen gemäß der Zielsetzung in angebrachter Reihenfolge und keiner chronologischen Ordnung. Die Stimulationsdauer betrug 24 Stunden. Nach RNA-Isolierung, Messung und Überführung in amplifizierbare cDNA werden die Ergebnisse der rtPCR dargestellt (siehe Kapitel 2.2.2- 2.2.11).

\subsubsection{Expression von ER $\beta$}

Zum Nachweis des spezifischen Einflusses des 8$\beta$-VE2 auf den ER $\beta$ folgen die Ergebnisse der rtPCR. Die Veränderungen werden in Abbildung 6 deutlich. Auf der Ordinatenachse ist die RNA-Expression in attomol/pg logarithmisch aufgeführt. Dagegen ist auf der Abszisse in Form eines Boxplots oder einer Balkengrafik Median, Quartil und Whisker des ER $\beta$ in RPMI, $50 \mu \mathrm{M}$ und $100 \mu \mathrm{M}$ 8 $\beta$-VE2 aufgetragen. Die Stimulation zeigt mit $50 \mu \mathrm{M}$ eine signifikante Steigerung des ER $\beta$ im Vergleich zum Kontrollmedium. Die Expression stieg unter dem Einfluss von $50 \mu \mathrm{M}$ $8 \beta-V E 2$

$(3,02$ attomol/ $\mu \mathrm{g} \pm 0,41, \mathrm{n}=3)$ um das 26 -Fache bei $\mathrm{p}=0,012$. Bei der Stimulation mit $100 \mu \mathrm{M}(3,69 \pm 0,10, n=3)$ fand eine Steigerung der Expression in Bezug zur RPMI Kontrolle um den Faktor 30 bei $p=0,0001$ statt. Auch dabei bestand eine Signifikanz im Vergleich zur Kontrolle. 


\section{$\operatorname{ER} \beta$}
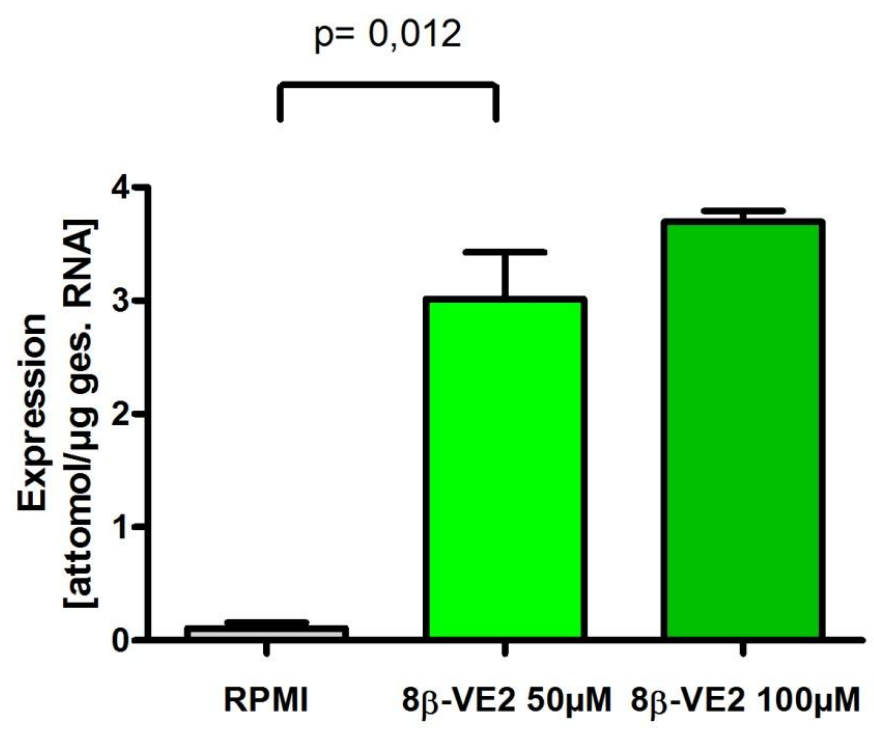

Abbildung 6: ER $\beta$-Expression in VCaP-Zellen unter $8 \beta$-VE2-Stimulation nach Auswertung der rtPCR

$3 \times 10^{5}$ VCaP-Zellen wurden in $50 \mu \mathrm{M}$ bzw. $100 \mu \mathrm{M} 8 \beta$-VE2-haltigem Nährmedium 24 Stunden lang stimuliert. Nach Ernte der Zellen wurde die mRNA isoliert und mittels quantitativer $r$ PPCR mit spezifischen Primern die Expression der ER $\beta$-mRNA bestimmt. Als $\mathrm{Ne}-$ gativkontrolle diente RPMI-Medium.

Zusammenfassend zeigte sich eine statistisch signifikante Steigerung des ER $\beta$ auf das 27-Fache mit $50 \mu M$ und auf das 34-Fache mit $100 \mu M$ 8ß-VE2 im Vergleich zur Kontrolle.

\subsubsection{Expression von PSA}

Gemäß den Beschreibungen in den Kapiteln 2.2.2- 2.2.11 folgt die Darstellung der Genexpression nach Stimulation mit 8ß-VE2 (siehe Abbildung 7). Es zeigte sich eine Signifikanz $(p=0,0018)$ bei einer gesunkenen Expression auf $3 \%$ bei der Stimulation mit $100 \mu \mathrm{M} 8 \beta-V E 2(0,36$ attomol/ $\mu \mathrm{g} \pm 0,06, \mathrm{n}=3)$ im Vergleich zur Kontrolle $(12,09$ attomol/ $\mu \mathrm{g} \pm 1,58, \mathrm{n}=3)$. Bei der Stimulation mit der niedrigeren Konzentration von $50 \mu \mathrm{M} 8 \beta-V E 2(6,83 \pm 1,15$ attomol/ $\mu \mathrm{g}, \mathrm{n}=3)$ sank die Konzentration bereits auf $56 \%$. Diese Senkung um 44\% war jedoch bei $p=0,0544$ nicht signifikant. Hervorzuheben ist, dass die doppelte Konzentration von $50 \mu \mathrm{M}$ auf $100 \mu \mathrm{M}$ 
$8 \beta$-VE2 eine massive Verringerung der Expression um 93\% $(6,47 \pm 1,15$ attomol/ $/ \mu \mathrm{g}$ ) zeigte.

\section{PSA}

$p=0,0018$

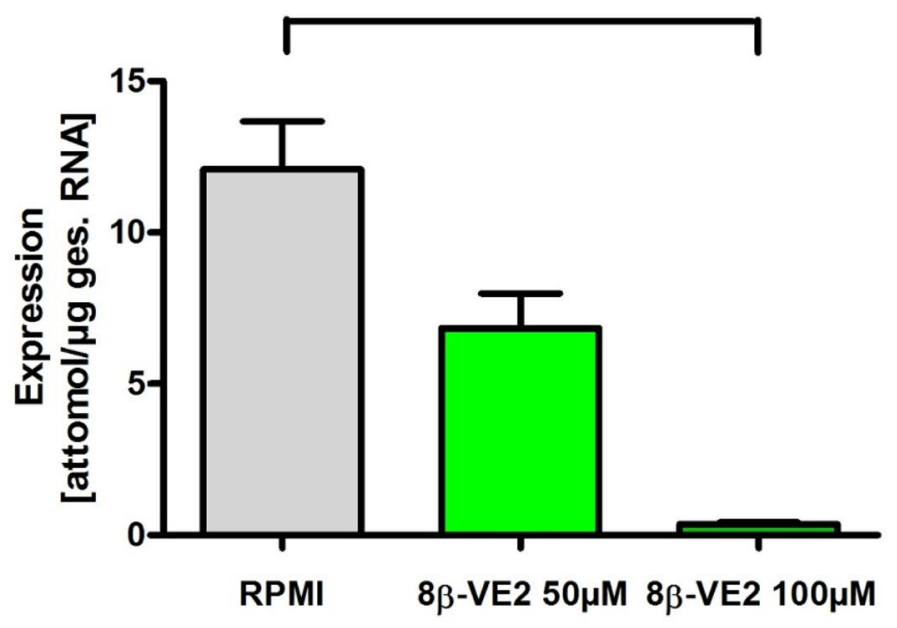

Abbildung 7: PSA-Expression in VCaP-Zellen unter 8 $\beta$-VE2-Stimulation nach Auswertung der rtPCR

$3 \times 10^{5}$ VCaP-Zellen wurden in $50 \mu \mathrm{M}$ bzw. $100 \mu \mathrm{M}$ 8ß-VE2-haltigem Nährmedium 24 Stunden lang stimuliert. Nach Ernte der Zellen wurde die mRNA isoliert und mittels quantitativer rtPCR mit spezifischen Primern die Expression der PSA-mRNA bestimmt. Als $\mathrm{Ne}-$ gativkontrolle diente RPMI-Medium.

Zusammenfassend zeigte sich eine Senkung der PSA-Expression um 93\%

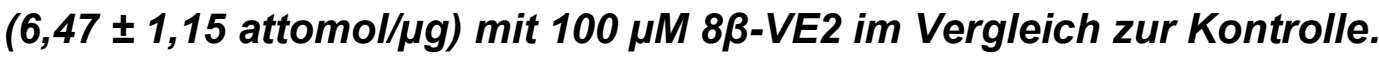

\subsubsection{Expression von ARfI}

Die Genexpression des Androgenrezeptors (full length) verringerte sich bei einer

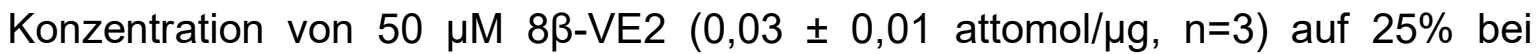
$p=0,0029$ in Bezug zur Mediumkontrolle. Damit ist die Konzentration der Expression des ARfl, wie in Abbildung 8 dargestellt, bereits in der geringeren Konzentration, signifikant gesunken. Obwohl mit $100 \mu \mathrm{M}(0,04 \pm 0,00, \mathrm{n}=3)$ eine leichte Steigerung im Vergleich zu $50 \mu \mathrm{M} 8 \beta$-VE2 beobachtet wurde, ist es im Vergleich zur Kontrolle bei $p=0,0011$ noch immer signifikant. 


\section{AR fl}

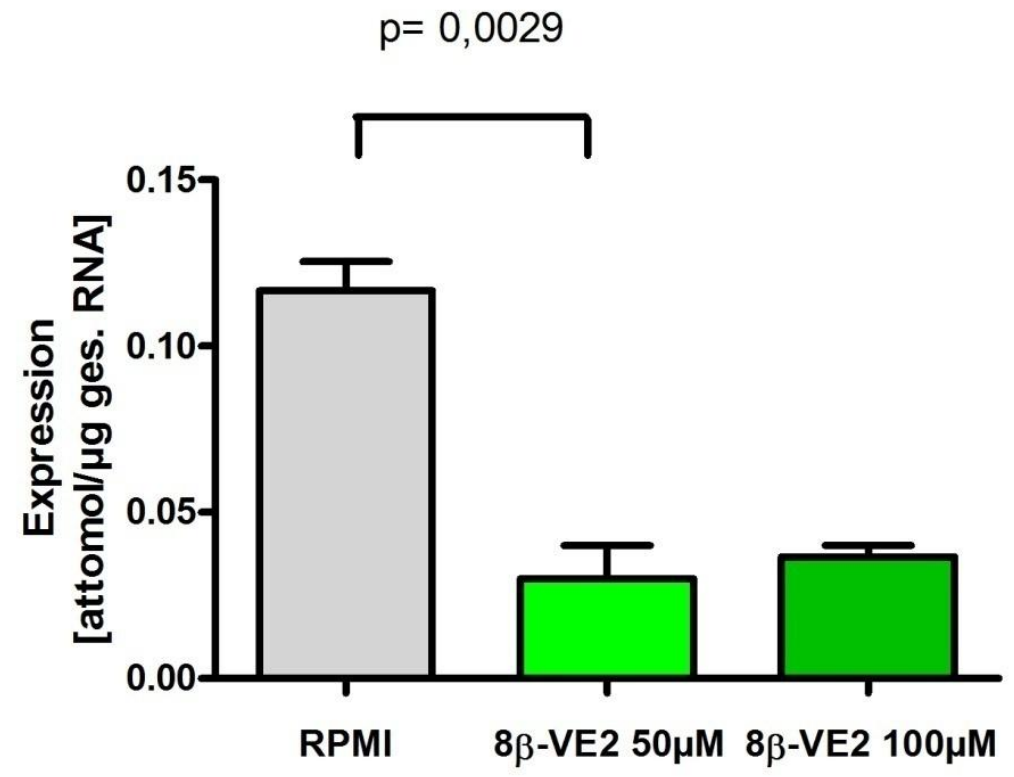

Abbildung 8: ARfl-Expression in VCaP-Zellen unter 8ß-VE2-Stimulation nach Auswertung der rtPCR

$3 \times 10^{5}$ VCaP-Zellen wurden in $50 \mu \mathrm{M}$ bzw. $100 \mu \mathrm{M}$ 8ß-VE2-haltigem Nährmedium 24 Stunden lang stimuliert. Nach Ernte der Zellen wurde die mRNA isoliert und mittels quantitativer rtPCR mit spezifischen Primern die Expression der ARfl-mRNA bestimmt. Als Negativkontrolle diente RPMI-Medium.

Zusammenfassend zeigte sich eine Verringerung der Konzentration von

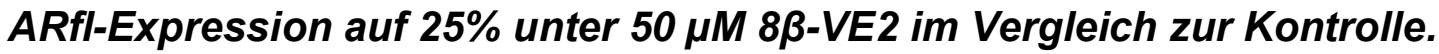

\subsubsection{Expression von AR-V7}

Ähnlich verhielt sich die Expression des AR-V7, als Spleißvariante des AR. Es zeigte sich eine Senkung um $97 \%$ bei der Stimulation mit $50 \mu \mathrm{M} 8 \beta-V E 2$ im Vergleich zur Kontrolle mit RPMI; 6,38 $\pm 2,05$ attomol/ug bei $n=3$ auf 0,17 $\pm 0,06$

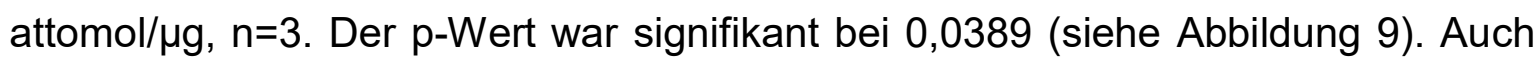
$100 \mu \mathrm{M} 8 \beta-V E 2(0,16 \pm 0,03$ attomol/ $\mu \mathrm{g}, \mathrm{n}=3)$ erbrachte eine weitere Senkung um

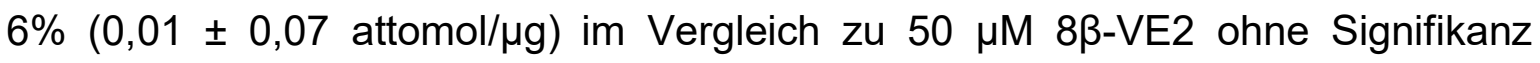
$(p=0,9243)$. 


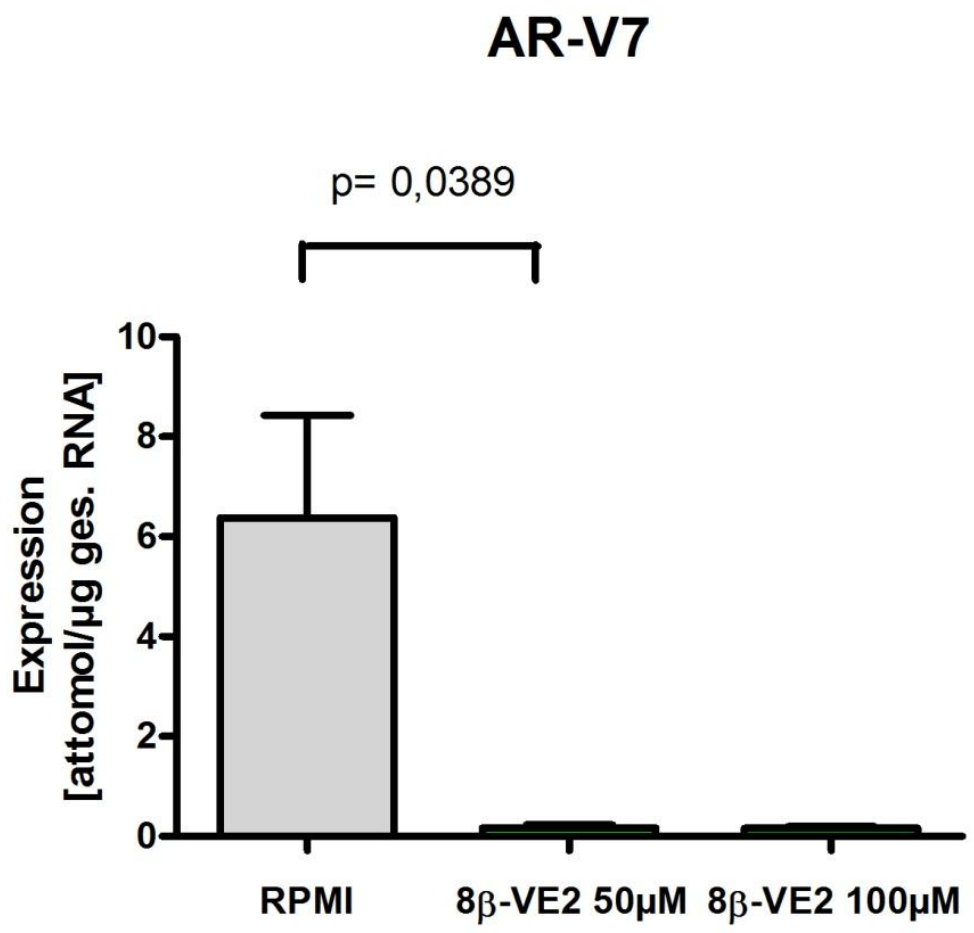

Abbildung 9: AR-V7-Expression in VCaP-Zellen unter 8 $\beta$-VE2-Stimulation nach Auswertung der rtPCR

$3 \times 10^{5}$ VCaP-Zellen wurden in $50 \mu \mathrm{M}$ bzw. $100 \mu \mathrm{M}$ 8ß-VE2-haltigem Nährmedium 24 Stunden lang stimuliert. Nach Ernte der Zellen wurde die mRNA isoliert und mittels quantitativer rtPCR mit spezifischen Primern die Expression der AR-V7-mRNA bestimmt. Als Negativkontrolle diente RPMI-Medium.

Zusammenfassend zeigte sich eine Senkung um $97 \%$ bei der Stimulation mit $50 \mu M$ 8ß-VE2 im Vergleich zur Kontrolle.

\subsubsection{Expression von CYP17A1}

Die Stimulation der Expression von CYP17A1 ist in Abbildung 10 dargestellt. Bei der Expression CYP17A1, welches kodierend für ein Enzym der Androgensynthese ist, war zunächst eine signifikante Steigerung um den Faktor 14 beim Stimulationsversuch mit $50 \mu \mathrm{M} 8 \beta$-VE2 (4,58 $\pm 0,40$ attomol/ $\mu g, n=3) \mathrm{im}$ Vergleich zur Kontrolle $(0,31 \pm 0,08$ attomol/ $\mu g, n=3)$ zu verzeichnen $(p=0,0005)$. Im Vergleich zur Stimulation mit $50 \mu \mathrm{M}$ sank bei der höheren Konzentration mit $100 \mu \mathrm{M}(2,23 \pm 0,24$ attomol/ $\mu \mathrm{g}, \mathrm{n}=3)$ die Expression CYP17A1 wieder ab; es be- 
stand jedoch immer noch eine signifikante Steigerung bei $p=0,0017$ im Vergleich zur Kontrolle.

\section{CYP17A1}

$$
p=0,0005
$$

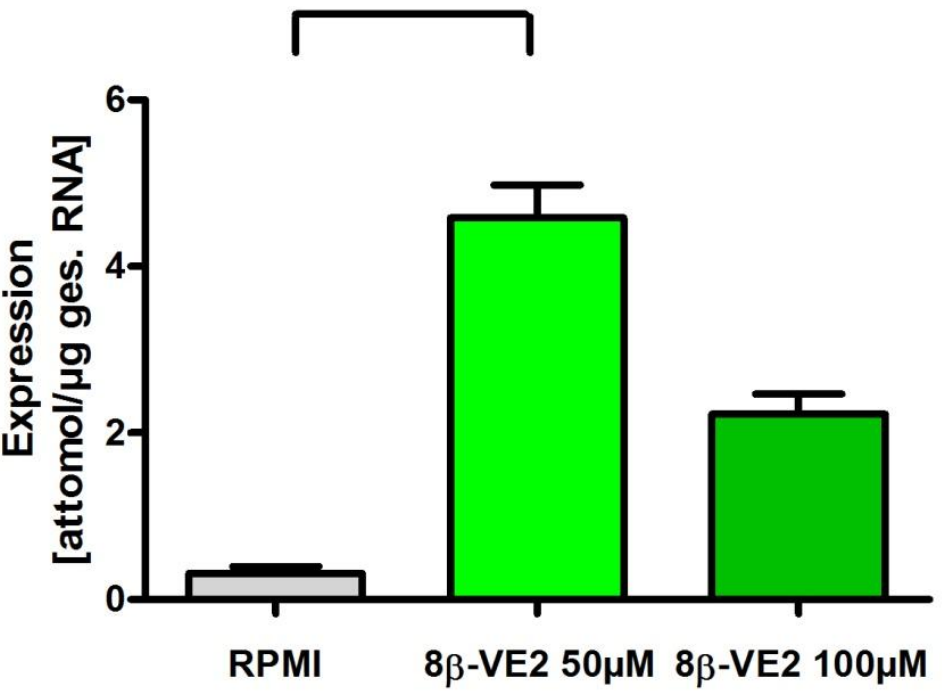

Abbildung 10: CYP17A1-Expression in VCaP-Zellen unter 8ß-VE2-Stimulation nach Auswertung der rtPCR

$3 \times 10^{5}$ VCaP-Zellen wurden in $50 \mu \mathrm{M}$ bzw. $100 \mu \mathrm{M}$ 8ß-VE2-haltigem Nährmedium 24 Stunden lang stimuliert. Nach Ernte der Zellen wurde die mRNA isoliert und mittels quantitativer rtPCR mit spezifischen Primern die Expression der CYP17A1-mRNA bestimmt. Als Negativkontrolle diente RPMI-Medium.

Zusammenfassend zeigte sich eine 15-fache Steigerung beim Stimulationsversuch mit $50 \mu M$ 8 $\beta$-VE2 im Vergleich zur Kontrolle ( $p=0,0005)$. Mit $100 \mu M$ 8ß-VE2 sank die Expression um 51\% (p=0,0071) im Vergleich zu $50 \mu M 8 \beta-$ VE2.

\subsubsection{Expression von AKR1C3}

Umgekehrt verhielt sich die Expression AKR1C3, welches ein weiteres wichtiges Enzym der Androgensynthese ist (Abbildung 11). Während das Kontrollmedium RPMI eine Konzentration von 4,91 $\pm 0,46$ attomol/ug bei $n=3$ aufwies, sank diese

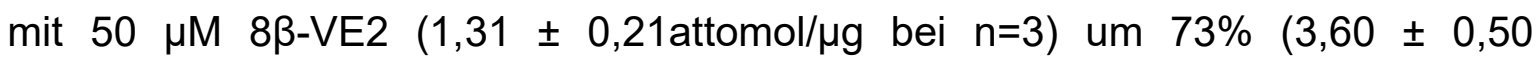


attomol/ug) bei $p=0,002$. Wohingegen diese mit $100 \mu \mathrm{M} 8 \beta$-VE2 $(2,79 \pm 0,60$ attomol/ $\mu \mathrm{g}, \mathrm{n}=3)$ wieder auf das 2-Fache $(1,48 \pm 0,63$ attomol/ $\mu \mathrm{g}) \mathrm{im}$ Vergleich zu $50 \mu \mathrm{M} 8 \beta-V E 2$ stieg bei $p=0,0804$ nicht signifikant.

\section{AKR1C3}

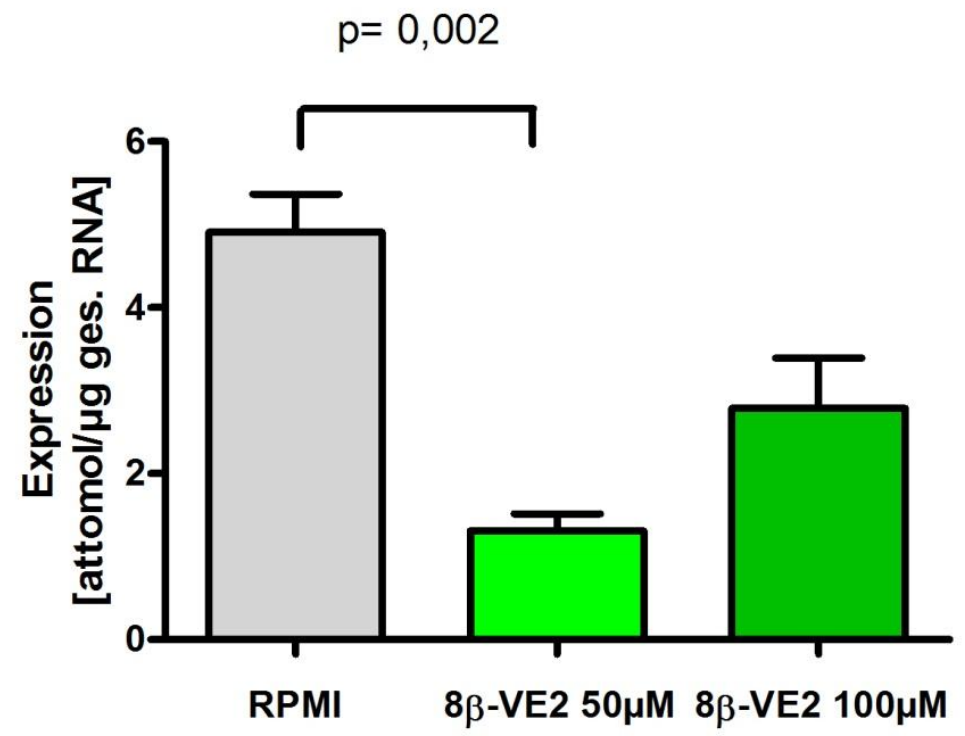

Abbildung 11: AKR1C3-Expression in VCaP-Zellen unter 8ß-VE2-Stimulation nach Auswertung der rtPCR

$3 \times 10^{5}$ VCaP-Zellen wurden in $50 \mu \mathrm{M}$ bzw. $100 \mu \mathrm{M}$ 8ß-VE2-haltigem Nährmedium 24 Stunden lang stimuliert. Nach Ernte der Zellen wurde die mRNA isoliert und mittels quantitativer rtPCR mit spezifischen Primern die Expression der AKR1C3-mRNA bestimmt. Als Negativkontrolle diente RPMI-Medium.

Zusammenfassend zeigte sich eine Senkung mit $50 \mu M$ 8ß-VE2 um $73 \%$ im Vergleich zur Kontrolle ( $p=0,002)$. Bei $100 \mu M$ 8ß-VE2 zeigte sich eine Steigerung auf mehr als das 2-Fache ( $p=0,0804$ nicht signifikant) im Vergleich $z u$ $50 \mu M 8 \beta-V E 2$.

\subsubsection{Expression von TMPRSS2-ERG}

Eine Genfusion, die in der Tumorprogression hochreguliert ist, sank bereits mit $50 \mu \mathrm{M} 8 \beta$-VE2 $(0,10 \pm 0,02$ attomol/ $\mu \mathrm{g}, \mathrm{n}=3)$ um $52 \%(0,11 \pm 0,04$ attomol/ $\mu \mathrm{g})$ 
verglichen mit RPMI $(0,21 \pm 0,03$ attomol $/ \mu g, n=3)$ signifikant $(p=0,0390)$ (Abbildung 12). Eine weitere Senkung ergab sich mit $100 \mu \mathrm{M} 8 \beta$-VE2 $(0,06 \pm 0,02$ attomol $/ \mu \mathrm{g}, \mathrm{n}=3)$ um $40 \%(0,04 \pm 0,03$ attomol $/ \mu \mathrm{g})$ im Vergleich zu $50 \mu \mathrm{M}$. Der $\mathrm{p}$ Wert war bei $p=0,2102$ nicht signifikant. RPMI in Bezug auf $100 \mu \mathrm{M}$ war mit $p=0,0127$ und einer Senkung um 71\% $(0,15 \pm 0,03$ attomol/ $/ \mathrm{gg})$ deutlich signifikant.

\section{TMPRSS2-ERG}

$$
p=0,039
$$
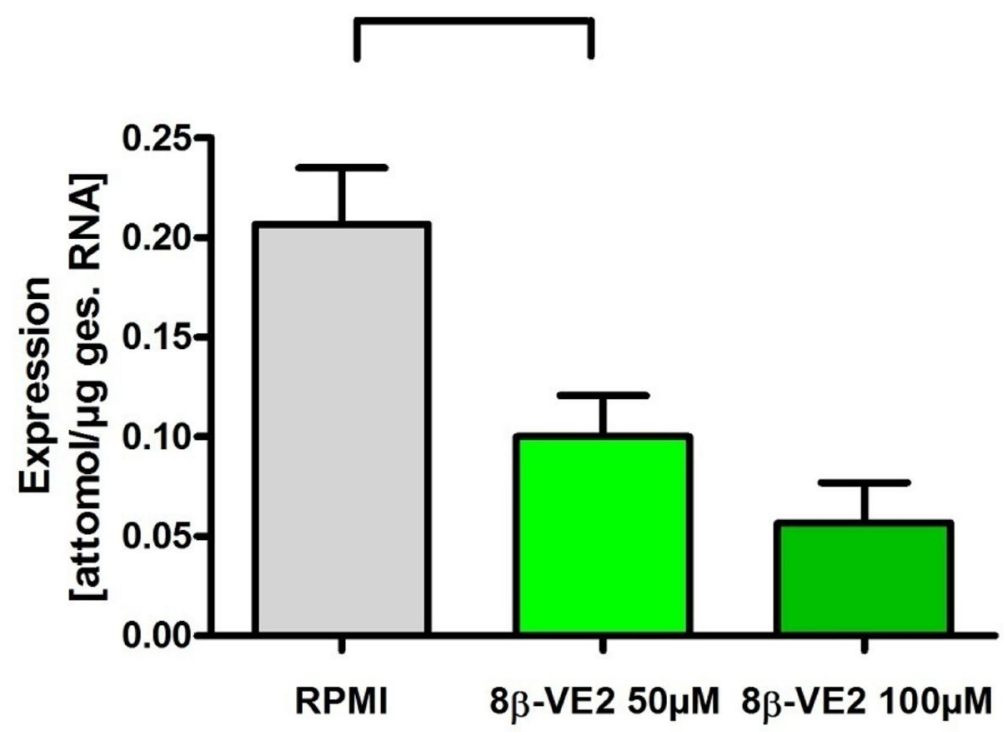

Abbildung 12: TMPRSS2-ERG-Expression in VCaP-Zellen unter 8ß-VE2-Stimulation nach Auswertung der $r$ PCR

$3 \times 10^{5} \mathrm{VCaP}$-Zellen wurden in $50 \mu \mathrm{M}$ bzw. $100 \mu \mathrm{M}$ 8ß-VE2-haltigem Nährmedium 24 Stunden lang stimuliert. Nach Ernte der Zellen wurde die mRNA isoliert und mittels quantitativer rtPCR mit spezifischen Primern die Expression der TMPRSS2-ERG-mRNA bestimmt. Als Negativkontrolle diente RPMI-Medium.

Zusammenfassend zeigte sich eine Senkung bei $50 \mu M$ 8ß-VE2 um 52\% verglichen mit RPMI ( $p=0,0390)$.

\subsubsection{VCaP-Zellen unter dem Einfluss von 8 $\beta$-VE2}

In Abbildung 13 sind die Ergebnisse aller untersuchten Gene nach der Stimulation der VCaP-Zellen mit $50 \mu \mathrm{mol}$ und $100 \mu \mathrm{mol} 8 \beta$-VE2 zusammenfassend aufgetra- 
gen. Es zeigten sich statistisch signifikante Steigerungen der Expression von ER $\beta$ auf das 34-Fache und CYP17A1 auf das 15-Fache bei einer Stimulation der VCaP-Zellen mit $50 \mu \mathrm{M} 8 \beta$-VE2. Eine weitere Erhöhung der Konzentration des Stimulus führte bei ERß zu einer weiteren, ebenfalls signifikant höheren Steigerung der Transkriptionsrate. Im Gegensatz dazu führte eine Steigerung des Stimulans gleichzeitig wieder zu einem Abfall der Expression von CYP17A1, auch dieser Wert war im Vergleich zu den unstimulierten Zellen signifikant erhöht.

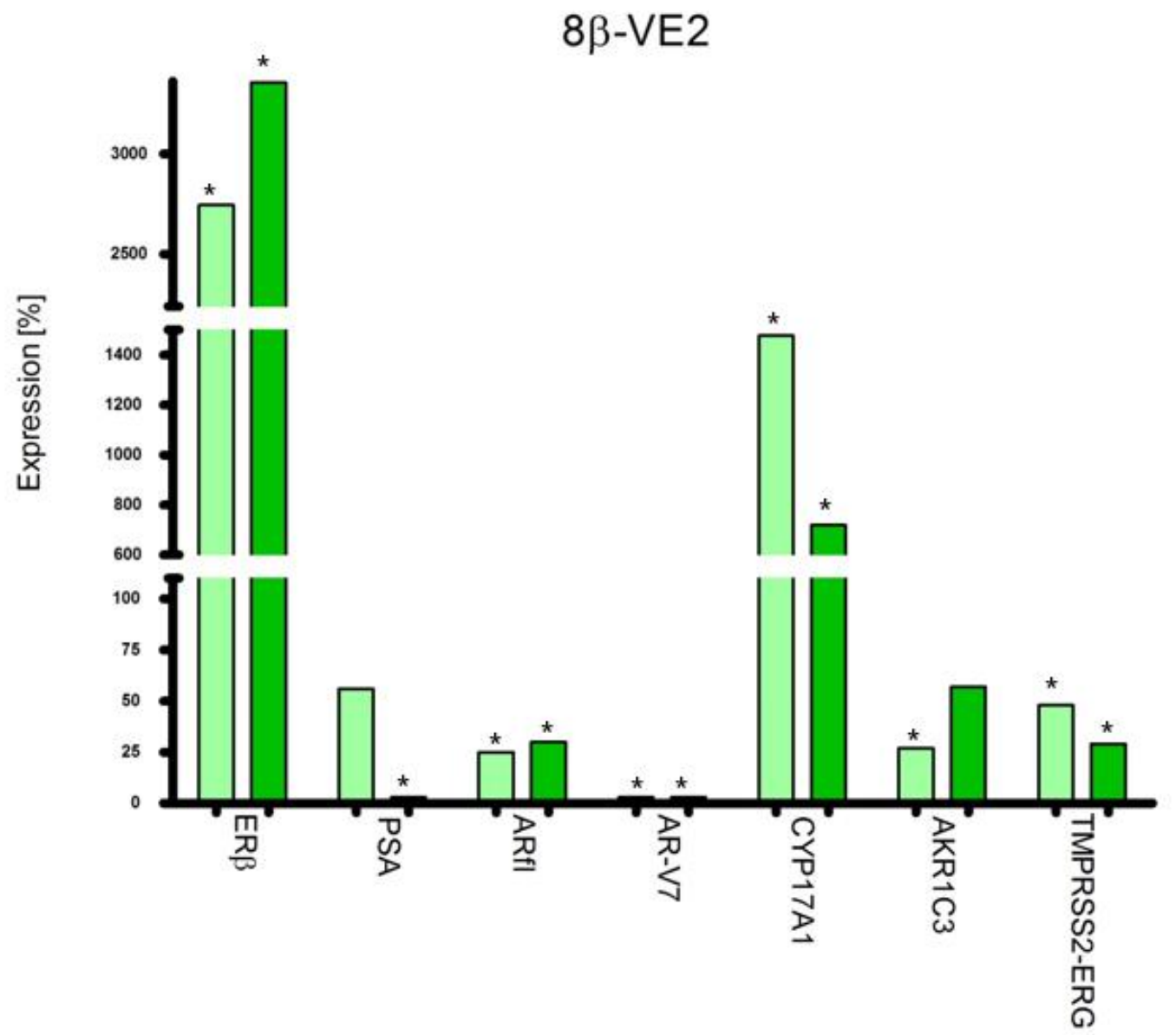

$50 \mu \mathrm{M}$

Abbildung 13: Zusammenfassung der Expression der untersuchten Gene in VCaP-Zellen unter 8ß-VE2-Stimulation nach Auswertung der rtPCR

Ordinate: RNA-Expression in \% der Mediumkontrolle. Abszisse: untersuchte Gene nach Stimulation mit $50 \mu \mathrm{M}$ (hellgrün) und $100 \mu \mathrm{M} 8 \beta$-VE2 (dunkelgrün) *: statistisch signifikante Veränderung im Vergleich zur Mediumkontrolle. 
Alle anderen Gene wurden durch die Verabreichung des 8 $\beta$-VE2 in ihrer Expression deutlich gehemmt. Durch die niedrige Konzentration von $8 \beta-V E 2$ wurde die RNA-Menge von PSA (nicht signifikant), ARfl, AR-V7, AKR1C3 und TMPRS:S2ERG (alle signifikant) gesenkt. Eine Erhöhung der Dosis führte lediglich bei PSA und TMPRSS2-ERG zu einem weiteren deutlichen Expressionsrückgang. ARfl und AKR1C3 wurden bei dagegen wieder stärker transkribiert.

Alle eben beschriebenen Gene sind mit Tumorprogression im Sinne der Zellproliferation, Invasion und Apoptose assoziiert. Als wichtige Enzyme der Androgenbiosynthese zeigten CYP17A1 und AKR1C3 als Gegenspieler auch ein gegensätzliches Expressionsmuster. CYP17A1 zeigte zunächst einen Expressionsanstieg bei $50 \mu \mathrm{M}$ und anschließendem Abfall bei der höheren Konzentration $8 \beta$-VE2. Als Gegenspieler zeigte AKR1C3 zunächst einen Abfall bei $50 \mu \mathrm{mol}$ mit anschließender Expressionssteigerung bei $100 \mu \mathrm{M} 8 \beta-\mathrm{VE} 2$.

\subsection{Stimulation der VCaP-Zellen mit DPN}

Es folgen die Ergebnisse der Stimulation der VCaP-Zelllinie unter dem selektiven ERß-Agonisten der ersten Generation DPN, jeweils mit $50 \mu \mathrm{M}$ und $100 \mu \mathrm{M}$ DPN. Zur Kontrolle wurde das Medium Ethanol (EtOH) verwendet. Die Ergebnisse folgen gemäß der Zielsetzung in angebrachter Reihenfolge und keiner chronologischen Ordnung. Die Stimulationsdauer betrug wie auch bei der 8$\beta$-VE2Stimulation 24 Stunden. Nach RNA-Isolierung, Messung und Überführung in amplifizierbare cDNA werden die Ergebnisse der rtPCR dargestellt (siehe Kapitel 2.2.2- 2.2.11).

\subsubsection{Expression von ER $\beta$}

Zum Nachweis des spezifischen Einflusses der DPN-Stimulation auf den ERß folgen die Ergebnisse der rtPCR. Die Veränderungen werden in Abbildung 14 gezeigt. Auf der Ordinatenachse ist die Expression in attomol/ug logarithmisch aufgeführt. Dagegen ist auf der Abszisse in Form einer Balkengrafik Median, Quartil und Whisker des ER $\beta$ mit EtOH, $50 \mu \mathrm{M}$ und $100 \mu \mathrm{M}$ DPN aufgetragen. Bei einer Stimulation mit $50 \mu \mathrm{M}$ DPN $(0,35 \pm 0,08$ attomol/ $\mu \mathrm{g}, \mathrm{n}=3)$ zeigte sich kaum eine Änderung bei einem Anstieg um 13\% (0,04 \pm 0,09) im Vergleich zur 
Mediumkontrolle $(0,31 \pm 0,03$ attomol/ $\mu \mathrm{g}, \mathrm{n}=3)$. Bestätigt durch den nicht signifikanten $\mathrm{p}$-Wert von $\mathrm{p}=0,6645$. Erst die höhere Konzentration von $100 \mu \mathrm{M}$ DPN $(0,81 \pm 0,12$ attomol $/ \mu g, n=3)$ bot signifikante Unterschiede $(p=0,0153)$ mit einem Anstieg auf das 3-Fache $(0,50 \pm 0,12$ attomol/ $\mu \mathrm{gg})$ im Vergleich zum Kontrollmedium. Auch die Differenz zwischen $50 \mu \mathrm{M}$ und $100 \mu \mathrm{M}$ zeigte eine signifikante Steigerung auf das 2 -Fache $(0,46 \pm 0,14$ attomol/ $\mu g)$, bei $p=0,0317$.

\section{ER $\beta$}

$$
p=0,0153
$$

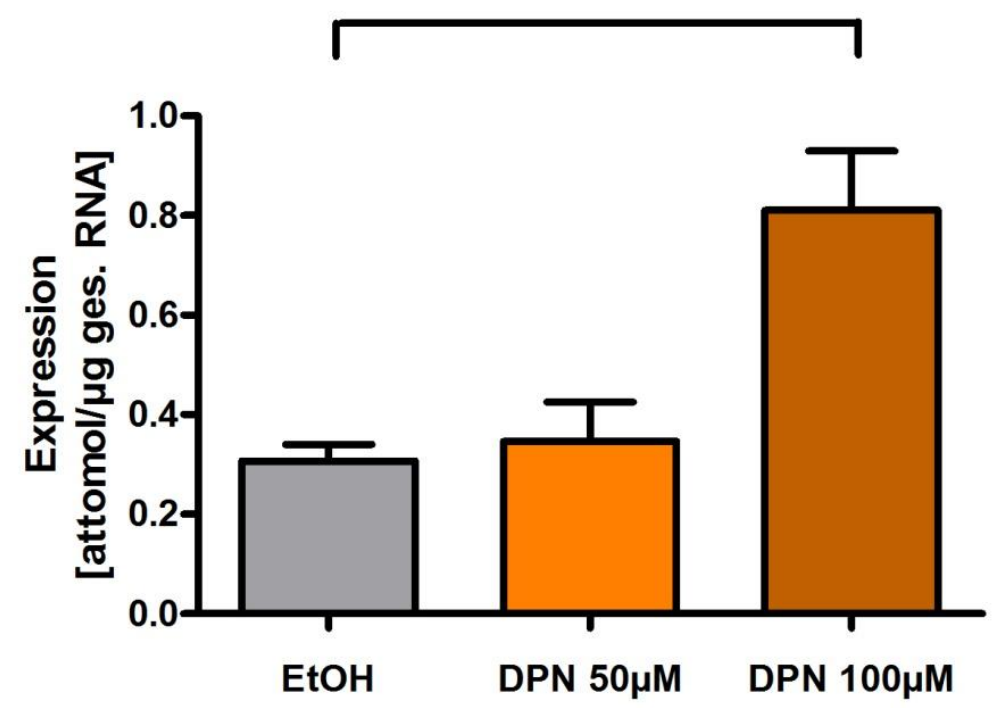

Abbildung 14: ERß-Expression in VCaP-Zellen unter DPN-Stimulation nach Auswertung der rtPCR

$3 \times 10^{5}$ VCaP-Zellen wurden in $50 \mu \mathrm{M}$ bzw. $100 \mu \mathrm{M}$ DPN-haltigem Nährmedium 24 Stunden lang stimuliert. Nach Ernte der Zellen wurde die mRNA isoliert und mittels quantitativer rtPCR mit spezifischen Primern die Expression der ERß-mRNA bestimmt. Als Negativkontrolle diente RPMI-Medium mit dem Lösungsmittel Ethanol.

Erst mit $100 \mu M$ DPN zeigen sich signifikante Unterschiede $(p=0,0153)$ bei einem Anstieg auf das 3-Fache im Vergleich zum Kontrollmedium.

\subsubsection{Expression von PSA}

Obwohl die PSA-Konzentration bereits im Medium EtOH (20,12 $\pm 2,30$ attomol/ $\mathrm{hg}$, $\mathrm{n}=3)$ relativ niedrig war, stieg diese signifikant bei $50 \mu \mathrm{M}$ DPN $(42,18 \pm 6,32$ 
attomol/ $\mu \mathrm{g}, \mathrm{n}=3)$ auf das 2-Fache an $(\mathrm{p}=0,0305)$. In der höheren Konzentration von $100 \mu \mathrm{M}$ DPN $(37,55 \pm 7,24$ attomol/ $\mu \mathrm{g}, \mathrm{n}=3)$ wurde eine leichte Senkung um $11 \%(4,63 \pm 9,61$ attomol/ $\mu \mathrm{g}, \mathrm{p}=0,6554)$ im Vergleich zu $50 \mu \mathrm{M}$ DPN beobachtet (Abbildung 15). Im Vergleich zur Mediumkontrolle war eine nicht signifikante Steigerung $(p=0,0833)$ um $87 \%(17,43 \pm 7,59$ attomol/ $/ \mathrm{mg})$ nachweisbar.

\section{PSA}

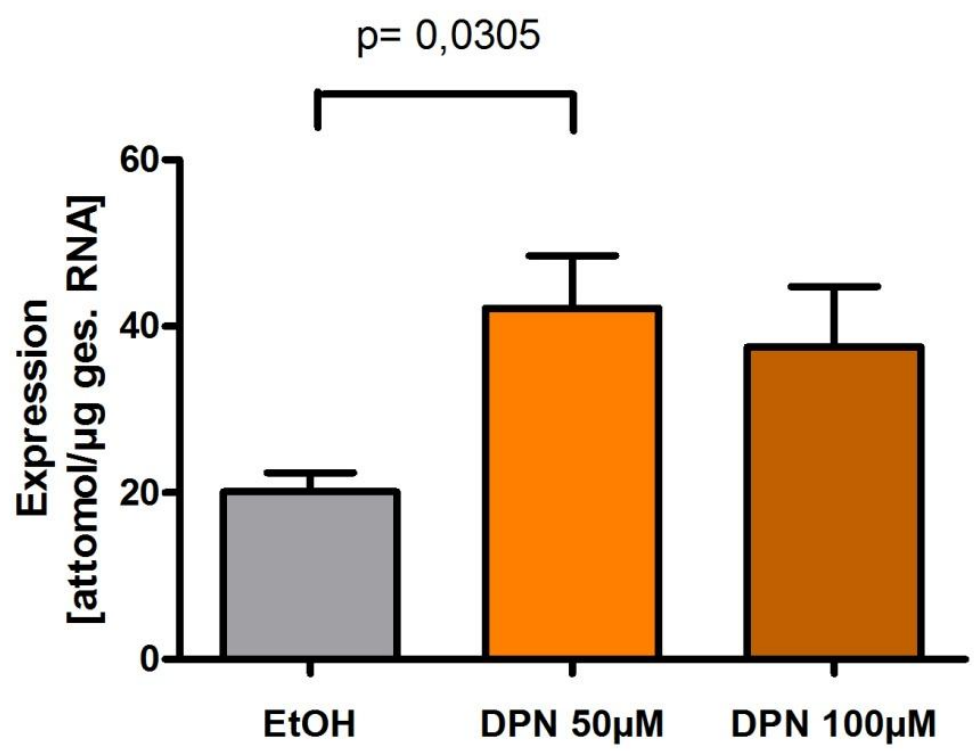

Abbildung 15: PSA-Expression in VCaP-Zellen unter DPN-Stimulation nach Auswertung der rtPCR

$3 \times 10^{5}$ VCaP-Zellen wurden in $50 \mu \mathrm{M}$ bzw. $100 \mu \mathrm{M}$ DPN-haltigem Nährmedium 24 Stunden lang stimuliert. Nach Ernte der Zellen wurde die mRNA isoliert und mittels quantitativer rtPCR mit spezifischen Primern die Expression der PSA-mRNA bestimmt. Als Negativkontrolle diente RPMI-Medium mit dem Lösungsmittel Ethanol.

Bei 50 MM DPN zeigte sich eine signifikante Steigerung auf das 2-Fache im Vergleich zur Kontrolle $(p=0,0305)$.

\subsubsection{Expression von ARfI}

Wie in Abbildung 16 dargestellt, war eine Steigerung der Expression des Androgenrezeptors (full length) sowohl mit $50 \mu \mathrm{M}$ als auch mit der höheren DPNKonzentration von $100 \mu \mathrm{M}$ (nicht dargestellt) nachweisbar. Die vergleichsweise 
geringe Konzentration in der Kontrolle $(0,15 \pm 0,06$ attomol/ $\mu \mathrm{g}, \mathrm{n}=3)$ stieg um den Faktor 2 bei einer Stimulation mit $50 \mu \mathrm{M}$ DPN $(0,50 \pm 0,06$ attomol/ $\mu \mathrm{g}, \mathrm{n}=3)$, bei einem signifikanten $p=0,0131$. Bei $100 \mu \mathrm{M}$ DPN $(1,48 \pm 0,63$ attomol/ $\mu \mathrm{g}, \mathrm{n}=3)$ zeigte sich ein weiterer Anstieg auf das 3-Fache verglichen mit $50 \mu \mathrm{M}$ DPN $(p=0,1994)$.

\section{AR fl}

$$
p=0,0131
$$

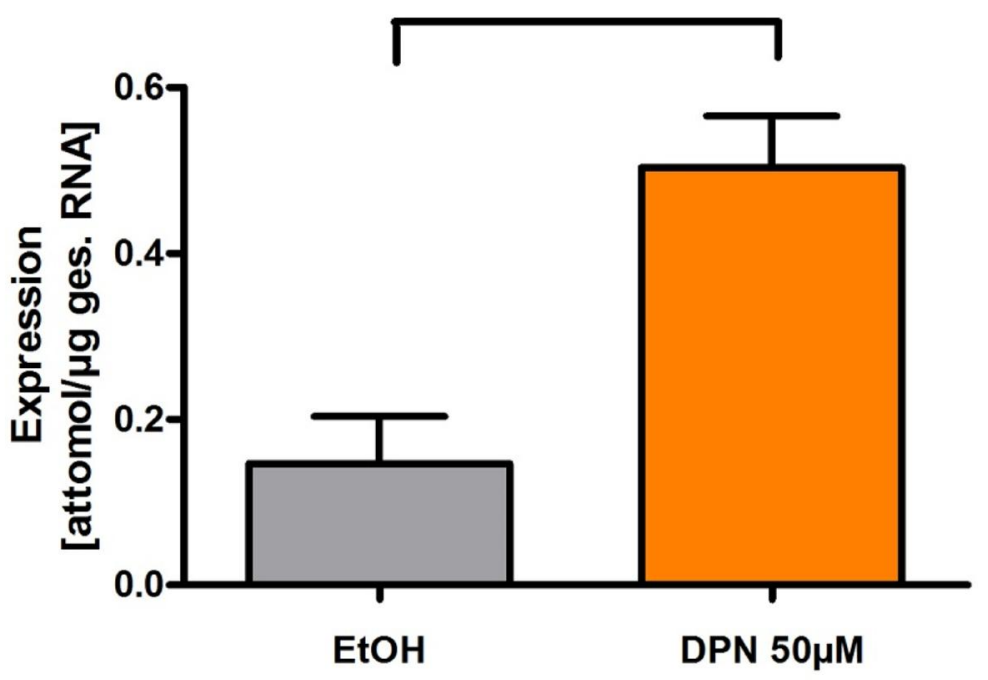

Abbildung 16: ARfl-Expression in VCaP-Zellen unter DPN-Stimulation nach Auswertung der rtPCR

$3 \times 10^{5}$ VCaP-Zellen wurden in $50 \mu \mathrm{M}$ bzw. $100 \mu \mathrm{M}$ DPN-haltigem Nährmedium 24 Stunden lang stimuliert. Nach Ernte der Zellen wurde die mRNA isoliert und mittels quantitativer rtPCR mit spezifischen Primern die Expression der ARfl-mRNA bestimmt. Als Negativkontrolle diente RPMI-Medium mit dem Lösungsmittel Ethanol.

Es zeigte sich eine Steigerung auf das 3-Fache bei der Stimulation mit $50 \mu M$ DPN ( $p=0,0131)$ im Vergleich zur Kontrolle.

\subsubsection{Expression von AR-V7}

Ähnlich verhielt sich auch die Spleißvariante AR-V7. Im Vergleich zur Kontrolle mit EtOH $(0,37 \pm 0,06$ attomol/ $\mu g, n=3)$ ergab sich für $50 \mu \mathrm{M}$ DPN $(2,85 \pm 0,72$ 
attomol/ $\mu \mathrm{g}, \mathrm{n}=3$ ) ein Anstieg auf das 8-Fache bei $\mathrm{p}=0,0268$ (Abbildung 17). Auch bei $100 \mu \mathrm{M}$ DPN $(5,13 \pm 1,70$ attomol/ $\mu \mathrm{g}, \mathrm{n}=3, \mathrm{p}=0,0487)$ verglichen mit $\mathrm{EtOH}$ zeigte sich eine signifikante Steigerung (nicht dargestellt).

\section{AR-V7}

$$
p=0,0268
$$

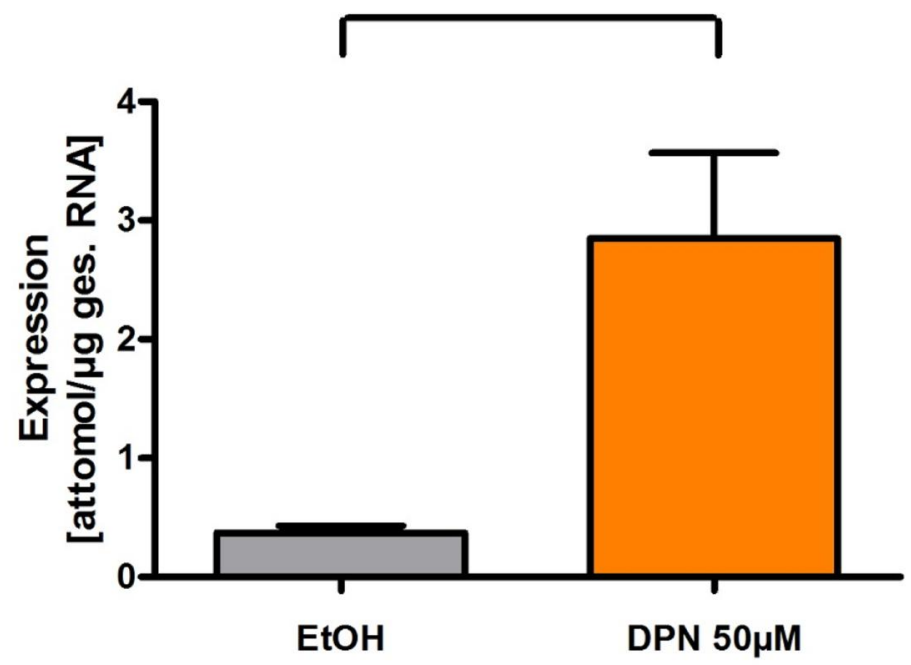

Abbildung 17: AR-V7-Expression in VCaP-Zellen unter DPN-Stimulation nach Auswertung der rtPCR

$3 \times 10^{5}$ VCaP-Zellen wurden in $50 \mu \mathrm{M}$ bzw. $100 \mu \mathrm{M}$ DPN-haltigem Nährmedium 24 Stunden lang stimuliert. Nach Ernte der Zellen wurde die mRNA isoliert und mittels quantitativer rtPCR mit spezifischen Primern die Expression der AR-V7-mRNA bestimmt. Als Negativkontrolle diente RPMI-Medium mit dem Lösungsmittel Ethanol.

Es zeigte sich ein Anstieg auf das 7-Fache bei $50 \mu M$ DPN im Vergleich zur Kontrolle $(p=0,0268)$.

\subsubsection{Expression von CYP17A1}

Das gegensätzliche Verhalten der beiden Enzyme der Androgensynthese war bei der Stimulation mit DPN weniger zu beobachten. Es konnte bei einer Steigerung von $42 \%$ keine Signifikanz zwischen Kontrollmedium $(0,12 \pm 0,05$ attomol/ $\mu \mathrm{g}, \mathrm{n}=3)$ und $50 \mu \mathrm{M}$ DPN $(0,17 \pm 0,02$ attomol/ $\mu \mathrm{g}, \mathrm{n}=3, \mathrm{p}=0,3937)$ nachgewiesen werden; ebenso verhielt es sich mit $100 \mu \mathrm{M}$ DPN $(0,25 \pm 0,09$ attomol/ $\mu \mathrm{g}, n=3, p=0,2731)$ 
bei einer Steigerung auf das 2-Fache im Vergleich zum Kontrollmedium (Abbildung 18). Weiterhin bestand keine Signifikanz im Vergleich von $50 \mu \mathrm{M}$ und $100 \mu \mathrm{M}$ DPN (Steigerung um 48\%, bei $p=0,4598$ ).

\section{CYP17A1}

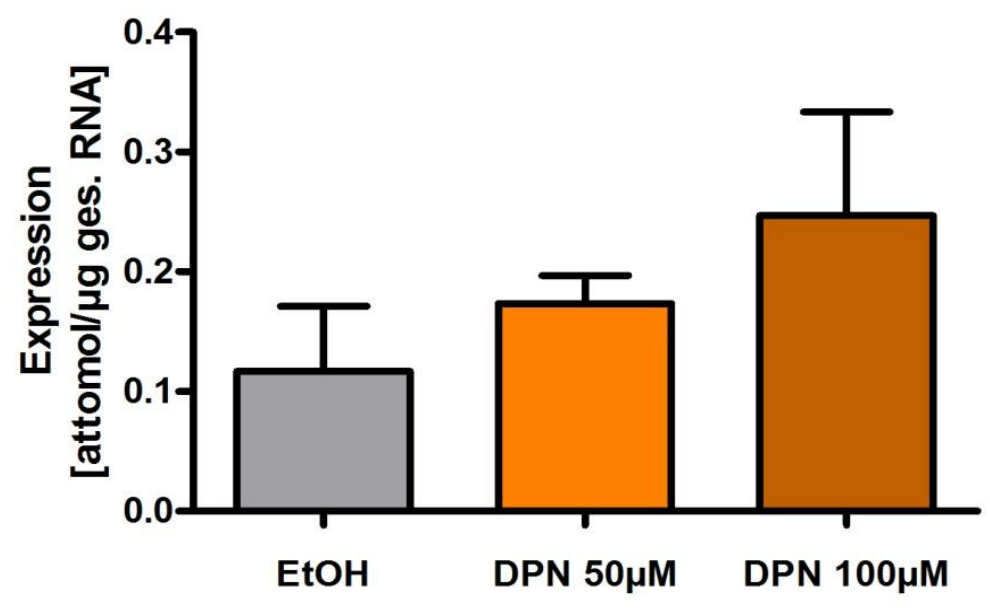

Abbildung 18: CYP17A1-Expression in VCaP-Zellen unter DPN-Stimulation nach Auswertung der rtPCR

$3 \times 10^{5}$ VCaP-Zellen wurden in $50 \mu \mathrm{M}$ bzw. $100 \mu \mathrm{M}$ DPN-haltigem Nährmedium 24 Stunden lang stimuliert. Nach Ernte der Zellen wurde die mRNA isoliert und mittels quantitativer rtPCR mit spezifischen Primern die Expression der CYP17A1-mRNA bestimmt. Als Negativkontrolle diente RPMI-Medium mit dem Lösungsmittel Ethanol.

Es zeigte sich eine Steigerung um $42 \%$ bei $50 \mu M$ DPN im Vergleich zur Kontrolle $(p=0,3937)$.

\subsubsection{Expression von AKR1C3}

Während sich im Vergleich von Kontrollmedium (1,50 \pm 0,22 attomol/ $\mu \mathrm{g}, \mathrm{n}=3)$ und $50 \mu \mathrm{M}$ DPN $(7,56 \pm 1,61$ attomol/ $\mu \mathrm{g}, \mathrm{n}=3)$ eine signifikante Steigerung $(p=0,0201)$ um den Faktor 4 zeigte, nahm die Konzentration mit $100 \mu \mathrm{M}$ DPN $(7,31 \pm 0,20$ attomol/ $\mu \mathrm{g}, \mathrm{n}=3, \mathrm{p}=0,8832$ ) verglichen zu $50 \mu \mathrm{M}$ DPN leicht ab (Abbildung 19). Im 
Vergleich von Mediumkontrolle und $100 \mu \mathrm{M}$ DPN war ein hoch signifikanter Anstieg $(p<0,0001)$ auf das 5-Fache zu beobachten.

\section{AKR1C3}

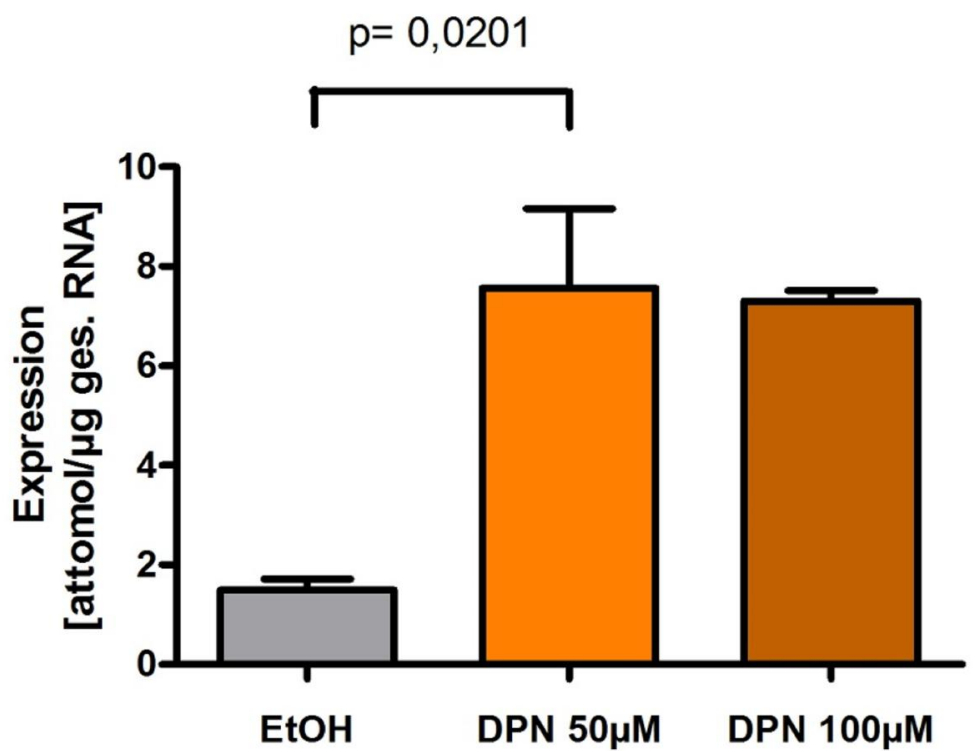

Abbildung 19: AKR1C3-Expression in VCaP-Zellen unter DPN-Stimulation nach Auswertung der rtPCR

$3 \times 10^{5}$ VCaP-Zellen wurden in $50 \mu \mathrm{M}$ bzw. $100 \mu \mathrm{M}$ DPN-haltigem Nährmedium 24 Stunden lang stimuliert. Nach Ernte der Zellen wurde die mRNA isoliert und mittels quantitativer rtPCR mit spezifischen Primern die Expression der AKR1C3-mRNA bestimmt. Als Negativkontrolle diente RPMI-Medium mit dem Lösungsmittel Ethanol.

Es zeigte sich eine signifikante Steigerung auf das 5-Fache mit $50 \mu M$ DPN im Vergleich zur Kontrolle $(p=0,0201)$.

\subsubsection{Expression von TMPRSS2-ERG}

Es zeigte sich zunächst ein nicht-signifikanter Anstieg um $48 \%$ bei $50 \mu \mathrm{M}$ DPN $(1,51 \pm 0,17$ attomol/ $\mu g, n=3, p=0,1707)$ im Vergleich zum Mediumkontrollwert $(1,02 \pm 0,24$ attomol/ $\mu g, n=3)$. Weiterhin zeigte sich ein signifikanter Abfall um $82 \%$ mit $100 \mu \mathrm{M}$ DPN $(0,27 \pm 0,12$ attomol/ $\mu g, n=3, p=0,0042)$ in Bezug zu $50 \mu \mathrm{M}$ 
DPN. Zwischen Kontrollmedium und $100 \mu \mathrm{M}$ DPN lag ein signifikantes Absinken um $74 \%$ bei $p=0,0477$ vor (Abbildung 20 ).

\section{TMPRSS2-ERG}

$$
p=0,0477
$$

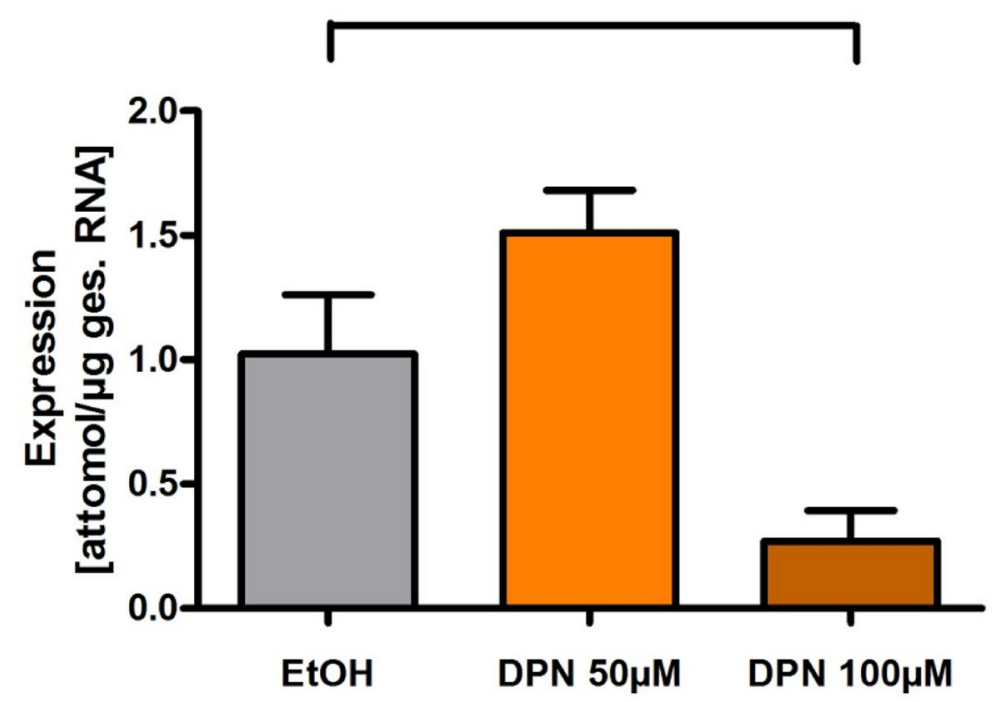

Abbildung 20: TMPRSS2-ERG-Expression in VCaP-Zellen unter DPN-Stimulation nach Auswertung der rtPCR

$3 \times 10^{5}$ VCaP-Zellen wurden in $50 \mu \mathrm{M}$ bzw. $100 \mu \mathrm{M}$ DPN-haltigem Nährmedium 24 Stunden lang stimuliert. Nach Ernte der Zellen wurde die mRNA isoliert und mittels quantitativer $r$ PCR mit spezifischen Primern die Expression der TMPRSS2-ERG-mRNA bestimmt. Als Negativkontrolle diente RPMI-Medium mit dem Lösungsmittel Ethanol.

Es zeigte sich ein nicht-signifikanter Anstieg ( $p=0,1707)$ um $48 \%$ von $50 \mu M$ DPN im Vergleich zum Mediumkontrollwert. Weiterhin trat ein signifikanter Abfall (p=0,0042) um 82\% bei $100 \mu M$ DPN in Bezug zu $50 \mu M$ DPN auf.

\subsubsection{VCaP-Zellen unter dem Einfluss von DPN}

In Abbildung 21 sind die Ergebnisse der Stimulation mit $50 \mu \mathrm{mol}$ und $100 \mu \mathrm{mol}$ DPN aller untersuchten Gene zusammenfassend aufgetragen. 


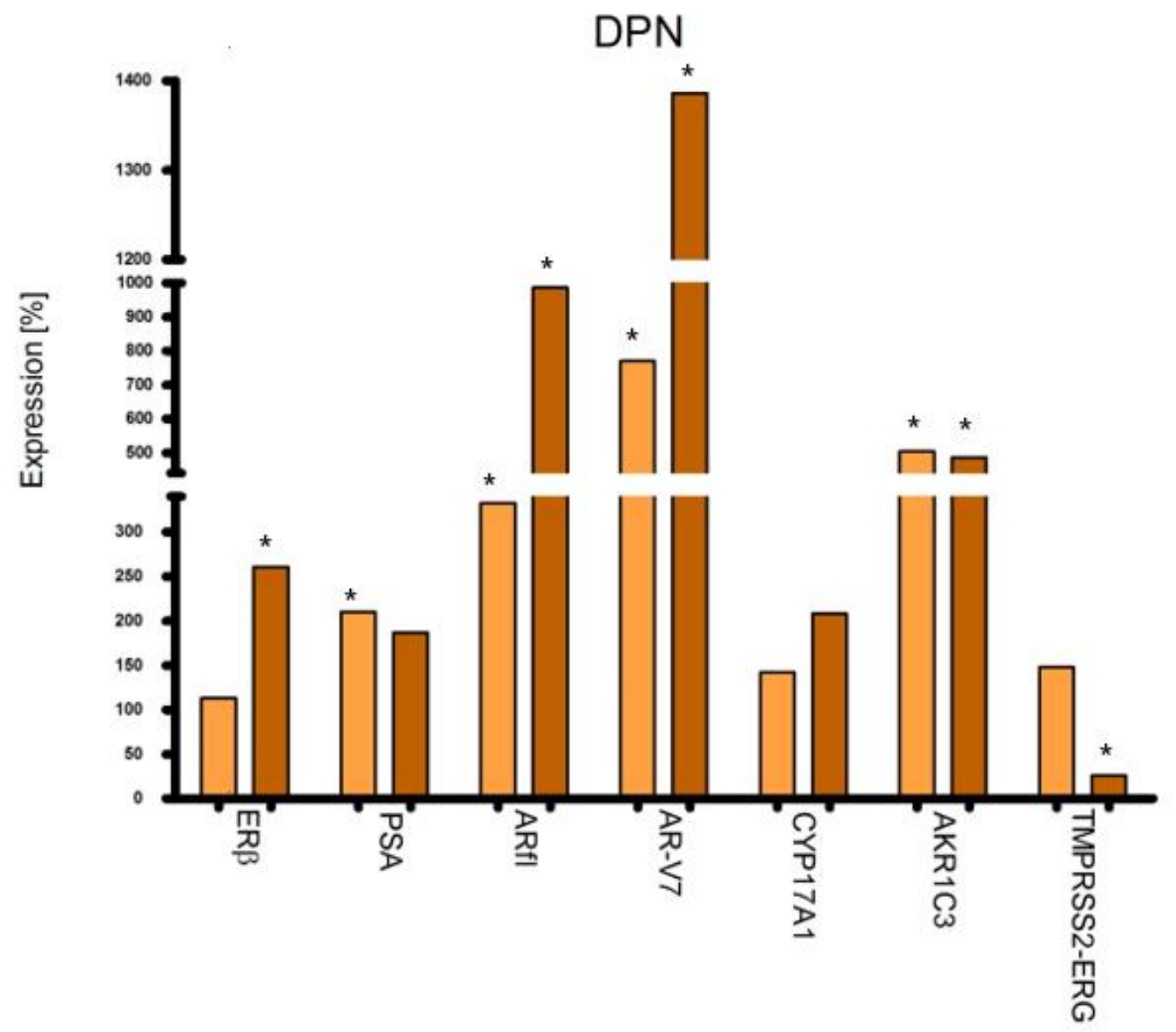

Abbildung 21: Zusammenfassung der Expression der untersuchten Gene in VCaP-Zellen unter DPN-Stimulation nach Auswertung der rtPCR

Ordinate: RNA-Expression in \% der Mediumkontrolle. Abszisse: untersuchte Gene nach Stimulation mit $50 \mu \mathrm{M}$ (hellbraun) und $100 \mu \mathrm{M}$ DPN (dunkelbraun) *: statistisch signifikante Veränderung im Vergleich zur Mediumkontrolle.

Eine Stimulation der VCaP-Zellen mit $50 \mu \mathrm{M}$ DPN hatte auf die Expression von ER $\beta$ und CYP17A1 annähernd keinen Einfluss. Erst bei einer Stimulation mit $100 \mu \mathrm{mol}$ DPN zeigte sich ein signifikanter ERß-Anstieg, allerdings blieb der CYP17A1-Anstieg unterhalb der statistischen Signifikanz. Weiterhin zeigten sich signifikante Anstiege bei PSA, ARfl und der Spleißvariante AR-V7. Ein Abfall der Tumor progressiven Gene lässt sich nur bei TMPRS:S2-ERG nachweisen. 


\subsection{Proteinexpression in VCaP-Zellen unter Stimulation von $8 \beta-V E 2$ und DPN}

Die Expression der Proteine wurde, wie in Kapitel 2.2.13 und 2.2.14 beschrieben, untersucht. Nach Vorbereitung des Versuchsansatzes wurde diese durch eine technische Mitarbeiterin der experimentellen urologischen Abteilung fertig gestellt. Zur Berechnung der Daten wurde die ImageJ-Methode verwendet.

\subsubsection{AR-Proteinexpression}

Es stellte sich eine Korrelation zwischen den Ergebnissen der gemessenen Konzentrationen in der rtPCR des AR und den Ergebnissen des Western Blots heraus. Abbildung 22 und Tabelle 13 zeigt deutlich, dass nach Stimulation mit $100 \mu \mathrm{M}$ 8ß-VE2 nach Korrektur der optischen Messung des $\alpha$-Tubulin eine erniedrigte Proteinsynthese des AR-Produktes stattfand. Nach der Stimulation mit $100 \mu \mathrm{M}$ DPN zeigte sich nach Korrektur der $\alpha$-Tubulin Dichtemessung eine gesteigerte Proteinsynthese des AR-Produktes (Abbildung 23).

\section{AR \\ a-Tubulin}

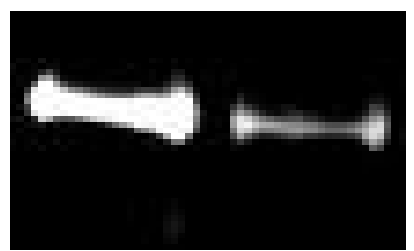

RPMI $8 \beta-V E 2$

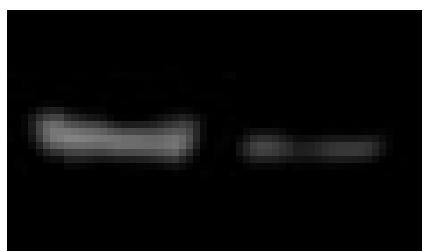

RPMI 8ß-VE2

Abbildung 22: Gelelektrophorese der AR-Expression und der $\alpha$-Tubulin-Expression in VCaP-Zellen nach 8ß-VE2-Stimulation

$3 \times 10^{5}$ VCaP-Zellen wurden in $100 \mu \mathrm{M} 8 \beta$-VE2-haltigem Nährmedium 48 Stunden lang stimuliert. Nach Ernte und Aufschluss der Zellen wurden gleiche Proteinmengen in einer nativen PAGE aufgetrennt, mittels Western-Blot auf eine Nitrozellulosemembran übertragen und anschließend mit anti-AR (links) bzw. anti-a-Tubulin (rechts) hybridisiert. Als sekundärer Antikörper wurde ein anti-Rabbit-Fluoreszenzmarker-Konjugat verwendet, der eine Quantifizierung der Proteinbande ermöglichte. Als Negativkontrolle diente RPMIMedium. 
Tabelle 13: Optische Dichte der AR-Expression und der $\alpha$-Tubulin-Expression nach $8 \beta$-VE2-Stimulation

\begin{tabular}{|c|c|c|c|c|}
\hline & $\begin{array}{r}\alpha-T u b u l i n \\
\left(D i c h t e / m^{2}\right)\end{array}$ & $\begin{array}{r}\text { AR } \\
(\text { Dichte/mm })\end{array}$ & $\begin{array}{r}\text { AR relativ } \\
\left(\text { Dichte/mm }{ }^{2}\right)\end{array}$ & $\begin{array}{c}\text { a-Tubulin-korrigierte } \\
\text { Änderung der AR- } \\
\text { Expression }\end{array}$ \\
\hline RPMI & 21.437 & 19.931 & 19.391 & \multirow{2}{*}{$\begin{array}{c}\text { Senkung auf } \\
90 \%\end{array}$} \\
\hline $8 \beta$-VE2 & 7.455 & 6.097 & 17.532 & \\
\hline
\end{tabular}

\section{AR}

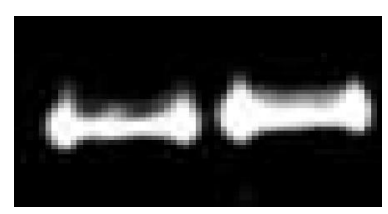

$\mathrm{EtOH}$ DPN

\section{a-Tubulin}

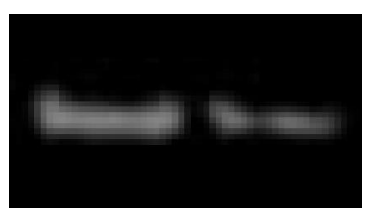

\section{$\mathrm{EtOH}$ DPN}

Abbildung 23: Gelelektrophorese der AR-Expression und der $\alpha$-Tubulin-Expression in VCaP-Zellen nach DPN-Stimulation

$3 \times 10^{5}$ VCaP-Zellen wurden in $100 \mu \mathrm{M}$ DPN-haltigem Nährmedium 48 Stunden lang stimuliert. Nach Ernte und Aufschluss der Zellen wurden gleiche Proteinmengen in einer nativen PAGE aufgetrennt, mittels Western-Blot auf eine Nitrozellulosemembran übertragen und anschließend mit anti-AR (links) bzw. anti- $\alpha$-Tubulin (rechts) hybridisiert. Als sekundärer Antikörper wurde ein anti-Rabbit-Fluoreszenzmarker-Konjugat verwendet, der eine Quantifizierung der Proteinbande ermöglichte. Als Negativkontrolle diente RPMIMedium mit Ethanol.

Tabelle 14: Optische Dichte der AR-Expression und der $\alpha$-Tubulin-Expression nach DPNStimulation

\begin{tabular}{|c|c|c|c|c|}
\hline & $\begin{array}{r}\alpha-T u b u l i n \\
\left(\text { Dichte } / \mathrm{mm}^{2}\right)\end{array}$ & $\begin{array}{r}\text { AR } \\
\left(\text { Dichte } / \mathrm{mm}^{2}\right)\end{array}$ & $\begin{array}{r}\text { AR relativ } \\
\left(\text { Dichte } / \mathrm{mm}^{2}\right)\end{array}$ & $\begin{array}{l}\text { a-Tubulin-korrigierte Ände- } \\
\text { rung der AR-Expression }\end{array}$ \\
\hline EtOH & 30.872 & 21.768 & 21.768 & \multirow{2}{*}{$\begin{array}{c}\text { Steigerung auf } \\
\text { das 2-Fache }\end{array}$} \\
\hline DPN & 15.959 & 26.092 & 50.474 & \\
\hline
\end{tabular}

Es ergab sich eine Senkung des AR auf $\mathbf{9 0 \%}$ nach $\mathbf{8} \beta$-VE2-Stimulation und eine Steigerung des AR auf das 2-Fache nach DPN-Stimulation in der $\alpha$ - 
Tubulin-korrigierten optischen Messung. Der Vergleich wurde jeweils auf das unstimulierte Kontrollmedium, RPMI für 8 8 -VE2 (Tabelle 13) und EtOH für DPN, bezogen (Tabelle 14).

\subsubsection{CYP17A1-Proteinexpression}

Die Ergebnisse des Western Blots korrelierten mit der Genexpression in der rtPCR unter 8 $\beta$-VE2-Stimulation. In der $r$ PPCR mit der DPN-Stimulation zeigten sich unterschiedliche Ergebnisse. Abbildung 24 zeigt deutlich, dass nach 8ß-VE2Stimulation mit $100 \mu \mathrm{M}$ nach $\alpha$-Tubulin-Korrektur auch eine Steigerung der Proteinsynthese des CYP17A1-Produktes stattfand. Nach der DPN-Stimulation mit 100 $\mu \mathrm{M}$ zeigte sich nach Korrektur der $\alpha$-Tubulin-Messung entgegen der rtPCR eine Senkung der Proteinbiosynthese des CYP17A1-Produktes (Abbildung 25).

Es ergab sich nach Korrektur der $\alpha$-Tubulin-Messung eine Steigerung der CYP17A1-Expression auf das 8-Fache nach 8ß-VE2-Stimulation und eine Senkung der CYP17A1-Expression auf 86\% nach DPN-Stimulation. Zum Vergleich diente das unstimulierte Kontrollmedium RPMI bei 8$\beta$-VE2 (Tabelle 15) und EtOH bei DPN (Tabelle 16).

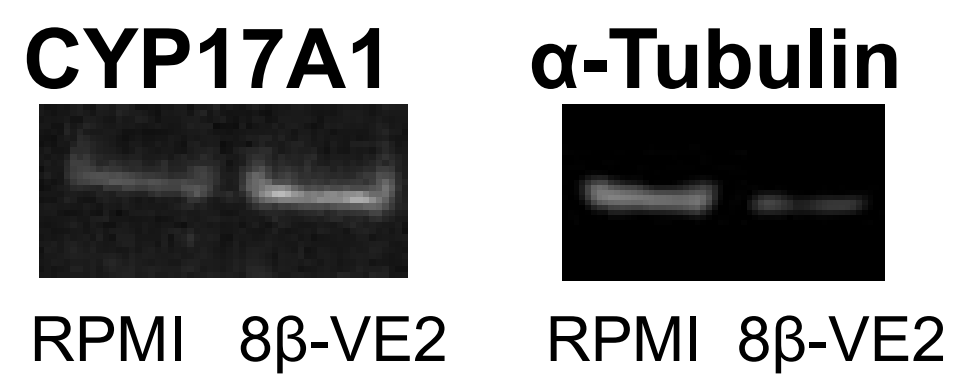

Abbildung 24: Gelelektrophorese der CYP17A1-Expression in VCaP-Zellen nach 8ß-VE2Stimulation

$3 \times 10^{5}$ VCaP-Zellen wurden in $100 \mu \mathrm{M} 8 \beta$-VE2-haltigem Nährmedium 48 Stunden lang stimuliert. Nach Ernte und Aufschluss der Zellen wurden gleiche Proteinmengen in einer nativen PAGE aufgetrennt, mittels Western-Blot auf eine Nitrozellulosemembran übertragen und anschließend mit anti-CYP17A1 (links) bzw. anti- $\alpha$-Tubulin (rechts) hybridisiert. Als sekundärer Antikörper wurde ein anti-Rabbit-Fluoreszenzmarker-Konjugat verwendet, der eine Quantifizierung der Proteinbande ermöglichte. Als Negativkontrolle diente RPMIMedium. 
Tabelle 15: Optische Dichte der CYP17A1-Expression nach 8ß-VE2- Stimulation

\begin{tabular}{|c|c|c|c|c|}
\hline & $\begin{array}{r}\alpha-T u b u l i n \\
\left(D i c h t e / m^{2}\right)\end{array}$ & $\begin{array}{r}\text { CYP17A1 } \\
(\text { Dichte/mm })\end{array}$ & $\begin{array}{r}\text { CYP17A1 relativ } \\
\left(\text { Dichte/mm }{ }^{2}\right)\end{array}$ & $\begin{array}{c}\alpha-T u b u l i n-k o r r i g i e r t e \\
\text { Änderung der CYP17A1- } \\
\text { Expression }\end{array}$ \\
\hline RPMI & 21.437 & 10.625 & 10.625 & \multirow{2}{*}{$\begin{array}{c}\text { Steigerung auf } \\
\text { das 8-Fache }\end{array}$} \\
\hline $8 \beta$-VE2 & 7.455 & 28.517 & 82.001 & \\
\hline
\end{tabular}

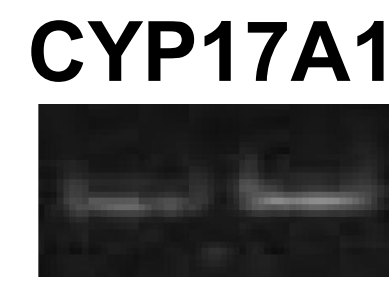

$\mathrm{EtOH} \quad \mathrm{DPN}$

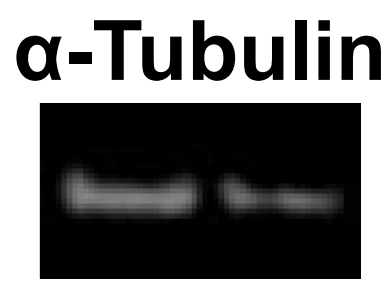

$\mathrm{EtOH} \quad \mathrm{DPN}$

Abbildung 25: Gelelektrophorese der CYP17A1-Expression in VCaP-Zellen nach DPNStimulation

$3 \times 10^{5}$ VCaP-Zellen wurden in $100 \mu \mathrm{M}$ DPN-haltigem Nährmedium 48 Stunden lang stimuliert. Nach Ernte und Aufschluss der Zellen wurden gleiche Proteinmengen in einer nativen PAGE aufgetrennt, mittels Western-Blot auf eine Nitrozellulosemembran übertragen und anschließend mit anti-CYP17A1 (links) bzw. anti- $\alpha-T u b u l i n$ (rechts) hybridisiert. Als sekundärer Antikörper wurde ein anti-Rabbit-Fluoreszenzmarker-Konjugat verwendet, der eine Quantifizierung der Proteinbande ermöglichte. Als Negativkontrolle diente RPMIMedium mit Ethanol.

Tabelle 16: Optische Dichte der CYP17A1-Expression nach DPN-Stimulation

\begin{tabular}{|c|c|c|c|c|}
\hline & $\begin{array}{r}\alpha-T u b u l i n \\
\left(D i c h t e / m^{2}\right)\end{array}$ & $\begin{array}{r}\text { CYP17A1 } \\
(\text { Dichte/mm²) }\end{array}$ & $\begin{array}{r}\text { CYP17A1 relativ } \\
\left(\text { Dichte } / \mathrm{mm}^{2}\right)\end{array}$ & $\begin{array}{l}\alpha-T u b u l i n-k o r r i g i e r t e \\
\text { Änderung der } \\
\text { CYP17A1-Expression }\end{array}$ \\
\hline $\mathrm{EtOH}$ & 30.872 & 11.020 & 11.020 & \multirow{2}{*}{$\begin{array}{c}\text { Senkung auf } \\
86 \%\end{array}$} \\
\hline DPN & 15.959 & 18.230 & 9.424 & \\
\hline
\end{tabular}

\subsection{Proliferationsverhalten der VCaP-Zellen nach Stimulation mit $8 \beta$ - VE2}

Die Untersuchungen zur Proteinexpression nach der Stimulation der VCaP-Zellen mit $8 \beta$-VE2 zeigte eine Abnahme der $\alpha$-Tubulin-Konzentration im Vergleich zur 
unstimulierten Kontrolle (Abbildung 22 und Abbildung 24). Es stellte sich die Frage, ob durch die Stimulation die Zellproliferation der Metastasezellen gehemmt werden kann. Dies wäre darüber hinaus ein wichtiger Fortschritt in der Tumorbekämpfung. Daher wurde das Proliferationsverhalten der Zellen wie in Kapitel 2.2.15 beschrieben anhand des BrdU-Tests untersucht. Es wurde das Wachstumsverhalten der VCaP-Zellen nach 8ß-VE2-Stimulation im Vergleich zum Kontrollmedium geprüft.

Die Extinktionsmessung steht im Verhältnis zur Proliferation der Zellen. Es zeigte sich eine nahezu gleichbleibende Proliferation der Zellen nach 8$\beta$-VE2-Stimulation $(0,13 \pm 0,00 ; n=6)$ verglichen mit dem Kontrollmedium RPMI $(0,14 \pm 0,01 ; n=6$; Abbildung 26).

\section{Proliferationsverhalten der VCaP-Zellen nach Stimulation mit 8 $\beta$ VE2}

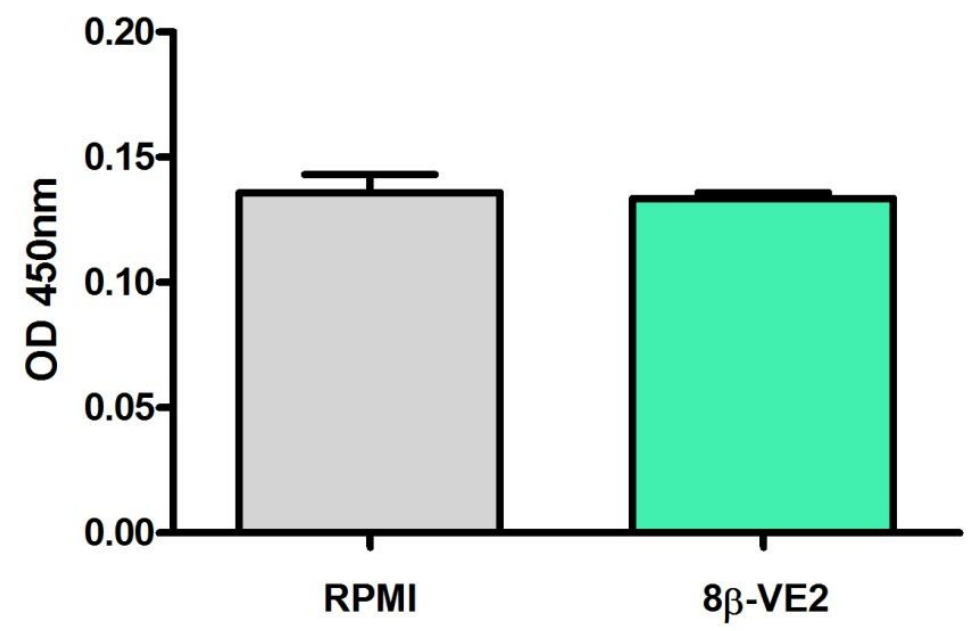

Abbildung 26: Proliferationsverhalten der VCaP-Zellen nach Stimulation mit 8B-VE2

Nach einer Vorinkubation wurden 5000 Zellen gleichzeitig mit $100 \mu \mathrm{M} 8 \beta$-VE2 stimuliert und mit $1 \mu \mathrm{M}$ BrdU versetzt. Nach 24 Stunden wurde die Menge des in die DNA eingebauten BrdU mittels ELISA als Extinktion bei $450 \mathrm{~nm}$ bestimmt. Als Kontrolle dienten Zellen, die nicht stimuliert wurden (RPMI). 


\section{Diskussion}

Das kastrationsresistente Prostatakarzinom ist gekennzeichnet durch eine hohe Expression des AR. Dieser wird permanent durch Androgene aktiviert, die im Tumorgewebe selbst unter anderem durch die Aktivität von CYP17A1 gebildet werden (Montgomery et al. 2008). Dies ist eines der größten Probleme einer hormonellen Therapie des fortgeschrittenen Karzinoms der Prostata, bei dem ein Androgenspiegel auf Kastrationsniveau eingestellt wird. Das CRPC kann dennoch weiterhin auf die AR Signalkette für Wachstum und Vermehrung zurückgreifen, auch wenn moderne Therapien die zirkulierende Androgenmenge reduzieren (de Bono et al. 2011) oder die Bindung der Androgene an die AR blockieren (Scher et al. 2012). Daher werden derzeit Therapien gesucht, die gleichzeitig AR und CYP17A1 inhibieren (Mostaghel et al. 2011).

Die in der hier vorgelegten Studie verwendeten VCaP-Zellen sind gekennzeichnet durch eine Hochregulation von CYP17A1 und AKR1C3, die in die Androgensynthese involviert sind und durch die Hochregulierung von ARfl und seiner Spleißvariante AR-V7 (Knuuttila et al. 2014) den Tumorprogress unterhalten. Die Verhältnisse in den VCaP-Zellen unter Androgendeprivation sind in Abbildung 27 veranschaulicht.

Um den Transkriptionsfaktor ER $\beta$ in den VCaP-Zellen zu aktivieren, wurden in der hier vorgelegten Untersuchung der starkaffine Ligand 8 $\beta$-VE2 mit starker Selektivität für ER $\beta$ herangezogen. Es konnte bereits gezeigt werden, dass Konzentrationen von $5 \mu \mathrm{M}$ und $25 \mu \mathrm{M}$ das Überleben der Zellen verhinderten und die Apoptose auslösten (Gehrig et al. 2017). Die in der hier vorliegenden Studie eingesetzten Konzentrationen lagen mit $50 \mu \mathrm{M}$ und $100 \mu \mathrm{M}$ deutlich darüber. Als weiteres Stimulationsmolekül wurde DPN ausgewählt, welches eine vergleichbare Selektivität für ER $\beta$ hat, aber dessen Bindungsstärke geringer ist als die des 8$\beta-V E 2$. 


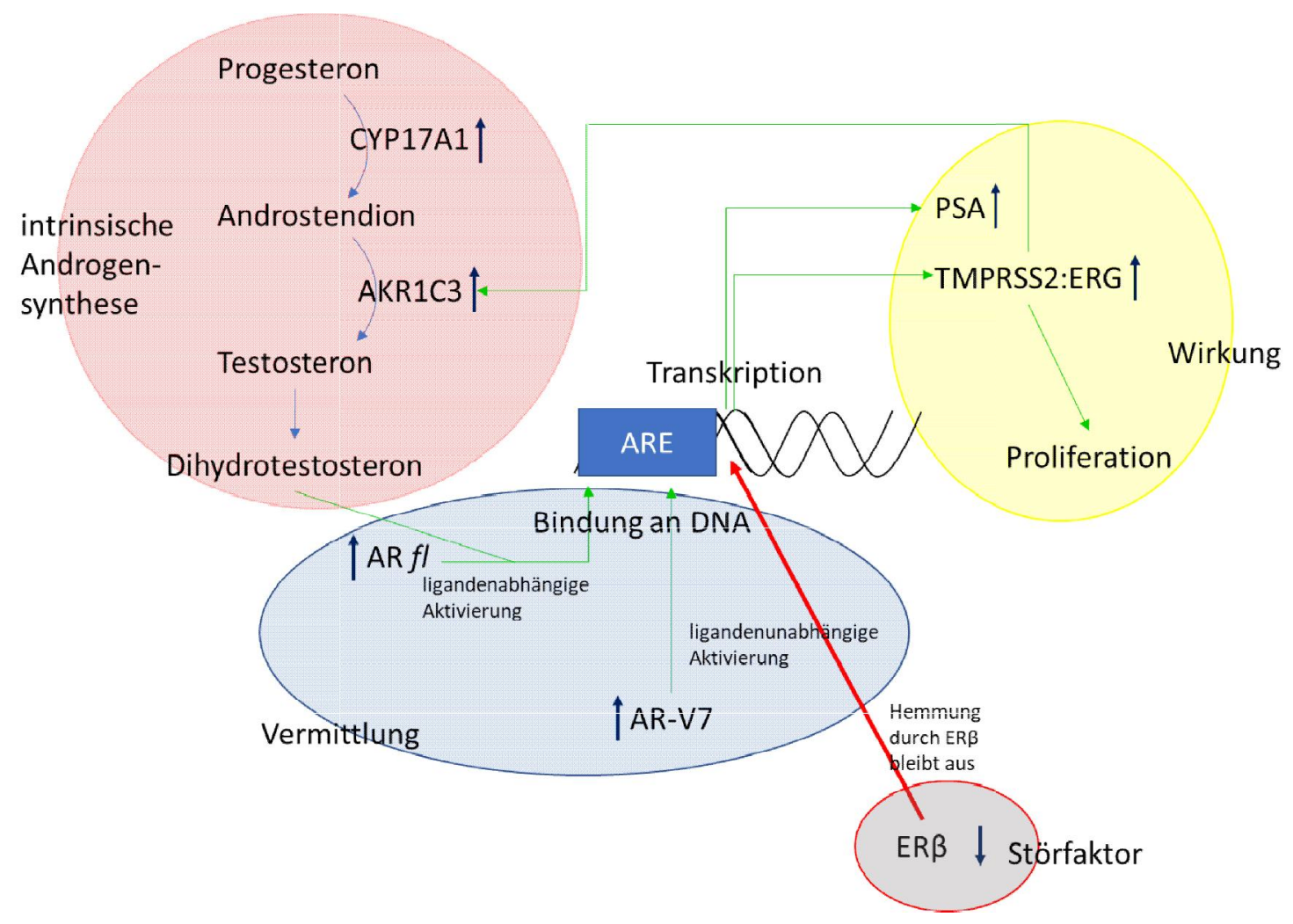

Abbildung 27: Verhältnisse in VCaP-Zellen, die androgenfrei kultiviert wurden

$\uparrow$ : in VCaP-Zellen hochregulierte Genprodukte; $\downarrow$ : in VCaP-Zellen herunterregulierte Genprodukte. Grüne Pfeile: positive Wirkung, dünne blaue Pfeile skizzieren den Stoffwechselweg zur Bildung von Dihydrotestosteron (schematisch). ARE: Androgenrezeptor Responsives Element. Durch die fehlende Hemmung der Proliferation durch ER $\beta$ schreitet das Tumorwachstum voran.

\subsection{8ß-VE2 senkt die AR-Konzentration in VCaP-Zellen}

Ein Hauptlokalisationspunkt des ER $\beta$ ist das gesunde Prostatagewebe. Dieser Transkriptionsfaktor gilt als Tumorsuppressor und schützt gegen eine gestörte Zellproliferation und Karzinogenese (Bonkhoff 2018). Seine Menge ist in Prostatakarzinomzellen, so auch in der VCaP-Zelllinie stark reduziert. Durch die Inkubation der Zellen in vitro mit 8$\beta-V E 2$ konnte eine Steigerung der Transkription von ER $\beta$ auf den etwa 30-fachen Wert festgestellt werden (Abbildung 6). Des Weiteren konnte die gesteigerte ER $\beta$-Expression durch $8 \beta$-VE2-Stimulation auch auf Proteinebene gezeigt werden (persönliche Mitteilung von Paul Thelen 2013). Dies bestätigte die Reversion durch die Stimulation.

Gründe für die stabile Herunterregulierung des ERß in den VCaP-Zellen liegen meist in der AR-Aktivierung zusammen mit Koaktivatoren, wie dem CREB binding 
protein (CBP). CBP setzt die Markierung und Herunterregulierung des ER $\beta$ über Kaskaden des PI3-K/Akt in Gang (Sanchez et al. 2012, Bouchal et al. 2011, Thelen et al. 2013). Weiterhin zeigte Stettner in seiner Arbeit das Wiederaufleben des AR und seine androgenen Effekte nach ERß-silencing durch knock down (Stettner et al. 2007).

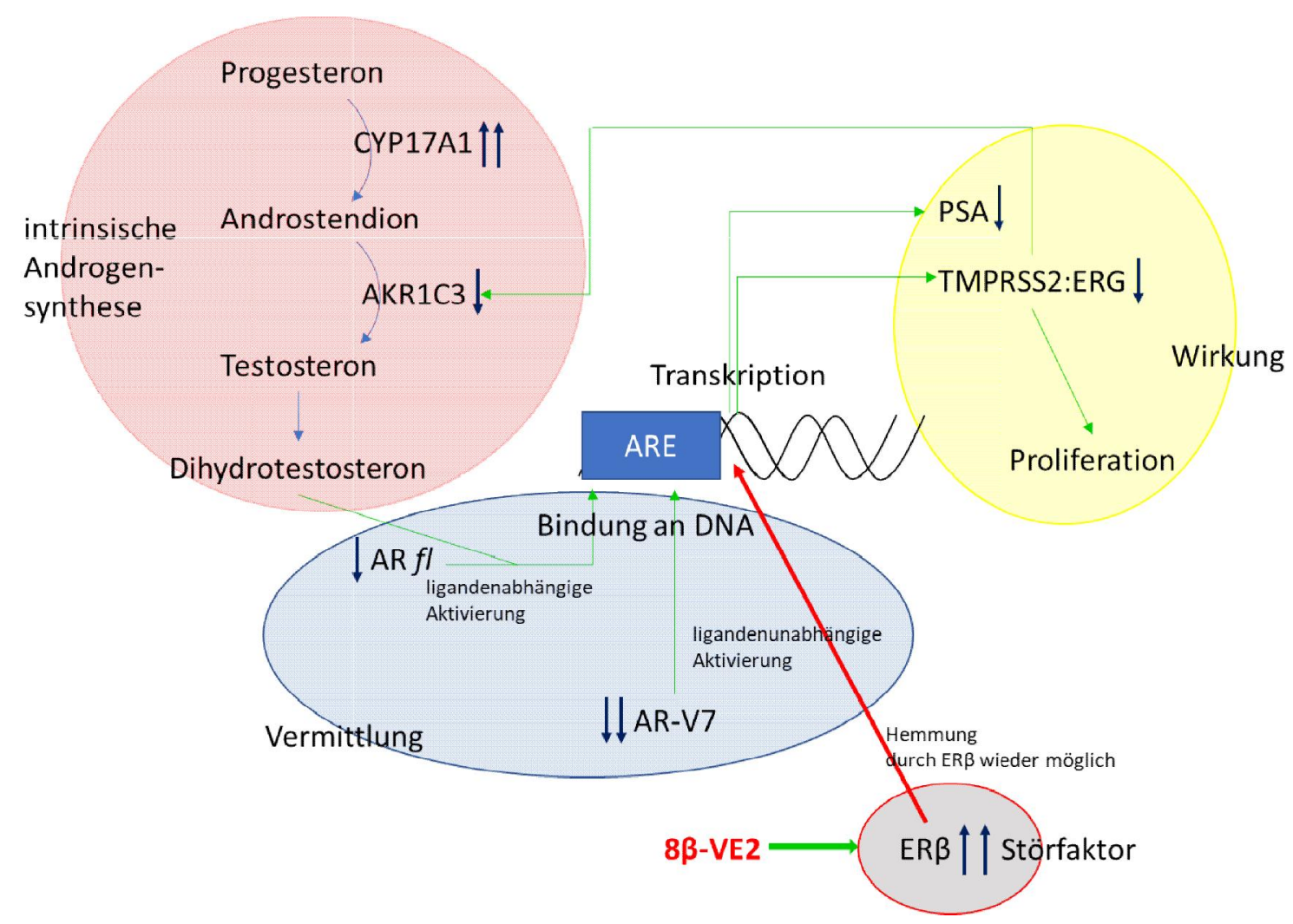

Abbildung 28: Verhältnisse in VCaP-Zellen, die androgenfrei kultiviert und mit dem selektiven ER $\beta$-Liganden $8 \beta$-VE2 stimuliert wurden

$\uparrow$ : hochregulierte Genprodukte; $\downarrow$ : herunterregulierte Genprodukte; doppelte Pfeile: besonders ausgeprägte Wirkung. Grüne Pfeile: positive Wirkung, dünne blaue Pfeile skizzieren den Stoffwechselweg zur Bildung von Dihydrotestosteron (schematisch). ARE: Androgenrezeptor Responsives Element. Durch die wieder mögliche Hemmung der Proliferation durch ER $\beta$ schreitet das Tumorwachstum nicht weiter voran und Apoptosevorgänge werden eingeleitet.

Während die Arbeitsgruppe um Gehrig bei der Stimulation der VCaP-Zellen mit $5 \mu \mathrm{M}$ oder $25 \mu \mathrm{M} 8 \beta$-VE2 eine Einschränkung der Proliferation der Zellen beobachtete (Gehrig et al. 2017), fehlte dieser Effekt in der hier vorgelegten Versuchsreihe (Abbildung 26). 
Die anti-androgenen Effekte durch ERß konnten bereits in LNCaP-Zellen, einer weiteren Zelllinie des Prostatakarzinoms, unter Stimulation Subtyp-selektiver Phytoöstrogene gezeigt werden (Stettner et al. 2007). Dieser Effekt wird nicht direkt durch Bindung des $A R$ hervorgerufen, sondern indirekt über die Aktivierung des ERB. Verschiedene Studien bestätigen diese Aussage (Walton et al. 2008, Leav et al. 2001, Stettner et al. 2007, Thelen et al. 2013).

Die Auswirkungen der Stimulation auf die untersuchten Parameter der VCaPZellen sind in Abbildung 28 schematisch zusammengefasst. Der mit dem Wiederaufleben von ER $\beta$ verbundene anti-androgene Effekt wurde durch die Stimulation der VCaP-Zellen durch 8ß-VE2 bestätigt (Abbildung 13). Unterschiedliche kastrationsresistente Mechanismen werden dadurch im CRPC kompensiert. So zeigte die 8$\beta$-VE2-Stimulation eine Expressionssenkung des in den VCaP-Zellen überexprimierten ARfl (Abbildung 8) auf etwa ein Viertel seiner Ausgangsrate. Die Spleißvariante AR-V7 wird durch die Stimulierung beinahe vollständig blockiert (Abbildung 9). Nicht nur die Transkription des AR und seiner Varianten wurde dadurch blockiert, auch eine Translation von möglicherweise noch vorhandener mRNA fand kaum mehr statt, was der Proteinnachweis mittels AR-spezifischem Antikörper zeigte (Abbildung 22, Tabelle 13). AR-V7 ist im CRPC vor allem dafür verantwortlich, dass eine basale AR-Aktivität unabhängig von tatsächlich vorhandenen Androgenen aufrechterhalten wird. Seine Aktivität ist allerdings nicht ausreichend, um die Aufgaben des $A R f l$ zu übernehmen, dennoch aktivieren beide AR-Varianten PSA und TMPRSS2 (Yu et al. 2014).

Somit könnte die beobachtete Senkung der Expression von PSA (Abbildung 7) und TMPRSS2-ERG (Abbildung 12) durch die Stimulierung der VCaP-Zellen durch $8 \beta-V E 2$ erfolgen. Demzufolge wäre dies auf das Fehlen der AR-Varianten zurückzuführen und damit ein indirekter Effekt des Stimulans. Bestätigt wird dieser Effekt durch die Arbeit der Arbeitsgruppe um Hargrove. Hier wurde ein spezifisches Pyrrol-imidazol Polyamid eingesetzt, welches direkt das ARE ausschaltet, indem es sequenzspezifisch die dreidimensionale Struktur der DNA ändert und so eine Aktivierung des ARE verhindert. Hargrove und ihre Mitarbeiter konnten zeigen, dass die Expression von TMPRSS2-ERG und PSA durch das Polyamid ver- 
gleichbar mit dem Effekt durch $8 \beta-V E 2$ herunterreguliert wurde (Hargrove et al. 2015).

Die Genfusion des TMPRSS2-ERG gilt als kennzeichnend für den CRPC und wird auch von der Modellzelllinie VCaP verstärkt exprimiert. In normalen Prostatazellen dagegen wird dieses Gen nicht exprimiert (Deramaudt et al. 2001). Die Expression des Fusionsgens führt zu einer Überexpression des ERG Transkriptionsfaktors (Tomlins et al. 2005). Gleichzeitig ist dies mit einer schlechten Prognose für die Patienten assoziiert, was sich vor allem bei der Behandlungsstrategie des Abwartens (watchful waiting) bemerkbar macht (Hägglöf et al. 2014, Demichelis et al. 2007).

Die Arbeitsgruppe um Wang konnte zeigen, dass unterschiedliche Verfahren des Silencings von TMPRSS2-ERG die Zellproliferation in VCaP-Zellen inhibiert (Wang et al. 2017, Urbinati et al. 2016, Urbinati et al. 2015). Eine verstärkte Expression von TMPRSS2-ERG führt zur Aktivierung von Plexin B1, das beim Prostatakarzinom für die Zellmigration und Zellinvasion verantwortlich gemacht wird (Liu et al. 2017). Weiterhin ist der mutierte Transkriptionsfaktor direkt mit der NOTCH Signaltransduktion über NOTCH 1 und 2 verknüpft (Mohamed et al. 2017). Dieser Signalweg kontrolliert während der Entwicklung eine Vielzahl von Entscheidungen über das Schicksal der Zellen (LaFoya et al. 2016).

Durch die Herunterregulation des TMPRSS2-ERG durch 8 $\beta-$ VE2 könnte damit auch das Potential zur Tumorgenese in den VCaP-Zellen erheblich verringert werden. Dennoch wurde TMPRSS2-ERG durch das Stimulans nicht im gleichen Maß beeinflusst wie $A R$ und $A R-V 7$, es konnte bei einer Konzentration von $50 \mu M$ lediglich eine Halbierung der TMPRSS2-ERG-Menge festgestellt werden, bei einer $100 \mu \mathrm{M}$ Konzentration eine Reduktion um etwa 70\% im Vergleich zu den nicht stimulierten VCaP-Zellen. Das deutet darauf hin, dass dieser Transkriptionsfaktor noch mindestens einer weiteren Regulationsmöglichkeit unterliegen muss, die in den VCaP-Zellen aktiv ist.

Ein Hinweis auf die Natur eines weiteren Aktivators ist die Arbeit der Gruppe um $\mathrm{Xu}$, die zeigen, dass die Expression des kernlokalisierten Rezeptors estrogenrelated receptor alpha (ERRa) und ERG in VCaP-Zellen positiv korreliert sind (Xu 
et al. 2018). Die Autoren konnten zeigen, dass diese Regulation unabhängig vom AR-Status der Zellen erfolgt. Ein weiterer Kandidat für die AR-unabhängige Regulation des TMPRSS2-ERG ist der Vitamin-D-Rezeptor (Roberts et al. 2017).

Durch die Überexpression des ERG wiederum wird in den VCaP-Zellen AKR1C3 beeinflusst. Eine Verringerung der ERG-Konzentration führt zu einer reduzierten Expression von AKR1C3, was wiederum in einer Reduktion der PSA-Expression resultiert (Powell et al. 2015). Dieser Effekt konnte ebenfalls in den Untersuchungen zu der hier vorgelegten Arbeit bestätigt werden. Eine Halbierung zumindest der mRNA-Menge des TMPRSS2-ERG hatte eine Reduktion der AKR1C3-mRNA um 73\% zur Folge (Abbildung 11). Eine weitere Reduktion des TMPRSS2-ERG kehrte diesen Effekt jedoch wieder teilweise um und eine Erhöhung der AKR1C3mRNA war zu verzeichnen. Dieser Effekt führt wiederum zu einer Steigerung der intrinsischen Androgen-Synthese im Tumorgewebe und zur Regulation des AR.

Eine Verminderung der AKR1C3-Expression resultiert in einer Senkung der PSASynthese, zumindest in 5a-Androstaendion behandelten VCaP-Zellen (Powell et al. 2015). Auch die Stimulation mit 8ß-VE2 hatte diesen Effekt zur Folge. Bei einer Konzentration von $100 \mu \mathrm{M} 8 \beta$-VE2 wurde die PSA-Expression fast vollständig unterdrückt. Da diese Entwicklung allerdings nicht mit der wiederansteigenden Expressionsrate des AKR1C3 in dieser Konzentration vereinbar ist, müssen auch an dieser Stelle weitere Regulationsmechanismen vorhanden sein (Karunasinghe et al. 2017).

Ein weiterer Schritt in der mehrstufigen Synthese der Androgene wird durch CYP17A1 katalysiert, dessen Expression auf mRNA-Ebene durch die Stimulation der Zellen mit 8$\beta$-VE2 gesteigert wurde (Abbildung 13). Allerdings wurde durch eine Erhöhung der Konzentration des Stimulans von $50 \mu \mathrm{M}$ auf $100 \mu \mathrm{M}$ die Expressionssteigerung teilweise revidiert. Die Stimulation mit $100 \mu \mathrm{M} 8 \beta$-VE2 resultierte in einer etwa 8-fachen Steigerung der mRNA-Menge (Abbildung 10), was gut mit der Erhöhung der Menge des CYP17A1-Proteins unter den gleichen Stimulationsbedingungen korrelierte (Tabelle 15). Eine Erhöhung der Expression von CYP17A1 deutet laut Bremmer und seinen Mitarbeitern auf einen effektiven Eingriff in die AR-Kaskade des CRPCs hin (Brenner et al. 2014). Allerdings stellt die- 
se Hochregulation eine weitere Herausforderung an eine adäquate Therapie dar (Mostaghel et al. 2011).

\subsection{DPN steigert die AR-Konzentration in VCaP-Zellen}

Obwohl DPN ebenso wie 8$\beta-V E 2$ in den VCaP-Zellen die Expression des ER $\beta$ erhöhte, zeigten sich doch wesentliche Unterschiede zwischen der Stimulierung mit den beiden Liganden. Die Wirkung des DPN ist in Abbildung 29 schematisch zusammengefasst. Die regulativen Vorgänge und die Unterdrückung wichtiger Tumorrepressoren konnte für die DPN-Stimulation nicht gezeigt werden. Dagegen verschoben sich die Expressionssteigerungen auf die Seite der Protoonkogene. Damit ist die Wirkungsweise von DPN als indirekte AR-Aktivierung zu sehen.

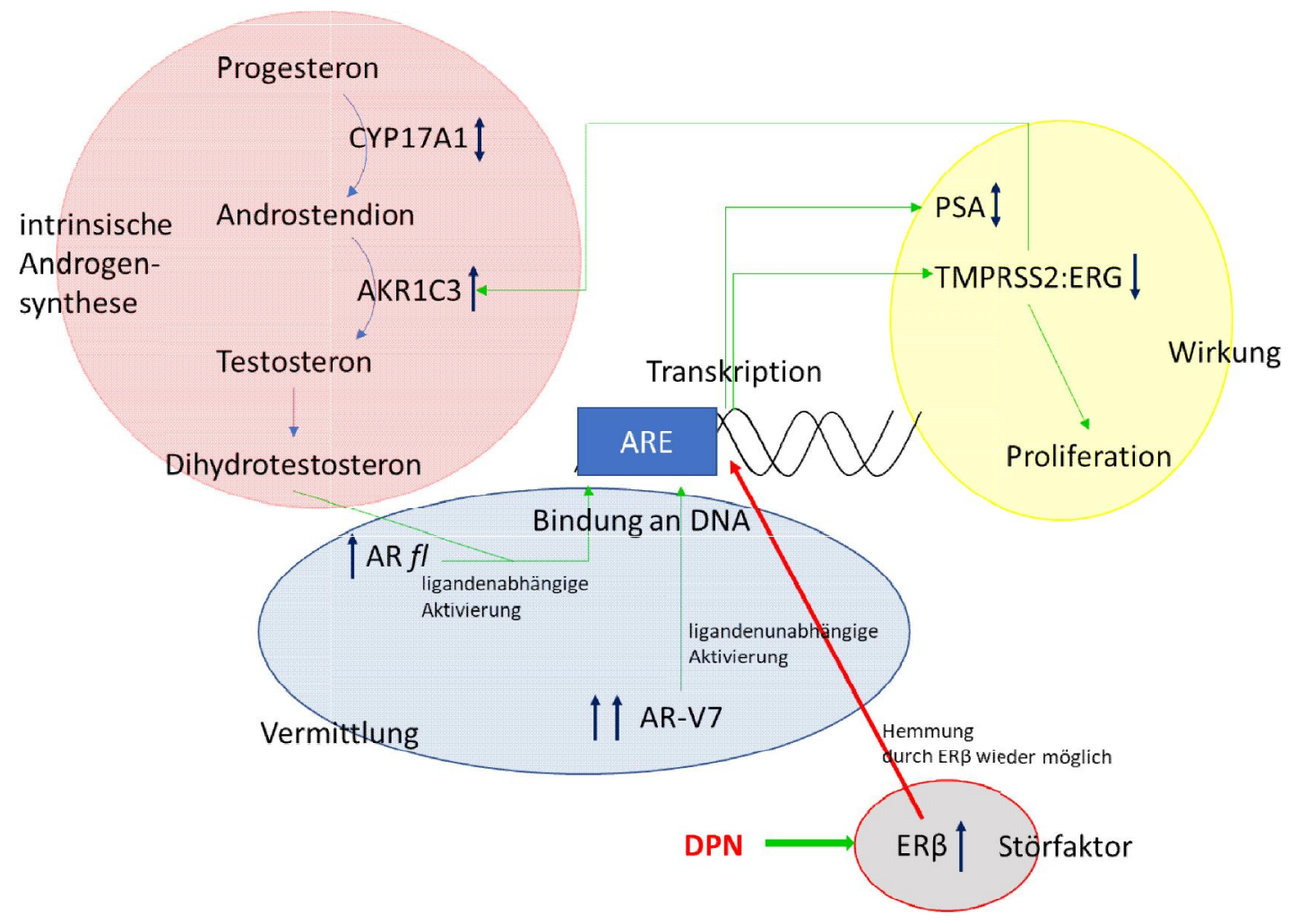

Abbildung 29: Verhältnisse in VCaP-Zellen, die androgenfrei kultiviert und mit dem selektiven ER $\beta$-Liganden $8 \beta$-VE2 stimuliert wurden

$\uparrow:$ hochregulierte Genprodukte; $\downarrow$ : herunterregulierte Genprodukte; doppelte Pfeile: besonders ausgeprägte Wirkung. Pfeile mit Doppelspitze: kaum Veränderung im Vergleich zu unstimulierten VCaP-Zellen. Grüne Pfeile: positive Wirkung, dünne blaue Pfeile skizzieren den Stoffwechselweg zur Bildung von Dihydrotestosteron (schematisch). ARE Androgenrezeptor Responsives Element. Die Hemmung durch die vermehrte ERßExpression reichte nicht aus, um zu einer Blockierung der AR-Signalkette zu führen. 
Während durch die Stimulation mit 8$\beta-V E 2$ sowohl die AR als auch die Bildung des DHT unterbunden werden konnte, war dieser Effekt durch die vergleichsweise geringe Expressionssteigerung des ER $\beta$ nach DPN-Stimulation nicht erfolgt. Im Gegenteil, durch die DPN-Stimulation wurde auch die Expression des AKR1C3 erhöht, wodurch eine verstärkte Bildung von DHT möglich war, das zusammen mit AR eine Steigerung der Expression der ARE-abhängigen Gene ermöglichte. Dennoch konnte lediglich eine Verdopplung der PSA-Transkription festgestellt werden (Abbildung 15) und die TMPRSS2-ERG-Expression wurde durch $100 \mu \mathrm{M}$ DPN blockiert (Abbildung 20).

Die Gesamtmenge aller AR-Varianten in den DPN-behandelten VCaP-Zellen verdoppelte sich lediglich während der Inkubationszeit. Im Gegensatz dazu konnte mindestens eine Versechsfachung der Menge der Transkripte gemessen werden (ARfl und AR-V7, Abbildung 16, Abbildung 17). Welche Faktoren für die Translation verantwortlich sind und welchen Einfluss die DPN-Stimulierung auf diese hatte, wurde jedoch nicht untersucht. Die Konzentration der CYP17A1-mRNA erhöhte sich durch die Stimulierung nur geringfügig und nicht statistisch signifikant (Abbildung 18). Im Gegensatz dazu sank die Menge des translatierten Proteins, jedoch ebenfalls nur geringfügig (Tabelle 16).

Andere Prostatakarzinom-Modelle zeigen durchaus stärkere Effekte, wenn ER $\beta$ mit DPN stimuliert wurde. So konnte die Arbeitsgruppe um Pravettoni eine Abnahme der Zellproliferation von DU145-Zellen beobachten (Pravettoni et al. 2007). Ein Grund für den schwachen Response der VCaP-Zellen auf DPN könnte die unterschiedliche Ausstattung der Zellen mit den Spleißvarianten des ER $\beta$ sein, die bei beiden Zellinien noch nicht untersucht wurde. Bislang werden 11 Varianten vermutet (Rettberg et al. 2014).

\subsection{Bedeutung für eine mögliche Therapie}

Die Stimulation mit 8$\beta-V E 2$ zeigte einen antagonistischen Effekt auf den AR als zentrale Schaltstelle des CRPC, während sich unter Stimulation mit DPN eher ein agonistischer Effekt, jedoch ohne Signifikanz auf den AR darstellte. Damit konnten 
abhängig vom spezifischen ER $\beta$-Liganden - trotz des ERß-Anstiegs - unterschiedliche Effekte auf den AR festgestellt werden.

Gründe für das Verlorengehen oder die Herunterregulierung von Tumorsuppressor-Genen in Karzinomen sind oft Methylierungen von DNAAbschnitten. Sie spielen eine wichtige Rolle bei der Tumorinitiation und Tumorprogression (Li et al. 2005). So ist auch der ERß-Promotor im Karzinom oft methyliert und führt so zu einer Suppression von ER $\beta$ (Suzuki et al. 2008, Warner und Gustafsson 2010).

Auch wichtige Gene für die Androgensynthese wurden vermutlich durch negative Rückkopplungsmechanismen als Antwort des verringerten AR gegensätzlich reguliert (Thelen et al. 2013, Bremmer et al. 2014). Es liegt nahe, dass die Expressionsminderungen und die regulativen Vorgänge mit der 8$\beta-V E 2-S t i m u l a t i o n ~ d e s$ ER $\beta$ zusammenhängen. Damit unterdrückt die durch $8 \beta-V E 2$ hervorgerufene ER $\beta$ Steigerung überexprimierte Tumorrepressorgene, die für die Proliferation und Progression des CRPC verantwortlich gemacht werden.

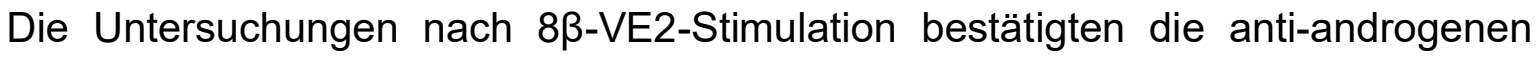
Effekte des ERß-selektiven Liganden. Studien nach ER $\beta$-silencing zeigen das erneute Ansteigen des AR und die damit verbundenen tumorprogressiven Kaskaden (Stettner et al. 2007). Daher stellt 8ß-VE2 als selektiver ER $\beta$-Ligand eine neue Therapiestrategie für das Prostatakarzinom dar. Mit den aktuellen Erkenntnissen, dass die Selektivität von $8 \beta-V E 2$ unzureichend sein könnte, rückt dieses jedoch wieder in den Hintergrund. Auch für DPN als ERß-spezifischen Liganden konnte dies bestätigt werden. Allerdings werden derzeit (Stand November 2018) noch keine klinischen Versuche mit einer der beiden Substanzen durchgeführt.

Es wäre denkbar, selektive Östrogenrezeptorliganden in der Rezidivprophylaxe nach kurativer Intervention durch radikale Prostatektomie oder Radiotherapie einzusetzen. Auch der Einsatz in der watchful waiting-Therapie für Patienten mit Prostatakarzinom sollte aufgrund des geringen Nebenwirkungsspektrums diskutiert werden. Es ist anzunehmen, dass weitere Therapieoptionen, die am Östrogenrezeptor, besonders am ER $\beta$, ansetzen, in der Behandlung des Prostatakarzinoms zum Einsatz kommen. 


\subsection{Schlussfolgerung und Ausblick}

Das metastasierte Prostatakarzinom kann bis heute nicht kurativ behandelt werden und entwickelt sich in vielen Fällen zum kastrationsresistenten Prostatakarzinom (CRPC). Dadurch ist die anfangs erfolgreiche anti-androgene Therapie auf wenige Jahre begrenzt, bis der AR durch verschiedene kompensatorische Mechanismen unempfindlich auf den Androgenentzug reagiert und sich ein CRPC entwickelt (Knudsen und Scher 2009).

Dazu zählen Mutationen, Überexpression und aktive Spleißvarianten des AR sowie Modifikationen in der Androgenkaskade, u. a. durch Rekrutierung von Koaktivatoren und tumoreigener Androgensynthese. Mutationen in der ligandenbindenden Domäne ermöglichen es auch für AR-unspezifische Liganden, wie Östrogene und Cortisol, eine Aktivierung des AR in Gang zu bringen. Auch Antiandrogene, z. B. Bicalutamid, können sich dadurch vom Antagonisten zum Agonisten entwickeln und eine Aktivierung des AR induzieren (Knudsen und Penning 2010, Waltering et al. 2012). Mutationen des AR sind unter Flutamid und Bicalutamid bereits aufgetreten.

In dieser Studie konnte gezeigt werden, dass $8 \beta$-VE2 ein potenterer Stimulator des ER $\beta$ ist als DPN. Um eine Therapie des CRPC zu entwickeln, die auf 8$\beta-V E 2$ basiert, wäre es im nächsten Schritt notwendig, eine optimale Konzentration des Wirkstoffes herauszufinden, die nicht nur in vitro, sondern auch in vivo an Xenograften des CRPC in der Maus oder Primaten wirkt. Dafür ist vermutlich eine Konzentration im Bereich von 5-25 $\mu \mathrm{M}$ ausreichend (Gehrig et al. 2017). Erst dann kann in Erwägung gezogen werden, den Wirkstoff auch am Menschen zu erproben.

Derzeit werden eher Kombinationsbehandlungen präferiert. So favorisiert die Arbeitsgruppe um Park Docetaxel und Histondeacetylase zur Behandlung von CRPC. Dadurch wird die Expression und Translokation des ARfl und seiner Varianten in den Nukleus verhindert (Park et al. 2018). Ein weiterer vielversprechender Ansatz ist die Gabe von Natrium-Selenit, dessen Aktivität durch die gleichzeitige Gabe von Carmustin gesteigert werden kann (Thamilselvan et al. 2016, 2017). Auch davon sind ARfl und seine Varianten betroffen. 
Aber auch Einzelsubstanzen werden in der Therapie des CRPC weitergesucht. So zeigte ein Wirkstoff aus dem Schwamm Rhizochalina incrustata, Rhizochalinin sowohl in vitro as auch in vivo vielversprechende Ergebnisse bei der Behandlung des CRPC (Dyshlovoy et al. 2016). Die Wirkung läuft ebenfalls über die ARKaskade. Am weitesten fortgeschritten sind derzeit die Untersuchungen an ODM204, einer nichtsteroidalen Substanz, die spezifisch CYP17A1 inhibiert und die AR-Signalkette auf der Rezeptorebene im gleichen Maß wie Enzalutamid blockiert (Oksala et al. 2018). Diese Substanz hat bereits die Phase der klinischen Studien erreicht (Peltola et al. 2018).

Allerdings haben sich bislang alle Bemühungen um eine endgültige Heilung des CRPC als erfolglos gezeigt. Die Karzinomzellen können mittels Spleißvarianten und Punktmutationen in den unterschiedlichsten Proteinen der Eindämmung der Proliferation und die Aktivierung der Apoptose verhindern. 


\section{Zusammenfassung}

Das Prostatakarzinom kann sich während und durch eine Absenkung des Androgenspiegels auf Kastrationsniveau zu einer kastrationsresistenten Form entwickeln und weiter wachsen. Bislang gibt es keine gesicherte Therapie, die ab diesem Punkt erfolgreich eingesetzt werden kann. ER $\beta$ ist ein wichtiger regulativer Tumorsuppressor im Prostatakarzinom, das im CRPC nicht mehr exprimiert wird. Es ist jedoch möglich, die Expression durch Stimulation der Zellen mit DPN oder $8 \beta$-VE2 wieder zu steigern. Die dafür verwendeten Konzentrationen waren $50 \mu \mathrm{M}$ und $100 \mu \mathrm{M}$.

In den Untersuchungen zu dieser Arbeit wurden die Auswirkungen der in der Karzinogenese wichtigen Gene ARfl und AR-V7, CYP17A und AKR1C3 sowie PSA und TPPRSS2:ERG nach ERß-Stimulation der CRPC-Modellzellinie VCaP untersucht. Weiterhin wurde die Proliferation der Zellen während der Stimulation analysiert. Zur Untersuchung der Genexpressionen wurden RNA und Proteine analysiert sowie ein BrdU-Proliferationstest durchgeführt.

Die Effekte der beiden selektiven Liganden waren unterschiedlich. Beide erzielten zwar eine Expressionssteigerung des ER $\beta$, die Stimulation mit 8 $\beta-V E 2$ führte dann zur Expressionssenkung wichtiger Protoonkogene und damit in Richtung Progressionshemmung, Zellzyklusarrest, Apoptose und Differenzierung der Zellen. Eine Stimulierung mit DPN dagegen resultierte in einer weit geringeren Expressionssteigerung von ER $\beta$ und nur einer geringen Beeinflussung der Protoonkogene.

Es zeigte sich nach $8 \beta$-VE2 Stimulation eine Herunterregulierung des für das CRPC zentralen ARfl sowie seiner Spleißvariante AR-V7. Weiterhin fand sich eine Expressionssenkung AR-regulierter Gene PSA und TMPRSS2-ERG, welches eine für die VCaP-Zelllinie typische maligne Genfusion ist. Aufgrund der verminderten Expression Androgen-regulierter Gene konnten veränderte Vorgänge bei für die Androgensynthese wichtigen Enzymen als Gegenregulation beobachtet werden. So zeigten sich eine Steigerung der CYP17A1-Expression und eine Senkung der AKR1C3-Expression als gegensätzliche Regulation. 
Dagegen ergaben sich durch die Stimulation mit DPN pro-androgene Auswirkungen in Richtung Proliferationssteigerung. Obwohl eine Expressionsteigerung des ER $\beta$ zu verzeichnen war, stieg die Expression des ARfl und seiner Spleißvariante AR-V7. Auch eine Zunahme der PSA-Expression war nachweisbar. Die Genfusion TMPRSS2-ERG nahm bei Konzentrationssteigerung des DPN ab. Insgesamt aber zeigten die Ergebnisse der DPN-Stimulation, dass DPN als Therapieoption ungeeignet ist.

Die anti-androgene Wirkungsweise des ER $\beta$ nach $8 \beta$-VE2-Stimulation weist auf den therapeutischen Nutzen dieser Substanz in der Behandlung des CRPC hin. Allerdings muss für $8 \beta-V E 2$ erst eine therapiegeeignete Wirkstoffkonzentration gefunden werden. Weiterhin müssen weitere in vitro und in vivo Versuche die Ergebnisse mit den VCaP-Zellen bestätigen. 


\section{Literatur}

Akakura K, Bruchovsky N, Goldenberg SL, Rennie PS, Buckley AR, Sullivan LD (1993): Effects of intermittent androgen suppression on androgen-dependent tumors. Apoptosis and serum prostate-specific antigen. Cancer $\underline{71}, 2782-2790$

Andersson S, Geissler WM, Patel S, Wu L (1995): The molecular biology of androgenic 17ß-hydroxysteroid dehydrogenases. J Steroid Biochem Mol Biol $\underline{53}$, 37-39

Attard G, Cooper CS, de Bono JS (2009): Steroid hormone receptors in prostate cancer: a hard habit to break? Cancer Cell $\underline{16}, 458-462$

Attard G, Reid AH, Yap TA, Raynaud F, Dowsett M, Settatree S, Barrett M, Parker C, Martins V, Folkerd E (2008): Phase I clinical trial of a selective inhibitor of CYP17, abiraterone acetate, confirms that castration-resistant prostate cancer commonly remains hormone driven. J Clin Oncol 26, 4563-4571

Bergh RC van den, Roemeling S, Roobol MJ, Aus G, Hugosson J, Ranniko AS, Tammela TL, Bangma CH, Schröder FH (2009): Outcomes of men with screen-detected prostate cancer eligible for active surveillance who were managed expectantly. Eur Urol $\underline{55}, 1-8$

Berthold D, Pond G, Soban F, De Wit R, Eisenberger M, Tannock I (2008): Docetaxel plus prednisone or mitoxantrone plus prednisone for advanced prostate cancer: updated survival in the TAX 327 study. J Clin Oncol 26, 242-245

Bonkhoff H (2018): Estrogen receptor signaling in prostate cancer: Implications for carcinogenesis and tumor progression. Prostate $\underline{78}, 2-10$

Bonkhoff $\mathrm{H}$, Berges $\mathrm{R}$ (2009): The evolving role of oestrogens and their receptors in the development and progression of prostate cancer. Eur Urol $\underline{55}, 533-542$

Bonkhoff H, Motherby H, Fixemer T (2003): Neue Einblicke in die Rolle der Östrogene und ihrer Rezeptoren im Prostatakarzinom. Urologe A 42, 1594-1601

Börgermann C, Sieverding M, Fornara P, Graefen M, Hammerer P, Semjonow A, Schröder F, Rübben H (2006): PSA 2010 - Aufbruch in eine neue Ära der Früherkennung des Prostatakarzinoms. Urologe A $\underline{45}, 127-133$ 
Bouchal J, Santer FR, Höschele PP, Tomastikova E, Neuwirt H, Culig Z (2011): Transcriptional coactivators p300 and CBP stimulate estrogen receptor-beta signaling and regulate cellular events in prostate cancer. Prostate $\underline{71}, 431-437$

Bremmer F, Jarry H, Strauß A, Behnes CL, Trojan L, Thelen P (2014): Increased expression of CYP17A1 indicates an effective targeting of the androgen receptor axis in castration resistent prostate cancer (CRPC). Springerplus $\underline{3}, 574$

Bussemakers MJ, Bokhoven A van, Verhaegh GW, Smit FP, Karthaus HF, Schalken JA, Debruyne FM, Ru N, Isaacs WB (1999): DD3: a new prostate-specific gene, highly overexpressed in prostate cancer. Cancer Res $\underline{59}$, 5975-5979

Byrns MC, Steckelbroeck S, Penning TM (2008): An indomethacin analogue, N-(4chlorobenzoyl)-melatonin, is a selective inhibitor of aldo-keto reductase 1C3 (type 2 3alpha-HSD, type 517 beta-HSD, and prostaglandin F synthase), a potential target for the treatment of hormone dependent and hormone independent malignancies. Biochem Pharmacol $\underline{75}$, 484-493

Cai C, Chen S, Ng P, Bubley GJ, Nelson PS, Mostaghel EA, Marck B, Matsumoto AM, Simon NI, Wang H, Chen S, Balk SP (2011): Intratumoral de novo steroid synthesis activates androgen receptor in castration-resistant prostate cancer and is upregulated by treatment with CYP17A1 inhibitors. Cancer Res $\underline{71}$, 6503-6513

Cai C, Wang H, Xu Y, Chen S, Balk SP (2009): Reactivation of androgen receptorregulated TMPRSS2:ERG gene expression in castration-resistant prostate cancer. Cancer Res $\underline{69}, 6027-6032$

Chen GG, Zeng Q, Tse GM, (2008): Estrogen and its receptors in cancer. Med Res Rev $\underline{28}, 954-974$

Chen M, Adeniji AO, Twenter BM, Winkler JD, Christianson DW, Penning TM (2012): Crystal structures of AKR1C3 containing an N-(aryl)amino-benzoate inhibitor and a bifunctional AKR1C3 inhibitor and androgen receptor antagonist. Therapeutic leads for castrate resistant prostate cancer. Bioorg Med Chem Lett. 22, 3492-3497

Culig Z, Hobisch A, Bartsch G, Klocker H (2000): Expression and function of androgen receptor in carcinoma of the prostate. Microsc Res Tech $\underline{5}$, 447-455 
de Bono JS, Logothetis CJ, Molina A, Fizazi K, North S, Chu L, Chi KN, Jones RJ, Goodman OB Jr, Saad F, Staffurth JN, Mainwaring P, Harland S, Flaig TW, Hutson TE, Cheng T, Patterson H, Hainsworth JD, Ryan CJ, Sternberg CN, Ellard SL, Fléchon A, Saleh M, Scholz M, Efstathiou E, Zivi A, Bianchini D, Loriot Y, Chieffo N, Kheoh T, Haqq CM, Scher HI; COU-AA-301 Investigators (2011): Abiraterone and increased survival in metastatic prostate cancer. N Engl J Med $\underline{364}, 1995-2005$

de Bono JS, Logothetis CJ, Molina A, Fizazi K, North S, Chu L, Chi KN, Jones RJ, Goodman OB Jr, Saad F (1995): Abiraterone and increased survival in metatatic prostate cancer. N Engl J Med 364, 1995-2005

de Bono JS, Oudard S, Ozguroglu M, Hansen S, Machiels J, Kocak I, Gravis G, Bodrogi I, Mackenzie MJ, Shen L (2010): Prednisone plus cabazitaxel or mitoxantrone for metastatic castrationresistant prostate cancer progressing after docetaxel. Lancet $\underline{376}, 1147-1154$

de Marzo AM, Platz EA, Sutcliffs S, Xu J, Grönberg H, Drake CG, Nakai Y, Isaacs WB, Nelson WG (2007): Inflammation in prostate carcinogenesis. Nat Rev Cancer $\underline{7}, 256-269$

Demichelis F, Fall K, Perner S, Andrén O, Schmidt F, Setlur SR, Hoshida Y, Mosquera JM, Pawitan Y, Lee C, Adami HO, Mucci LA, Kantoff PW, Andersson SO, Chinnaiyan AM, Johansson JE, Rubin MA (2007): TMPRSS2:ERG gene fusion associated with lethal prostate cancer in a watchful waiting cohort. Oncogene $\underline{26}, 4596-4599$

Deramaudt TB, Remy P, Stiegler P (2001): Identification of interaction partners for two closely-related members of the ETS protein family, FLI and ERG. Gene 274, 169-177; Erratum in: Gene 2001 278: 265

Dey P, Barros RP, Warner M, Ström A, Gustafsson JÅ (2013): Insight into the mechanisms of action of estrogen receptor $\beta$ in the breast, prostate, colon, and CNS. J Mol Endocrinol $\underline{51}$, T61-74

Dozmorov MJ, Azzarello JT, Wren JD, Fung K-M, Yang Q, Davis JS, Hurst RE, Culkin DJ, Penning TM, Lin HK (2010): Elevated AKR1C3 expression promotes prostate cancer cell survival and prostate cell-mediated endothelial cell tube formation: implications for prostate cancer progressioan. BMC Cancer $\underline{10}, 672$ 
Dyshlovoy SA, Otte K, Alsdorf WH, Hauschild J, Lange T, Venz S, Bauer CK, Bähring R, Amann K, Mandanchi R, Schumacher U, Schröder-Schwarz J, Makarieva TN, Guzii AG, Tabakmakher KM, Fedorov SN, Shubina LK, Kasheverov IE, Ehmke H, Steuber T, Stonik VA, Bokemeyer C, Honecker F, von Amsberg G (2016): Marine compound rhizochalinin shows high in vitro and in vivo efficacy in castration resistant prostate cancer. Oncotarget. 7, 69703-69717.

Ellem SJ, Risbridger GP (2007): Treating prostate cancer: a rationale for targeting local oestrogens. Nat Rev Cancer $\underline{7}, 621-627$

Feldman BJ, Feldman D (2001): The development of androgen-independent prostate cancer. Nat Rev Cancer 1, 134-145

Fung KM, Samara EN, Wong C, Metwalli A, Krlin R, Bane B, Liu CZ, Yang JT, Pitha JV, Culkin DJ, Kropp BP, Penning TM, Lin H-K (2006): Increased expression of type $23 \alpha-$ hydroxysteroid dehydrogenase/type 5 17ß-hydroxysteroid dehydrogenase (AKR1C3) and its relationship with androgen receptor in prostate carcinoma. Endocr Relat Cancer $\underline{13}$, $169-180$

Ganzer R, Wieland WF, Bach T, Rossler W, Blana A (2007): Hormontherapie des Prostatakarzinoms - Übersicht und aktueller Stand. Dtsch Med Wochenschr 132, 161-166

Gehrig J, Kaulfuß S Jarry H, Bremmer F, Stettner M, Burfeind P, Thelen P (2017): Prospects of estrogen receptor $\beta$ activation in the treatment of castration-resistant prostate cancer. Oncotarget $\underline{8}, 34971-34979$

Graefen M, Hammerer P, Haese A, Huland H (2000): Therapieoptionen des hormonrefraktären Prostatakarzinoms. Urologe A $\underline{39}, 267-273$

Haese A, Graefen M, Steuber T, Becker C, Noldus J, Erbersdobler A, Huland E, Huland H, Lilja H (2003): Total and Gleason grade 4/5 cancer volumes are major contributors of human kallikrein 2 , whereas free prostate specific antigen is largely contributed by benign gland volume in serum from patients with prostate cancer or benign prostatic biopsies. $J$ Urol $\underline{170}, 2269-2273$

Haese A, Taille A de la, Poppel H van, Marberger M, Stenzl A, Mulders PF, Huland H, Abbou CC, Remzi M, Tinzl M (2008): Clinical utility of the PCA3 urine assay in European men scheduled for repeat biopsy. Eur Urol $\underline{54}, 1081-1088$ 
Hägglöf C, Hammarsten P, Strömvall K, Egevad L, Josefsson A, Stattin P, Granfors T, Bergh A (2014): TMPRSS2-ERG expression predicts prostate cancer survival and associates with stromal biomarkers. PLoS One $\underline{9}$, e86824

Hall JM, McDonnell DP (2005): Coregulators in nuclear estrogen receptor action: from concept to therapeutic targeting. Mol. Interv $\underline{5}, 343-357$

Hara M, Koyanagi Y, Inoue T, Fukuyama T (1971): [Some physico-chemical characteristics of " -seminoprotein", an antigenic component specific for human seminal plasma. Forensic immunological study of body fluids and secretion. VII]. Nihon Hoigaku Zasshi $\underline{4}$, 322-324

Hargrove AE, Martinez TF, Hare AA, Kurmis AA, Phillips JW, Sud S, Pienta KJ, Dervan PB (2015): Tumor Repression of VCaP Xenografts by a Pyrrole-Imidazole Polyamide. PLoS One. 10, e0143161.

Harrington WR, Sheng S, Barnett DH, Petz LN, Katzenellenboge JA, Katzenellenbogen BS (2003): Activities of estrogen receptor alpha- and beta-selective ligands at diverse estrogen responsive gene sites mediating transactivation or transrepression. Mol Cell Endocrinol 206, 13-22

Heidenreich A, Ohlmann CH (2005): Therapieoptionen des hormonrefraktären Prostatakarzinoms. Urologe A $\underline{44}, 1303-1304,1306-1314$

Hörnberg E, Ylitalo EB, Crnalic S, Antti H, Stattin P, Widmark A, Bergh A, Wikström P (2011): Expression of androgen receptor splice variants in prostate cancer bone metastases is associated with castration-resistance and short survival. PLoS ONE $\underline{6}$, e19059

Huggins C, Hodges CV (1941): Studies on prostatic cancer. I. The effect of castration, of estrogen and androgen injection on serum phosphatases in metastatic carcinoma of the prostate. Cancer Res 1 , 293-297

Hugosson J, Carlsson S, Aus G, Bergdahl S, Khatami A, Lodding P, Pihl CG, Stranne J, Holmberg E, Lilja $H$ (2010) Mortality results from the Göteborg randomised populationbased prostate-cancer screening trial. Lancet Oncol 11, 725-732

Hussain S, Lawrence MG, Taylor RA, Lo CY; APC BioResource, Frydenberg M, Ellem SJ, Furic L, Risbridger GP (2012): Estrogen receptor $\beta$ activation impairs prostatic regeneration by inducing apoptosis in murine and human stem/progenitor enriched cell populations. PLoS ONE $\underline{7}$, e40732 
Karunasinghe N, Masters J, Flanagan JU, Ferguson LR (2017): Influence of Aldo-keto Reductase 1C3 in Prostate Cancer - A Mini Review. Curr Cancer Drug Targets 17, 603616

Knudsen KE, Penning TM (2010): Partners in crime: deregulation of AR activity and androgen synthesis in prostate cancer. Trends Endocrinol Metab 21, 315-324

Knudsen KE, Scher HI (2009): Starving the addiction: new opportunities for durable suppression of AR signaling in prostate cancer. Clin Cancer Res $\underline{15}$, 4792-4798

Knuuttila M, Yatkin E, Kallio J, Savolainen S, Laajala TD, Aittokallio T, Oksala R, Häkkinen M, Keski-Rahkonen P, Auriola S, Poutanen M, Mäkelä S (2014): Castration induces up-regulation of intratumoral androgen biosynthesis and androgen receptor expression in an orthotopic VCaP human prostate cancer xenograft model. Am J Pathol 184, 2163-2173

Korenchuk S, Lehr JE, MClean L, Lee YG, Whitney S, Vessella R, Lin DL, Pienta KJ (2001): VCaP, a cell-based model system of human prostate cancer. In Vivo $\underline{15}$, 163-168

Kumar-Sinha C, Tomlins SA, Chinnaiyan AM (2008): Recurrent gene fusions in prostate cancer. Nat Rev Cancer $\underline{8}, 497-511$

LaFoya B, Munroe JA, Mia MM, Detweiler MA, Crow JJ, Wood T, Roth S, Sharma B, Albig AR (2016): Notch: A multi-functional integrating system of microenvironmental signals. Dev Biol $\underline{418}, 227-241$

Landers KA, Burger MJ, Tebay MA, Purdie DM, Scells B, Samaratunga H, Lavin MF, Gardiner RA (2005): Use of multiple biomarkers for a molecular diagnosis of prostate cancer. Int J Cancer $\underline{114}, 950-956$

Leitman DC, Paruthiyil S, Vivar OI, Saunier EF, Herber CB, Cohen I, Tagliaferri M, Speed TP (2010): Regulation of specific target genes and biological responses by estrogen receptor subtype agonists. Curr Opin Pharmacol 10, 629-636

Leav I, Lau KM, Adams JY, Mc Neal JE, Taplin ME, Wang J, Singh H, Ho SM (2001): Comparative studies of the estrogen receptors beta and alpha and the androgen receptor in normal human prostate glands, dysplasia, and in primary and metastatic carcinoma. Am J Pathol $\underline{159}$, 79-92 
Leon CG, Locke JA, Adomat HH, Etinger SL, Twiddy AL, Neumann RD, Nelson CC, Guns ES, Wasan KM (2010): Alterations in cholesterol regulation contribute to the production of intratumoral androgens during progression to castration-resistant prostate cancer in a mouse xenograft model. Prostate $\underline{70}, 390-400$

Lewis MJ, Wiebe JP, Heathcote JG (2004): Expression of progesterone metabolizing enzyme genes (AKR1C1, AKR1C2, AKR1C3, SRD5A1, SRD5A2) is altered in human breast carcinoma. BMC Cancer $\underline{4}, 27$

Li LC, Carroll PR, Dahiya R (2005): Epigenetic changes in prostate cancer: implication for diagnosis and treatment. J Natl Cancer Inst $\underline{97}, 103-105$

Liu B, Gu X, Huang T, Luan Y, Ding X (2017): Identification of TMPRSS2-ERG mechanisms in prostate cancer invasiveness: Involvement of MMP-9 and plexin B1. Oncol Rep. 37, 201-208.

Locke JA, Guns ES, Lehman ML, Ettinger S, Zoubeidi A, LupikA, Margiotti K, Fazli L, Adomat $\mathrm{H}$, Wasan KM (2010): Arachidonic acid activation of intratumoral steroid synthesis during prostate cancer progression to castration resistance. Prostate $\underline{70}, 239-251$

Loukola A, Chadha M, Penn SG, Rank D, Conti DV, Thompson D, Cicek M, Love B, Bivolarevic V, Yang Q (2004): Comprehensive evaluation of the association between prostate cancer and genotypes/haplotypes in CYP17A1, CYP3A4, and SRD5A2. Eur J Hum Genet 12, 321-332

Lu S, Tsai SY, Tsai MJ (1997): Regulation of androgen-dependent prostatic cancer cell growth: androgen regulation of CDK2, CDK4, and CKI p16 genes. Cancer Res $\underline{57}, 4511-$ 4516

Mak P, Leav I, Pursell B, Bae D, Yang X, Taglienti CA, Gouvin LM, Sharma VM, Mercurio AM (2010): ERbeta impedes prostate cancer EMT by destabilizing HIF-1alpha and inhibiting VEGF-mediated snail nuclear localization: implications for Gleason grading. Cancer Cell $\underline{17}, 319-332$

Manas ES, Xu ZB, Unwalla RJ, Somers WS (2004): Understanding the selectivity of genistein for human estrogen receptor-beta using X-ray crystallography and computational methods. Structure $\underline{12}, 2197-2207$ 
McPherson SJ, Hussain S, Balanathan P, Hedwards SL, Niranjan B, Grant M, Chandrasiri UP, Toivanen R, Wang Y, Taylor RA (2010): Estrogen receptor-beta activated apoptosis in benign hyperplasia and cancer of the prostate is androgen independent and TNFalpha mediated. Proc Natl Acad Sci USA 107 , 3123-3128

Meyers MJ, Sun J, Carlson KE, Marriner GA, Katzenellenbogen BS, Katzenellenbogen JA (2001): Estrogen receptor-beta potency-selective ligands: structure-activity relationship studies of diarylpropionitriles and their acetylene and polar analogues. J Med Chem $\underline{44}$, $4230-4251$

Mohamed AA, Tan SH, Xavier CP, Katta S, Huang W, Ravindranath L, Jamal M, Li H, Srivastava M, Srivatsan ES, Sreenath TL, McLeod DG, Srinivasan A, Petrovics G, Dobi A, Srivastava S (2017): Synergistic Activity with NOTCH Inhibition and Androgen Ablation in ERG-Positive Prostate Cancer Cells. Mol Cancer Res 15, 1308-1317

Monroe DG, Secreto FJ, Subramaniam M, Getz BJ, Khosla S, Spelsberg TC (2005) Estrogen receptor alpha and beta heterodimers exert unique effects on estrogen- and tamoxifen-dependent gene expression in human U2OS osteosarcoma cells. Mol Endocrinol $\underline{19}, 1555-1568$

Montgomery RB, Mostaghel EA, Vessella R, Hess DL, Kalhorn TF, Higano CS, True LD, Nelson PS (2008): Maintenance of intratumoral androgens in metastatic prostate cancer: a mechanism for castration-resistant tumor growth. Cancer Res $\underline{68}, 4447-4454$

Mostaghel EA, Marck BT, Plymate SR, Vassella RL, Balk S, Matsumoto AM, Nelson PS, Montgomery RB (2011): Resistance to CYP17A1 inhibition with abiraterone in castrationresistant prostate cancer: induction of steroidogenesis and androgen receptor splice variants. Clin Cancer Res 17 , 5913-5925

Mukherji D, Eichholz A, de Bono JS (2012): Management of metastatic castrationresistant prostate cancer: recent advances. Drugs $\underline{72}, 1011-1028$

Nilsson S, Gustafsson J-A: Estrogene receptors: their actions and functional roles in health and disease. In: Bunce C M, Campbell MJ (Hrsg.): Nuclear receptors: current concepts and future challenges Springer Netherlands, o. O. 2010, 91-141

Nilsson S, Koehler KF, Gustafsson JA (2011): Developement of subtype-selective oestrogen receptor-based therapeutics. Nat Rev Drug Discov $\underline{10}, 778-792$ 
Oksala R, Moilanen A, Riikonen R, Rummakko P, Karjalainen A, Passiniemi M, Wohlfahrt G, Taavitsainen P, Malmström C, Ramela M, Metsänkylä HM, Huhtaniemi R, Kallio PJ, Mustonen MV (2018): Discovery and development of ODM-204: A Novel nonsteroidal compound for the treatment of castration-resistant prostate cancer by blocking the androgen receptor and inhibiting CYP17A1. J Steroid Biochem Mol Biol. 2018 Feb 10. pii: S0960-0760(18)30078-5.

Papsidero LD, Wang MC, Valenzuela LA, Murphy GP, Chu TM (1980): A prostate antigen in sera of prostatic cancer patients. Cancer Res $\underline{40}, 2428-2432$

Park SE, Kim HG, Kim DE, Jung YJ, Kim Y, Jeong SY, Choi EK, Hwang JJ, Kim CS (2018): Combination treatment with docetaxel and histone deacetylase inhibitors downregulates androgen receptor signaling in castration-resistant prostate cancer. Invest New Drugs. $\underline{36}, 195-205$.

Partin AW, Catalona WJ, Southwick PC, Subong EN, Gasior GH, Chan DW (1996): Analysis of percent free pro-state-specific antigen (PSA) for prostate cancer detection: influence of total PSA, prostate volume and age. Urology $\underline{48}, 55-61$

Peltola KJ, Bono P, Jones RH, Vjaters E, Nykänen P, Vuorela A, Oksala R, Pohjanjousi P, Mustonen MVJ, Fizazi K, Massard C (2018): ODM-204, a Novel Dual Inhibitor of CYP17A1 and Androgen Receptor: Early Results from Phase I Dose Escalation in Men with Castration-resistant Prostate Cancer. Eur Urol Focus. 2018 Sep 4. pii: S24054569(18)30241-4. doi: 10.1016/j.euf.2018.08.022. [elektronische Vorabveröffentlichung]

Perner S, Schmidt FH, Hofer MD, Kuefer R, Rubin M (2007): Die TMPRSS2-ETSGenfusion beim Prostatakarzinom. Urologe A $\underline{46}, 754-760$

Persissi V, Rosenfeld MG (2005): Controlling nuclear receptors: the circular logic of cofactor cycles. Nat Rev Mol Cell Biol $\underline{6}, 542-554$

Popa I, Fradet Y, Beaudry G, Hovington H, Beaudry G, Tetu B (2007): Identification of PCA3 (DD3) in prostatic carcinoma by in situ hybridization. Mod Pathol 20, 1121-1127

Powell E, Xu W (2008): Intermolecular interactions identify ligand-selective activity of estrogen receptor alpha/ beta dimers. Proc Natl Acad Sci USA $\underline{105}, 19012-19017$ 
Powell K, Semaan L, Conley-LaComb MK, Asangani I, Wu YM, Ginsburg KB, Williams J, Squire JA, Maddipati KR, Cher ML, Chinni SR (2015): ERG/AKR1C3/AR Constitutes a Feed-Forward Loop for AR Signaling in Prostate Cancer Cells. Clin Cancer Res 21, 25692579

Pravettoni A, Mornati O, Martini PG, Marino M, Colciago A, Celotti F, Motta M, Negri-Cesi $P$ (2007): Estrogen receptor beta (ERbeta) and inhibition of prostate cancer cell proliferation: studies on the possible mechanism of action in DU145 cells. Mol Cell Endocrinol $\underline{263}$, 46-54

Rassow J, Hauser K, Netzker R, Deutzmann R: Duale Reihe Biochemie. 2. Auflage; Thieme, Stuttgart 2008

Rettberg JR, Yao J, Brinton RD (2014): Estrogen: a master regulator of bioenergetic systems in the brain and body. Front Neuroendocrinol $\underline{35}, 8-30$

Robert Koch-Institut (2017): Krebs in Deutschland 2013/2014. Beiträge zur Gesundheitsberichterstattung des Bundes. 11. Ausgabe; Robert Koch-Institut und die Gesellschaft der epidemiologischen Krebsregister in Deutschland e.V., Berlin 2017

Roberts JM, Martin RS, Piyarathna DB, MacKrell JG, Rocha GV, Dodge JA, Coarfa C, Krishnan V, Rowley DR, Weigel NL (2017): Vitamin D receptor activation reduces VCaP xenograft tumor growth and counteracts ERG activity despite induction of TMPRSS2:ERG. Oncotarget $\underline{8}, 44447-44464$

S3-Leitlinie Prostatakarzinom: Interdisziplinäre Leitlinie der Qualität S3 zur Früherkennung, Diagnose und Therapie der verschiedenen Stadien des Prostatakarzinoms. Langversion 5.0, April 2018 siehe http://awmf.org/uploads/tx_szleitlinien/043022OLI_S3_Prostatakarzinom_2018-04.pdf [Zugriff am 22.05.2019]

Sadar MD (2011): Small molecule inhibitors targeting the Achilles` heel of androgen receptor activity. Cancer Res $\underline{71}$, 1208-1213

Saijo K, Collier JG, Li AC, Katzenellenbogen JA, Glass CK (2011): An ADIOL-ERß-CtBP transrepression pathway negatively regulates microglia-mediated inflammation. Cell $\underline{145}$, 584-595

Salagierski M, Schalken JA (2012): Molecular diagnosis of prostate cancer: PCA3 and TMPRSS2:ERG gene fusion. J Urol $\underline{187}, 795-801$ 
Salami SS, Schmidt F, Laxman B, Regan MM, Rickman DS, Scherr D, Bueti G, Siddiqui J, Tomlins SA, Wei JT (2013): Combining urinary detection of TMPRSS2:ERG and PCA3 with serum PSA to predict diagnosis of prostate cancer. Urol Oncol $\underline{31}, 566-571$

Sanchez M, Picard N, Sauvé K, Tremblay A (2012): Coordinate regulation of estrogen receptor $\beta$ degradation by Mdm2 and CREB-binding protein in response to growth signals. Oncogene $\underline{32}, 117-126$

Scher HI, Fizazi K, Saad F, Taplin ME, Sternberg CN, Miller K, de Wit R, Mulders P, Chi KN, Shore ND, Armstrong AJ, Flaig TW, Fléchon A, Mainwaring P, Fleming M, Hainsworth JD, Hirmand M, Selby B, Seely L, de Bono JS; AFFIRM Investigators (2012): Increased survival with enzalutamide in prostate cancer after chemotherapy. $\mathrm{N}$ Engl J Med $\underline{367}, 1187-1197$

Schröder F, Crawford ED, Axcrona K, Payne H, Keane TE (2012): Androgen deprivation therapy: past, present and future. BJU Int $\underline{109}, 1-12$

Schröder FH, Hugosson J, Roobol MJ, Tammela TL, Ciatto S, Nelen V, Kwaitkowski M, Lujan M, Lilja H, Zappa M (2009): Screening and prostate-cancer mortality in a randomized European study. N Engl J Med 360, 1320-1328

Schulz WA, Burchardt M, Cronauer MV (2003): Molecular biology of prostate cancer. Mol Hum Reprod $\underline{9}$, 437-448

Setlur SR, Mertz KD, Hoshida Y, Demichelis F, Lupien M, Perner S, Sboner A, Pawitan Y, Andrèn O, Johnson LA (2008): Estrogen-dependent signaling in a molecularly distinct subclass of aggressive prostate cancer. J Natl Cancer Inst $\underline{100}, 815-825$.

Seton-Rogers S (2013): Therapeutic resistance: two steps ahead. Nat Rev Cancer $\underline{13}$, 382-383

Stamey TA, Yang N, Hay AR, McNeal JE, Freiha FS, Redwine E (1987): Prostate-specific antigen as a serum marker for adenocarcinoma of the prostate. $\mathrm{N}$ Engl J Med $\underline{317}, 909-$ 916

Stettner M, Kaulfuss S, Burfeind P, Scheyer S, Strauss A, Ringert R-H, Thelen P (2007): The relevance of estrogen receptor-beta expression to the antiproliferative effects observed with histone deacetylase inhibitors and phytoestrogens in prostate cancer treatment. Mol Cancer Ther $\underline{6}, 2626-2633$ 
Stettner M, Krämer G, Strauss A, Kvitkina T, Ohle S, Kieseier BC, Thelen P (2012): Longterm antiepileptic treatment with histone deacetylase inhibitoers may reduce the risk of prostate cancer. Eur J Cancer Prev 21, 55-64

Strauss A, Sürig S, Loertzer H, Ringert RH, Thelen P (2009): Beneficial effects of antiepileptic drugs in prostate cancer cells. J Urol $\underline{181}, 480$

Suzuki F, Akahira J, Miura I, Suzuki T, Ito K, Hayashi S, Sasano H, Yaegashi N (2008): Loss of estrogen receptor beta isoform expression and its correlation with aberrant DNA methylation of the $5^{\prime}$-untranslated region in human epithelial ovarian carcinoma. Cancer Sci $\underline{99}$, 2365-2372

Thamilselvan V, Menon M, Stein GS, Valeriote F, Thamilselvan S (2017): Combination of Carmustine and Selenite Inhibits EGFR Mediated Growth Signaling in AndrogenIndependent Prostate Cancer Cells. J Cell Biochem. 118, 4331-4340.

Thamilselvan V, Menon M, Thamilselvan S (2016): Combination of carmustine and selenite effectively inhibits tumor growth by targeting androgen receptor, androgen receptorvariants, and Akt in preclinical models: New hope for patients with castration resistant prostate cancer. Int J Cancer. $\underline{139}, 1632-1647$.

Thelen P, Geschwend J, Wolff J-M, Miller K (2016): Resistenzmechanismen unter antihormoneller Therapie des fortgeschrittenen Prostatakarzinoms. Aktuel Urol 4ㄱ, 79-85

Thelen P, Heinrich E, Bremmer F, Trojan L, Strauss A (2013): Testosterone boosts for treatment of castration resistant prostate cancer: an experimental implementation of intermittent androgen deprivation. Prostate $\underline{73}, 1699-1701$

Thelen P, Scharf JG, Burfeind P, Hemmerlein B, Spengler B, Christoffel V, Ringert RH, Seidlova-Wuttke D (2005): Tectorigenin and other phytochemicals extracted from leopard lily Belamcanda chinensis affect new and established targets for therapies in prostate cancer. Carcinogenesis $\underline{26}, 1360-1367$

Thelen P, Schweyer S, Hemmerlein B, Wuttke W, Seseke F, Ringert RH (2004): Expressional changes after histone deacetylase inhibition by valproic acid in LNCaP human prostate cancer cells. Int J Oncol $\underline{24}, 25-31$

Thelen P, Strauß A, Stettner M, Kaulfuß S, Ringert R-H, Loertzer H (2010): Antiandrogene Strategien im Prostatakarzinom: Rekonstitution des $\beta$-Östrogenrezeptors. Urologe A $\underline{49}$, $1124,1126-1128,1130$ 
Tomlins SA, Laxman B, Varambally S, Cao X, Yu J, Helgeson BE, Cao Q, Prensner JR, Rubin MA, Shah RB (2008): Role of the TMPRSS2-ERG gene fusion in prostate cancer. Neoplasia $\underline{10}, 177-188$

Tomlins SA, Rhodes DR, Perner S, Dhanasekaran SM, Mehra R, Sun XW, Varambally S, Cao X, Tchinda J, Kuefer R (2005): Recurrent fusion of TMPRSS2 and ETS transcription factor genes in prostate cancer. Science $\underline{310}, 644-648$

Tran C, Ouk S, Clegg NJ, Chen Y, Watson PA, Arora V, Wongvipat J, Smith-Jones PM, Yoo D, Kwon A (2009): Development of a second-generation antiandrogen for treatment of advanced prostate cancer. Science $\underline{324}, 787-790$

Tsai HT, Penson DF, Makambi KH, Lynch JH, Van Den Eeden SK, Potosky AL (2013): Efficacy of intermittent androgen deprivation therapy vs conventional continuous androgen deprivation therapy for advanced prostate cancer: a meta-analysis. Urology $\underline{82}, 327-33$

Urbinati G, Ali HM, Rousseau Q, Chapuis H, Desmaële D, Couvreur P, MassaadMassade L (2015): Antineoplastic Effects of siRNA against TMPRSS2-ERG Junction Oncogene in Prostate Cancer. PLoS One $\underline{10}$, e0125277

Urbinati G, de Waziers I, Slamiç M, Foussignière T, Ali HM, Desmaële D, Couvreur P, Massaad-Massade L (2016): Knocking Down TMPRSS2-ERG Fusion Oncogene by siRNA Could be an Alternative Treatment to Flutamide. Mol Ther Nucleic Acids. $\underline{5}$, e301

Verhamme KM, Dieleman JP, Bleumink GS, van der Lei J, Sturkenboom MC, Artibani W, Begaud B, Berges R, Borkowski A, Chappel CR (2002): Incidence and prevalence of lower urinary tract symptoms suggestive of benign prostatic hyperplasia in primary carethe Triumph project. Eur Urol $\underline{42}, 323-328$

Vis AN, Schröder FH (2009): Key targets of hormonal treatment of prostate cancer. Part 1: the androgen receptor and steroidogenic pathways. BJU Int 104, 438-448

Wadelius M, Andersson AO, Johansson JE, Wadelius C, Rane E (1999): Prostate cancer associated with CYP17 genotype. Pharmacogenetics $\underline{9}, 635-639$

Waltering KK, Urbanucci A, Visakorpi T (2012): Androgen receptor (AR) aberrations in castration-resistant prostate cancer. Mol Cell Endocrinol $\underline{360}, 38-43$ 
Walton TJ, Li G, Seth R, McArdle SE, Bishop MC, Rees RC (2008): DNA demethylation and histone deacetylation inhibition co-operate to re-express estrogen receptor beta and induce apoptosis in prostate cancer cell-lines. Prostate $\underline{68}, 210-222$

Wang MC, Valenzuela LA, Murphy GP, Chu TM (1979): Purification of a human prostate specific antigen. Invest Urol $\underline{17}, 159-163$

Wang S, Yang Q, Fung KM, Lin HK (2008): AKR1C2 and AKR1C3 mediated prostaglandin D2 metabolism augments the PI3K/Akt proliferative signaling pathway in human prostate cancer cells. Mol Cell Endocrinol 289, 60-66

Wang Z, Wang Y, Zhang J, Hu Q, Zhi F, Zhang S, Mao D, Zhang Y, Liang H (2017): Significance of the TMPRSS2:ERG gene fusion in prostate cancer. Mol Med Rep. 16, 54505458

Warner M, Gustafsson JA (2010): The role of estrogen receptor beta (ERbeta) in malignant diseases--a new potential target for antiproliferative drugs in prevention and treatment of cancer. Biochem Biophys Res Commun $\underline{396}$, 63-66

Watson PA, Chen YF, Balbas MD, Wongvipat J, Socci ND, Viale A, Kim K, Sawyers CL (2010): Constitutively active androgen receptor splice variants expressed in castrationresistant prostate cancer require full-length androgen receptor. Proc Natl Acad Sci 107, 16759-16765

Xu Z, Wang Y, Xiao ZG, Zou C, Zhang X, Wang Z, Wu D, Yu S, Chan FL (2018): Nuclear receptor ERRa and transcription factor ERG form a reciprocal loop in the regulation of TMPRSS2:ERG fusion gene in prostate cancer. Oncogene. doi: 10.1038/s41388-0180409-7 [elektronische Vorabveröffentlichung]

Yu Z, Chen S, Sowalsky AG, Voznesensky OS, Mostaghel EA, Nelson PS, Cai C, Balk SP (2014): Rapid induction of androgen receptor splice variants by androgen deprivation in prostate cancer. Clin Cancer Res 20, 1590-1600

Yuan X, Balk SP (2009): Mechanisms mediating androgen receptor reactivation after castration. Urol Oncol 27, 36-41

Yuan X, Cai C, Chen S, Yu Z, Balk SP (2014): Androgen receptor functions in castrationresistant prostate cancer and mechanisms of resistance to new agents targeting the androgen axis. Oncogene $\underline{33}$, 2815-2825 
Zhao H, Coram MA, Nolley R, Reese SW, Young SR, Peehl DM (2012): Transcript levels of androgen receptor variant $\mathrm{AR}-\mathrm{V} 1$ or $\mathrm{AR}-\mathrm{V} 7$ do not predict recurrence in patients with prostate cancer at indeterminate risk for progression. J Urol $\underline{188}, 2158-2164$ 


\section{Danksagung}

Ganz besonders herzlich danke ich meinem ehemaligem Doktorvater Herrn PD Dr. rer. nat. Paul Thelen. Ihm verdanke ich die Möglichkeit zu dieser Dissertation, die Bereitstellung des Themas und das Arbeiten in seiner experimentellen Arbeitsgemeinschaft. Ebenso für seine fortwährende freundliche Unterstützung und Hilfsbereitschaft sowie die kritischen Anmerkungen und Anregungen.

Mein besonderer Dank gilt meinem Doktorvater Herrn Prof. Dr. med. Lutz Trojan, in dessen Abteilung die Studie durchgeführt wurde und welcher nach dem Ausscheiden von PD Dr. rer. nat. Thelen meine Dissertation freundlicherweise übernommen hat. Seine kritischen Anmerkungen und Anregungen trugen letztendlich zum Abschluss der Arbeit bei.

Meinem fachlichen Betreuer Herrn Dr. med. Oliver Hahn danke ich ganz herzlich für die freundliche Unterstützung und Hilfsbereitschaft.

Im Besonderen möchte ich Frau Marion Striepe für die technische Einarbeitung, Beratung und vor allem für die Unterstützung bei meinen experimentellen Untersuchungen danken.

Ferner möchte ich Frau Kerstin Meyer-Willmes für die fachlichen Informationen und Ratschläge vorab und während der Arbeit danken.

Auch gilt mein Dank an alle nicht namentlich genannten, die mich in der Korrektur der Dissertation mit Hilfestellungen und aufbauenden Worten unterstützt haben. 